W. Frhr.v. d. Osten-Sacken, Berichtigungen u. Ergänzungen usw. 181

\title{
Berichtigungen und Ergänzungen zu Waldes Lateinischem Etymologischem Wörterbuch, 2. Auflage, aus dem Gebiet der Slavistik und Lituanistik.
}

Da Waldes Lateinisches Etymologisches Wörterbuch den Lesern der IF. schon seit Jahren gut bekannt ist, wäre jetzt kaum der geeignete Ort und Zeitpunkt für eine Würdigung der Bedeutung dieses Werkes, sei es auch nur für das Spezialgebiet der Slavistik und Lituanistik. Dennoch kann ich es mir hier am Eingang einer Abhandlung, die sich vielfach mit unrichtigen Auffassungen und ungenauen Angaben Waldes in bezug auf slavische und baltische Worte und Sippen beschäftigen soll, nicht versagen, ausdrücklich $\mathrm{zu}$ betonen, daß ich keineswegs den unschätzbaren Wert des Waldeschen Werkes für die Wissenschaft verkenne. Ich muß im Gegenteil bekennen, daß ich bei meinen etymologischen und sonstigen sprachwissenschaftlichen Studien kein anderes Buch so intensiv und so freudig benutzt habe, wie gerade den Walde, und daß ich das Bewußtsein habe, ihm unendlich viel nie versiegende Anregung zu verdanken. Es ist meine Überzeugung, daß die Unentbehrlichkeit Waldes für jeden Slavisten, der nicht nur Philologe im engsten Sinne des Wortes sein will, auch dann nicht aufhören wird, wenn Bernekers Slavisches Etymologisches Wörterbuch vollendet sein wird, schon allein darum, weil Walde die indogermanischen Beziehungen der Sippen weit eingehender veranschaulicht, als es Berneker in Anbetracht des ungeheuren Umfangs seines slavischen Wortschatzes tun kann.

Die Unrichtigkeiten und Ungenauigkeiten, die uns hier beschäftigen werden, sind zumeist derartige, wie sie in einem so umfassenden etymologischen Wörterbuche unausbleiblich sind, denn man kann von dem Verfasser eines solchen Werkes nicht die gleiche Detailkenntnis in allen denjenigen Sprachen und Sprachzweigen, die er in den Bereich seiner Darstellung mit einbeziehen muB, voraussetzen. $\mathrm{Er}$ ist vielfach auf Arbeiten anderer angewiesen und dann nicht in der Lage an den ihm vorliegenden Worten und Etymologien strenge Kritik zu üben. Er tut gut daran, die fremden Ansichten auch da, wo er ihre Berechtigung nicht nachprüfen kann, zu registrieren und ist berechtigt, die Aufdecknng etwaiger Irrtümer den Benutzern 
seines Buches zu überlassen. Die bei Walde zu findenden Irrtümer im Slavischen und Baltischen rühren hauptsächlich von anderen her und sind in der indogermanistischen Literatur weit verbreitet. Ein Ankämpfen gegen die Verschleppung derselben besteht sporadisch wohl auch schon fast ebenso lange wie die Irrtümer selbst. Aber in einem etymologischen Werke befinden sich Etymologien auf einem weit exponierteren Platze und wirken viel autoritativer, als etwa in Grammatiken, wo sie hauptsächlich als Beispiele bei Demonstrierung lautlicher und morphologischer Probleme dienen, oder in Zeitschriftenaufsätzen, deren breitere Darstellung das Interesse auch auf andere Momente hinlenkt und nicht immer über die schwachen Seiten der betreffenden Auffassungen unbemerkt hinweggleiten kann. Demgemäß erscheint mir Waldes vielbenutztes Wörterbuch mit seinem reichhaltigen Wortmaterial eine geeignete Grundlage, um gewissen in der Indogermanistik verbreiteten Irrtümern aufzuspüren, deren Entstehung zu erklären und gegebenen Falles Verbesserungsvorschläge zu machen. Es ist $\mathrm{m}$. E. zu bedauern, daß eine derartige Arbeit, wie ich sie hier unternommen habe, nicht schon vor Erscheinen der zweiten Auflage des Walde veröffentlicht worden ist, desgleichen, daß Berneker in seinem Et. Wb. (hier zitiert: Berneker) manche günstige Gelegenheit hat vorübergeben lassen, wo er bequem hätte Walde auf den einen oder anderen Irrtum aufmerksam machen können. Wenn z. B. Berneker gewisse zu beanstandende Worte und Wortauffassungen bei Walde überhaupt nicht erwähnt (s. unten s. v. fäbula, fiber wegen ksl. brunatbri, gannio wegen gagnati, genius, glomus, gula wegen russ. goltb, laevus wogen lett.l'auns) oder doch nur positiv Richtiges darüber äußert (cattus, defendo, lacio, bes. wegen čech. lákati), so genügt das noch nicht obne weiteres, um in allen Fällen daraus die Tatsache, daß Irrtümer vorliegen, zu erkennen; ja auch in Fällen wie serb. prökola (scalpo) wäre eine Erwähnung von Waldes abweichender Erklärung nicht unpraktisch gewesen. Ich meine, Etymologen tun gut daran, sich in diesen Sachen gegenseitig in die Hände zu arbeiten. Es ist nun kaum möglich, daß der eine Verfasser seine Worte an der Hand des Werkes des andern eingehend verifiziert; er wird das immer nur da tun, wo er Grund zur Skepsis hat. Wohl aber wird er häufig einen Blick hineintun, um die allgemeine Behandlung der Sippen zu vergleichen; und dabei 
werden ihm kurze Hinweise auf seine Irrtümer die Arbeit ungemein erleichtern, während über eine bloß richtige Bemerkung das Auge oft achtlos hinweggleitet.

Was die Gründe der falschen Auffassungen über eine Reihe slavischer und baltischer Worte in der Indogermanistik und speziell auch bei Walde anbetrifft, so sind diese Irrtümer zum großen Teile durch unsachliche Angaben der Wörterbücher verschuldet, die teils ungenau, teils direkt unrichtig, teils nicht erschöpfend genug sind und durch Verschweigen gewisser Nebenumstände den unbefangenen Leser leicht zu Mißverständnissen veranlassen können. Vgl. unten die Beispiele für einseitige und mehrdeutige Bedeutungsangaben (abg. cèna ' $\tau 1 \mu n^{\prime}$ ', ksl. slota 'hiems', posivo 'benignus', lit. bóti 'wonach fragen', lett. l'auns 'link, übel' s. v. caerimōnia, caleo, cīvis, fābula, laevus), für falsch erschlossene Nominative, Präsentia und Infinitive (cattus, derbiōsus, fodio) und für Nichtbezeichnung etymologisch wertloser

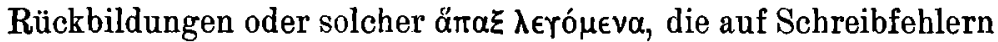
resp. künstlichen Abstraktionen beruhen können (gero, hêrēs, pariês, spiro, vielleicht auch grunda wegen grędz). Wer sich in den Wörterbüchern solcher Sprachen, die ihm wenig bekannt sind, nicht durch Quellenangaben, etymologische Hinweise (bei Komposita und Ableitungen), gute Beispiele usw. über Provenienz, Gebrauchssphäre, Lebendigkeit und dgl. der Wörter genügend orientieren kann, der fällt leicht auf Wörter primären Aussehens mit scheinbar prägnanter Bedeutung herein, die oft eine so verblüffende Ähnlichkeit mit anderssprachigen Worten haben, daß eine etymologische Verbindung mit diesen sich ohne weiteres zu ergeben scheint, vgl. die Zusammenstellungen abg. lačiti: lat. lancināre (s. v. lacer); russ. májatz: lat. mölès (s.v.); ksl. rëprjo : ahd. rāfo 'Balken, Sparren'; tężiti : griech. cıххóc; lit. té-

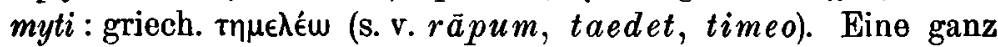
besonders schwere Sache für den Etymologen ist die Wahl der Sippenvertreter einer bestimmten Sprache oder eines Sprachzweiges. Selbst, wenn man die in Frage stehenden Sprachen gut kennt, ist die Wortwahl nicht immer leicht, weil verschiedene Gesichtspunkte mit einander kollidieren. Teils wird man Worte wählen wollen, die ein möglichst altertümliches Gepräge haben, teils aber wird man dem gegenwärtigen Sprachstadium Rechnung tragen und solche Worte nehmen, die für das Sprachgefühl als Mittelpunkte der Sippen gelten können. Wenn man nicht gar 
zu viel Raum für jeden einzelnen Sprachzweig zur Verfügung hat, wird man durch eine geschickte Gruppierung der Worte, durch Klammern, kurze Zusätze und dgl. der Möglichkeit falscher Eindrücke und Schlußfolgerungen bei den Lesern vorzubeugen suchen. Wer aber kein Sprachgefühl hat, sondern nur auf Wörterbücher angewiesen ist, wird zwischen geeigneten und ungeeigneten Worten nicht unterscheiden können und wird oft beliebige junge oder seltene Worte wählen, die entweder nichts positiv Bemerkenswertes bieten oder ohne Kommentar mehrdeutig sind, wobei auch etwas gewagte Wortgleichungen mit unterlaufen, s. unten clueo, cruentus, flagro, grunda (wegen gredz), locus, $(p l u o)$. Wie weit man in der Korrektur einer ungeeigneten Wortwahl zu gehen hat, bleibt dem subjektiven Empfinden des Einzelnen überlassen. Es läßt sich wohl kaum leugnen, daß derartige Korrekturen den ferner stehenden pedantisch und kleinlich erscheinen mögen. Anderseits aber ist ein Etymologisches Wörterbuch leider oft der Ort, aus den die Sprachforscher ihre Kenntnisse über den Wortvorrat fremder Sprachen schöpfen, und es erscheint mir doch erstrebenswert, die Zirkulation ungesicherter Worte oder falscher morphologischer Vorstellungen auch da einzuschränken zu suchen, wo die Etymologie als solche nicht darunter leidet. Es sind oft nur geringfügige Änderungen (Beobachtung einer rationellen Reihenfolge, Zufügung anderer Worte oder Formen und dgl.), die einen störenden Eindruck verwischen können, s. unten callis, cannabis, cōniveo, foria, habeo, mico, plōro, ravus (wegen reva), scrobis. Ich habe zwar keine systematische Untersuchung über Waldes Wortwahl angestellt, habe aber doch häufig Änderungsvorschläge gemacht. Es ist mir wohl bewußt, daß ein Etymologe beim Registrieren fremder Ansichten auch da, wo ihm an sich besseres Wortmaterial zur Verfügung steht, von seinen Quellen abhängig ist. Wenn ich hie und da auch in solchen Füllen andere Worte genannt habe, so ist das mehr zur Orientierung der Leser geschehen, als zur Verbesserung von Waldes Darstellungsweise.

Im Slavischen sind es namentlich das Lexicon Palaeoslovenicum von Miklosich und das Etymologische Wörterbuch desselben Verfassers (hier bezeichnet Lex. Pal. und Et. Wb.), und im Litauischen Nesselmanns Wörterbuch der Littauischen Sprache und Kurschats Littauisch-Deutsches Wörterbuch (hier 
bezeichnet Ness(elmann) und KLD resp. Kurschat), letzteres namentlich in bezug auf die dem Verfasser selbst unbekannten und von ihm in eckige Klammern gesetzten Worte (hier KLD[), deren unkritische Benutzung viele Versehen hervorgerufen hat.

Viele aus Miklosich übernommene scheinbar altkirchenslavische Worte stammen bekanntlich aus jungen Quellen, die zwar zur slavischen Kirchensprache im weitesten Sinne des Wortes gerechnet werden können, aber doch auch Neubildungen und Kunstbildungen der letzten Jahrhunderte enthalten, so daß in allen Fällen, wo wir keine guten literarischen Belege für die Worte haben, Vorsicht angebracht ist. Während wir bei den Worten des Lex. Pal. wenigstens dié Sicherheit haben, daß Miklosich sie tatsächlich in einer kyrillisch oder glagolitisch geschriebenen Quelle vorgefunden und nur äußerliche graphische Veränderungen an ihnen vorgenommen hat, scheint es; als ob er im Et. Wb. sogar selbst Worte konstruiert hat, d. h. teils aus Ableitungen Grundwörter abstrahiert, teils aus ihm persönlich bekannten Worten der modernen Sprachen ihre ksl. Entsprechungen erschlossen hat, wobei sogar eine durch falsche Etymologisierung hervorgerufene Vernachlässigung der Lautgesetze zu beobachten ist, s. das unten über čutiti, mlachavbmlochavs, gagnąti und kinegr (s. v. caveo, flaccus, gannio, genius) Gesagte. Wenn die Etymologien sonst haltbar sind, können wir die scheinbar abg. Worte oft durch Worte der modernen Sprachen (fiber, humulus, ornus, spiro wegen brunatznz, chbmělb, jasenz und jasika, pachъ) oder durch andere Bildungen der selben Wurzel (gero, grunda, hêrês wegen žestz, grẹdz jazdz) ersetzen. Übrigens empfiehlt es sich, die auch in russ. Überlieferung belegten Worte bei Sreznevskij Materialy dlja slovarja drevne-russkago jazyka po pisımennymz pamjatnikamz Petersburg $1893 \mathrm{ff}$. (zitiert Sreznevskij Mat.) zu suchen, da dort bessere Belege sind und sich leichter Schlußfolgerungen philologischer Art ziehen lassen, als bei Miklosich Lex. Pal.

Walde bezeichnet die (meist indirekt) auf Miklosich zurückgehenden ksl. Worte mit geringen Ausnahmen ohne Rücksicht auf ihre Quellen als altbulgarisch (ab.). Diese Bezeichnungsweise als einzige erscheint mir auch dann ungeeignet, wenn man alle unsicheren oder notorisch jungen Worte ganz ausscheidet und durch bessere ersetzt. Wir können natürlich an Walde nicht den Anspruch stellen, daß er sich genau nach den Quellen der 
einzelnen Worte umsieht und sie demgemäß nach Bernekers Methode je nach ihrer Provenienz als abg., ksl., russ.-ksl., nbulg.ksl., serb.-ksl. bezeichnet; auch würde diese von Berneker mit Recht angewandte Scheidung für ein nichtslavistisches Werk zu subtil sein und den Leser unnütz verwirren. Es kommt noch hinzu, daß man in solchen Fällen wie doly, gag(z)nati, grẹda (s. unten dolium,.gannio, grunda) und bruto 'Nagel' (serb.ksl. brutb; vgl. Walde s. v. farcio und Bernekers Artikel brutb) die aus vielen Gründen (namentlich bei alten und weitverbreiteten Worten) praktische abg. Lautform nur dann der Schreibung zugrunde legen darf, wenn man die Zusätze mbg., russ., serb. vermeidet. Wo es sich um volkstümliche und kulturhistorisch interessante Worte einer Einzelsprache aus alter Zeit handelt, wie z. B. bei aserb. sebrb 'freier Bauer', tragb 'Nachkommen' (unten Sabini und traho), wird man allerdings die Bezeichnung aserb., aruss. usw. und die jüngere Lautgestalt vorziehen; bei sebrb wäre die ksl. Lautform *sębrz auch schon des - $\varrho$ - wegen zu vermeiden, denn theoretisch könnte man unter Umständen neben russ. sjabrz 'Nachbar, Freund' aus *sębro auch ein nasalloses südslavisches *sebrz verteidigen, während z. B. für russ.-ksl. grjada neben poln. grzeda auch der rigoroseste Theoretiker eine Grundform urslav. *grjada neben *gręda für ausgeschlossen halten muß.

Soweit ich die Verhältnisse überblicken kann, würde es sich leicht durchführen lassen, wenn man in einem solchen Werke wie Walde im allgemeinen die Bezeichnungsweise ksl. anwenden und abg. (ab.) nur für solche Worte reservieren würde, über deren Vorkommen in den sog. 'pannonischen' Quellen man sich an der Hand ron Berneker, der Glossare in Leskiens Handbuch der abg. Sprache und in Meillets Etudes sur l'Étymologie et le Vocabulaire du Vieux Slare (hier zitiert: Meillet Etudes) und des Lex. Pal. von Miklosich orientiert hat, oder auch nur für diejenigen, auf deren 'pannonische' Provenienz man aus besonderen Gründen aufmerksam machen will. Ich habe hier darauf verzichtet, bei Waldes Worten die Berechtigung der Bezeichnung abg. nachzuprüfen, insofern es sich mir nicht um Ausscheidung unsicherer oder notorisch junger Worte handelte. Wo ich aber hier Waldes Worte mit einem Prädikat anführe, da gebrauche ich abg. nur in den Fällen, wo diese Bezeichnung berechtigt ist; doch mögen sich auch unter den Worten, die ich vorsichtshalber als ksl. bezeichne, 'pannonische' befinden. 
Nesselmann und die älteren deutschen Bearbeiter der litauischen Sprache, deren Grammatiken und Wörterbücher er benutzt hat (Ruhig, Mielcke usw.), haben das Litauische selbst meist nur wenig oder garnicht beherrscht, und sie verstanden es nicht, alle gelesenen oder gehörten Worte ihrem in der Grundlage verhältnismäßig gut ausgebildeten orthographischen. System anzupassen. Die Linguisten nun, die Nesselmann oder Kurschat (bei KLD[ ist die Schreibweise der Quellen meist beibehalten worden) benutzen, fassen diese Worte meistens so auf, als wenn sie in Kurschats Orthographie geschrieben wären, was vielfach zu morphologischen Irrtümern führt. Ein sehr in die Augen springender Punkt bei der Untersuchung von Nesselmanns Worten ist z.B. die auch schon bei seinen Vorgängern vorhandene und bei KLD[ beibebaltene Nichtbezeichnung der Palatalität, was teils auf Nachlässigkeit (unten s. v. derbiōsus, graculus), teils auf Unkenntnis des graphischen Palatalitätsausdruckes der älteren Quellen zu beruhen scheint. Letzteres betrifft insbesondere die l-Laute, s. unten caleo, minus und Fn., vìlis, volo. Andere Beispiele, betreffend die graphische Wiedergabe bei Nesselmann und KLD[, werden unten s. v. dens, fiber, leo, lètum, pecu, vetus erwähnt.

Eine weitere Quelle für Irrtümer besteht in der Tendenz mancher Etymologen, Komposita, Ableitungen usw. aus ihrem natürlichen Zusammenhang zu reißen, um sie auf Grund einer zufälligen oft nur scheinbaren Ähnlichkeit mit Worten aus anderen Sprachzweigen in anderweitige Verbindungen zu bringen. Beispiele s. unten s. v.horior, lacertus, mólēs, nāvus, pannus, patro, viésco. Die Neigung so zu verfahren, von der ich mich keineswegs freisprechen kann, liegt ja sehr nahe, zumal wenn man die Worte aus den Wörterbüchern schöpft und über ihren wirklichen Bedeutungsumfang und dgl. nicht orientiert ist; vielfach erschwert einem auch die ungenügende Kenntnis der 'Sachen' einige bei gewissen Worten und Wortsippen vorliegende scheinbar weit auseinanderliegende Bedeutungen miteinander zu kombinieren; und un dieser Notwendigkeit zu entgehen, sucht man als Rettungsmittel nach einem anderweitigen Anschluß für die unverständliche Bedeutung. In einigen der Fälle aber, mit denen wir es hier zu tun haben werden (russ. ugoditz nebst čech. hoditi, cech. pesky, zátroditi s. v. defendo, pēnis, vas), kann ich meine Verwunderung darüber nicht unterdrücken, daß 
Slaven, bei denen wir doch wenigstens in der eigenen Muttersprache ein lebendiges Sprachgefühl erwarten dürfen, der Worterklärung Gewalt angetan haben, wobei mich in dem einen Falle (závoditi) sogar die ungenaue Bedeutungsangabe befremdet. Zur Orientierung des Lesers möchte ich meiner eigentlichen Abhandlung einige Worte über die von mir zur Revision von Waldes litauischem Wortmaterial verwerteten Hülfsmittel sowie über graphische resp. orthographische Fragen vorausschicken. Zunächst habe ich die von mir vor einigen Jahren zum Zwecke grammatischer Ausbeute angelegte, alphabetisch geordnete, Zettelsammlung der in Szyrwids Diction ariu m triu m linguarum (poln.-lat.-lit. Wtb.; bezeichnet Szyrwid Dict.), 5. Auflage, Wilna 1713, vorhandenen litauischen Worte in ausgiebiger Weise benutzt, wobei ich zum Vergleich auch einige Notizen aus der in manchen Punkten abweichenden 4. Auflage desselben Werkes (Wilna 1677; hier unterschieden als Dict. IV und Dict. V), sowie auch das Predigtbuch desselben Verfassers, betitelt Punkty Kazań (Punktay Sakimu), hrsg. von Garbe Göttingen 1884 (Heft 4 von Bezzenbergers Lit. und Lett. Drucken des 16. und 17. Jahrhunderts, zitiert: Szyrwid Punktay Sakimu) zu Rate gezogen habe. Da Szyrwid eine der Hauptquellen von Nesselmann und KLD[ ist, konnte ich manchen Irrtümmern auf die Spur kommen (fodio, graculus, leo, rugio, vgl. insbesondere mollis wegen des angeblichen lit. mildus). Die Verdeutschung von Szyrwids Worten macht insofern gewisse Schwierigkeiten, als die vielfach in mehreren Bedeutungen vorkommenden polnischen Stichworte und besonders die lateinischen Entsprechungen derselben durchaus nicht immer ausreichen, um die genaue Bedeutung der litauischen Worte zu ersehen. Vorsichtshalber habe ich daher meist vermieden, deutsche Bedeutungsangaben zu geben und habe sowohl die polnischen als auch die lateinischen Worte zugefügt; zu beachten ist dabei, da $B$ in erster Linie die polnischen Worte als direkte Entsprechungen der litauischen in Betracht kommen, da die lateinischen sich unter Umständen auf andere Bedeutungsnuancen der Stichworte beziehen können.

Das sonst von mir verwertete litauische Wortmaterial stammt in der Hauptsache aus drei Quellen: 1) Juškevič Litorskij Slovarj (zitiert Juškevič; bisher ist nur der erste Band A-J erschienen); 2) Doritsch Beiträge zur litauischen Dialektologie, hrsg. von der lit. literar. Gesellschaft, 
Tilsit 1911 1) (zitiert: Doritsch Beiträge); 3) Professor Leskiens handschriftliche Zettelsammlung zu einem Litauischen Wörterbuch, aus der ich mir vor einigen Jahren mit Erlaubnis des Verfassers Notizen gemacht habe, die ich hier verwerten durfte. Die mir meist nicht zugänglich gewesenen Quellen Leskiens zitiere ich in der Regel mit vollem Titel (über Erscheinungsjahr, Druckort und dgl. orientiert Leskien Nom. 156 ff.); die angewandten Abkürzungen D.B.S. und Jass. Pam. bedeuten Budą senowęs Lëtuwiû Kalnienû ir Żamajtiû iszraszę Pagał Senowęs Rasztû Jokyb's Laukys (d. i. Dowkont), St. Petersburg 1845 , und Pamoksłay pagal ewangelios szwentos żodżiu ant wisu nedielu par metus surasziti par kunegu Rapolu Jassykiewicze, 2 Teile, Wilna 1855, 1857.

Die aus Nesselmann und Juškevič stammenden Worte habe ich mit Ausnahme der Akzentuation in die in der Sprachwissenschaft übliche und auch von Walde angewandte Orthographie umgesetzt und habe nur in Fällen, wo es mir zur Klärung irgend einer Frage nötig erschien, daneben auch die Originalschreibung zugefügt. Dagegen erschien es mir ratsam, bei den altlitauischen Worten aus Szyrwid und aus Leskiens handschriftlichem Wörterbuch sowie bei den streng phonetisch geschriebenen Dialektworten aus den Beiträgen von Doritsch die Originalorthographie beizubehalten, da ihre Kenntnis das Verständnis der sich daran knüpfenden Erörterungen erleichtert, und da im allgemeinen aus der ganzen Darstellung klar hervorgehen dürfte, in welcher Weise eine etwa wünschenswert erscheinende Umsetzung in literarische Gestalt zu erfolgen hätte. Was die Akzentuation bei Juškevic und in den Dialekttexten anbetrifft, so weicht sie bei den auch in der preub.-lit. Literatursprache bekannten Worten oft von der dortigen Betonung ab und ist daher bei den aus Kurschats Sprache nicht bekannten Worten nur mit Vorsicht als Kriterium für die Richtigkeit von Etymologien usw. zu verwerten. Beispiele s. unten s. v. ca.pio (atkempu), fla.gro (blyszkiu), fui, fülìgo, grunda, lāma, līs, rapio, valeo (veldeti), vetus, umbra. Und um einer verkehrten Ausbeutung der Akzentuation vorzubeugen, wäre es vielleicht praktischer, wenn Walde z. B. auch bei aliksnis, kropti, bebrus,

1) Die in diesem Werke enthaltenen dialektischen Texte geben durch ihre streng phonetische, durch keinerlei theoretische Erwägungen beeinflubte, Scbreibung ein anschauliches Bild von der lebendigen Sprache. 
grìdyju, mildingai (s. v. alnus, carpo, fiber, gradior, mollis) den Akzent fortlassen würde, falls er es nicht vorzieht, den dialektischen Charakter der Worte zu betonen.

Da Walde in der Schreibung seiner slavischen und baltischen Worte meist von seinen Quellen abhängig ist, ergeben sich naturgemäß bei ihm Inkongruenzen in der Bezeichnung derselben Laute und Lautgruppen. So schreibt er z. B. im Lettischen neben $w$ auch $v$ sowie $\delta$, o neben $i$ und gebraucht im Litauischen promiscue $i r, i l$ und $i r, i l$. Bei der Transkription der kyrillischen Schrift fällt besonders die wechselnde Bezeichnung der Palatalität (ksl. und russ. meist durch -j-, klruss. durch den Apostroph und selten durch den Palatalitätsstrich; vor - $b$ wird sie ksl. und russ. meist garnicht bezeichnet) und sonst einzelner Lautungen (russ. $l a, l o, l u$, klruss. $t a, t o, t u$, z. B. russ. golubbj, klruss. hotúbyj) in den verschiedenen Sprachen, teilweise auch in éiner Sprache, auf. Auch im Setzen der auslautenden - $z$ und $-b$ herrscht Verwirrung, vgl. in Waldes Glossar ksl. olëj, rěpij, neben pokojz, ubojz, russ. kubaréc, plov, storož neben karpzo, ovëst. Da es sich hier nicht um Fehler handelt, sondern um verschiedene Auswahl unter gebräuchlichen Transkriptionsmethoden, habe ich mich in der Regel um diese Inkonsequenzen nicht gekümmert. Auch in der Verbesserung von Schreib- und Druckfehlern, im Setzen, Ändern und Beseitigen der Akzente und im Ersetzen des Apostrophs durch den Palatalitätsstrich im Kleinrussischen und Lettischen habe ich mich in der Regel auf diejenigen Worte beschränkt, übor die ich schon aus anderen Gründen etwas zu sagen hatte. Die slovenischen Worte, die Walde meist unakzentuiert und in einer veralteten, auf Miklosich zurückgehenden, Schreibung zitiert, habe ich durch Setzung von Akzenten und diakritischen Zeichen in die jetzt in der Wissenschaft übliche Schreibung (s. Berneker S. 5) umgesetzt, wobei ich namentlich auf die Unterscheidung der Zeichen $e$ (aus $e, e), \dot{e}$ (aus $\ddot{e}$ ) und a (aus z, b) Gewicht gelegt habe. In der Transkription der kyrillischen Schrift habe ich mich möglichst Walde anzupassen gesucht, der vielfach von Bernekers Methode abweicht, und schreibe z. B. abg. kolja, ksl. kljuditi, brznja gegenüber Bernekers kol'o, kl'uditi, brrńa. Nur babe jch dabei die Inkonsequenzen innerhalb einer Sprache möglichst zu vermeiden gesucht. Bernekers Stichworte gebe ich der leichteren Auffindbarkeit halber in seiner Schreibweise. 
Neben der Verfolgung des eigentlichen Zweckes dieser Abhandlung, auf die bei Walde vorkommenden Irrtümer hinzuweisen, habe ich es mir auch angelegen sein lassen, za dem von ihm verwerteten Wortmaterial noch weiteres mir semasiologisch oder formal interessant erscheinendes zuzufügen, abweichende Auffassungsmöglichkeiten zu beleuchten und überbaupt eine Reihe von mir beobachteter Tatsachen, die mit den von ihm behandelten Worten und Wortsippen in näherem oder fernerem $\mathrm{Zu}$ sammenhange stehen, mitzuteilen. Wenn meine Auseinandersetzungen dadurch vielfach derartige sind, daß ihr Inhalt von Walde für seine nächste Auflage nicht verwertet werden kann, so glaubte ich sie dennoch bei dieser Gelegenheit mit zur Sprache bringen zu dürfen, da sie diejenigen Forscher, die sich für Waldes Etymologien interessieren, über manche dazu in Beziehung stehende Einzelheiten unterrichten und zu einem kritischen Nachdenken über wortgeschichtliche Fragen veranlassen können.

Da ich die ganze Zeit über, während deren ich mich mit dieser Abhandlung beschäftigt habe, nicht allzuviel Nachschlagebücher zur Verfügung hatte, hätte ich die Arbeit kaum ausfübren können, wenn ich nicht in liebenswürdigster Weise von verschiedenen Personen mit Auskünften unterstïtzt worden wäre. Herr Professor Leskien, der mir seinerzeit, wie schon oben bemerkt, seine bandschriftliche Zettelsammlung überlassen hatte, hat mir jetzt auch noch verschiedene Anfragen beantwortet (s. die Artikel ferio, valeo, vas), wofür ich ihm auch an dieser Stelle meinen aufrichtigsten Dank ausspreche. Von anderen Herrn sind es in erster Linie mein Freund Dr. A. Doritsch in Sofia und Herr cand. phil. Fr. Specht in Dessau, die mich durch ihre aufopfernde Mitarbeit zum größten Danke verpflichten. Es wäre nicht möglich, sie an allen denjenigen Stellen, wo ich meine Kenntnisse nur auf ihre stets bereitwilligst erteilten erschöpfenden Auskünfte zurückführen kann, zu zitieren; es sei hier nur ausdrücklich hervorgehoben, daß ich meine Arbeit keineswegs als eine selbständige bezeicbnen kann. Außerdem sind es noch Herr Dr. H. von Ulaszyn in Leipzig, den ich an den betreffenden Stellen zitiere, und Frau Dr. phil. E. FigullaRamberg in Berlin, die mir hauptsächlich in polonistischen Fragen manche Anregung geboten haben, wofür ich ihnen herzlichsten Dank ausspreche. 
Abella. - Lies jablanb (ksl.) statt jablanz.

adūlo. - Wegen lit. valaĩ s. unten vìlis.

aedes. - Nach Berneker s. v. ěstëja ist ěech. niestëja zu korrigieren in čech. nistëj oder iñ ačech. niestëjè F. Plur.; die slovenischen Formen lauten istéje, stéje F. Plur.; andere slovenische sowie auch sorbische Formen s. bei Berneker a. a. 0 .

alcē. - Für die aus Miklosich Et. Wb. stammende Ansicht, daß poln. tos, čech. los, osorb. tos 'Elen' aus russ. lost ds. entlehnt seien, fehlen triftige Gründe. Lautlich ist das lo- im Westslavischen nicht weniger normal, als in Russischen, und sachliche Bedenken stehen der Echtheit des westslavischen Wortes auch kaum entgegen. Wenn auch heutzutage im Gebiete der Čechen und Sorben der Elch nicht vorkommt, so ist das doch auf dem größten Teile des deutschen Sprachgebietes, wo das Wort elch heimisch ist, gleichfalls der Fall, ohne daß wir hier von einer Entlehnung reden können; ähnlich steht es auch mit den Worten bär und wolf. In früheren Zeiten ist die Ausbreitung all dieser Tiere eben eine weit größere gewesen, als jetzt. Derartige Tiernamen pflegen sich in der mündlichen Überlieferung des Volkes noch lange zu erhalten, wobei wohl auch die Volkssagen konservierend wirken. Wenn eine Entlehnung stattfindet, so kann man höchstens von einer Entlehnung aus einer älteren Periode derselben Sprache reden. Auch Torbiörnsson Liquidametathese I, 65 hält das westslavische Wort für ererbt; russischer Ursprung wäre m. E. nur dann anzunehmen, wenn es sich um ein gelehrtes Wort des naturgeschichtlichen Unterrichts handeln würde.

alnus. - Doritsch Beiträge $\S 377$ Nr. 21 bietet zu lit. alksnis, elksnis 'Erle' die interessante altertümliche Form mit Mittelvokal aliksnis aus vier einander benachbarten Mundarten Russisch-Litauens; das - $\{$ - ist wegen ksl. jelbcha, ahd. elira wohl als ursprüngliche Kürze anzusehen. Dadurch gewinnt das von Berneker s. v. jelbcha konstruierte balt. *alis-ni-s eine Stütze; ob aber Berneker auch in der Annahme einer lautgesetzlichen Entstehung von alksnis aus *alis-ni-s vermittelst Synkope des Mittelvokals (der 'Einschub' des Gutturals, der gemeinlitauischlettisch ist, dürfte dann älter sein, als die Synkope) recht hat, vermag ich nicht zu entscheiden; eher möchte ich eine Vermischung der Stämme *al(e)s- und *alis- (vielleicht Kontamination von *ales- und *ali-) annehmen. 
Berichtigungen u. Ergänzungen zu Waldes Lat. Etym. Wörterbuch, 193

ancus. - Lies qkotb (abg.) statt ąkotb.

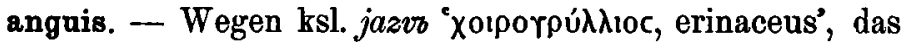
mit ježzs 'Igel' nichts zu tun hat, s. Berneker s. v. ëzvo.

aper, ibex. - Russ. jebátb, ai. yábhati sind Synonyma von lat. futuere, können also durch das meinem Sprachgefühle nach lediglich kausativische nhd. begatten nicht wiedergegeben werden.

aro. - Lies aru (lett.) statt ar'u und ratajb (ksl.) statt rataj. augur. - Lett. fchürētës 'lauern' (im Glossar richtig geschrieben) hat $-\bar{u}$ - und nicht $-u$-. Auch empfiehlt es sich, in sprachwissenschaftlichen Werken die lett. Infinitivendungen $-\bar{a} t$, $-\bar{e} t$, -it wie auch sonstige lettische Formantien mit etymologisch langem $\nabla$ okal mit dieser Länge zu schreiben, wenn die Formen auch vielfach mit kurzem Vokal gesprochen werden; s. auch unten s. v. callis, fallo, fel und scandula.

aurōra. - Wegen slav. (j)ustro, (j)utro 'Morgen' s. Arch. slav. $\mathrm{Ph} .35,55 \mathrm{ff}$.

bēta. - Wegen klruss. bótva (so betont) 'Mangold', russ. bótvá 'Beetenlaub' s. Arch. slav. Ph. 34, $555 \mathrm{ff}$; wegen slavischer Abkömmlinge aus lat. betta und blitum s. auch Berneker s. v. blitva.

bibo. - Wegen lit. pénas s. unten opimus und pinnus.

caballus, mannus. - Der in den russ. Wörterbüchern auf Grund poetischer Quellen angesetzte Akzent in aruss. komon 'Pferd' (kómonz) ist besser fortzulassen; denn die Betonung des Wortes in der gesprochenen Prosa braucht nicht notwendig der in der Poesie zufällig belegten gleich gewesen zu sein.

caelebs. - Lies cégzchъ (ksl.) statt kĕgbchı (1. Aufl. richtig) und l'audis (lett.) statt laudis.

caelum. - Ksl. sinz (io-Stamm; phonetisch genauer durch sinib oder sinjb zu bezeichnen; ein *sinz existiert nicht) bedeutet nicht 'grau', sondern 'blau'. - Lett. schk'ists hat zwei Bedeutungen: 1) 'dünnflüssig' = lit. skýstas und 2) 'rein, klar, keusch' $=$ abg. cistz. Letztere Bedeutung könnte auf dem Einflußß des russ. čistyj beruhen.

caerimōnia. - Abg. cěna kenne ich nur in den Bedeutungen 'Preis, Schätzung, Würdigung', nicht aber in der Bedeutung 'Ehre'. Die Bedeutungsangabe des abg. Wortes durch 'Ehre' (merkwürdigerweise verdeutscht auch Berneker abg. cèna s. v. durch 'Ehre" (sogar an erster Stelle) neben 
'Preis') scheint auf falscher Übersetzung von griech. $\tau \mu \eta \dot{~ z u}$ beruhen. Im Lateinischen steht an den betreffenden Bibelstellen pretium.

caleo. - Ksl. slota bezeichnet nicht eine Jahreszeit, wie wir aus dem 'hiems' bei Miklosich Lex. Pal. und Et. Wb. schließen könnten, sondern eine Witterungsart und kann infolgedessen nicht durch 'Winter' verdeutscht werden; vgl. die Beispiele im Lex. Pal., wo das Wort mit mrazz 'Frost', znojo 'Hitze' und mit velika vétra 'große (heftige) Winde' koordiniert gebraucht wird, und die modernen Bedeutungen, die zwischen 'nasses Wetter' und 'winterliches Wetter' scbwanken, z. B. russ. dial. slota 'schlackeriges, nasses Wetter, Schnee und Regen usw.', serb. slöta 'feiner Regen', cech. slota 'Schneegestöber, schlechte Witterung'. Wenn wir dem 'hiems' Rechnung tragen und zugleich beachten, daß das Wort in der Verbindung mrazoms $i$ slotoju $i$ znojems (russ.-ksl. Instr. Sing.) nicht gleichbedeutend mit mrazb sein kann, werden wir es am besten mit "naßkalte Witterung, Schlackerwetter' übersetzen. - Lies szarmà (lit.) statt szarnà, vgl. KLD s. v., Leskien Nom. 424. - Lies srên (nslov.) statt srên. - Der lit. dial. Name des 'August', der bei Nesselmann 518a szillus geschrieben wird, ist nach der zweifellos richtigen Vermutung bei KLD und Leskien Nom. 323 besser als szilius, denn als *szilus, aufzufassen; denn Nesselmanns $l$ und $l l$ (dieses bezeichnet die Kürze des vorhergehenden Vokals, wie auch $r r$, s. unten dirru s. v. derbiōsus) können seiner Schreibpraxis gemäß auch als $l^{\prime}$ gelesen werden (Fälle, wo das geschehen muß, s. unten s. v. minus, vĩlis, volo), und bei einer solchen augenscheinlich jungen, vielleicht sogar künstlichen, Bildung können wir nur das produktive ' $u$-Formans und nicht das bei Substantiven erstarrte $u$-Formans erwarten.

callis. - Es würde sich empfehlen, neben abg. klada 'Holz, Balken' auch die russ. Form kolbda 'Holzblock, Klotz' anzuführen, damit nicht ein Leser mißverständlich in abg. kladdieselbe Ablautstufe sieht wie in lat. clädess. - Die konstruierte vorslavische Grundform von cech. klest, klest' 'Zweig' muß, da -e- auf urslav. -é- zurückgeht (Berneker s. v. klěsno, klěščo, dessen Etymologie aber abweicht), *klëdti- (vorslav. Gestalt; urslav. ist nur *klěstz möglich, da -ëdt- ein Anachronismus wäre) geschrieben werden. - Lies kléstiti (nslov.) statt klèstiti. - Lett. kluburāt 'hinken' muß mit langem -ā-geschrieben werden; vgl. oben augur. 
cannabis. - Neben poln. pienka 'Hanf' wäre an erster Stelle die mit Rücksicht auf russ. penzká (Ulaszyn - brieflich - nimmt Entlehnung des wenig gebräuchlichen veralteten poln. Wortes aus dem Russischen an) ältere (allerdings seltenere) Form pieńka anzuführen.

capio. - Lies $k^{\prime} e p j u$ (lett.) statt k'epju. - Daß aruss. čeps neben dem jetzt gewöhnlichen russ. cépb 'Kette' eine lautlich entstandene dialektische Nebenform sei, ist mir nach Kenntnisnahme von Bernekers Artikel cép'o 2. zweifelhaft geworden; denn es ist daraus zu ersehen, daß neben russ. pricépitzsja "sich an etwas festhalten, anklammern', cèpkij 'gut kletternd, zäh, klebrig' usw. auch ein slav. čep- in ähnlichen Bedeutungen vorhanden ist, vgl. noch das bei Berneker fehlende russ. dial. čepátz 'anhaken, hängen bleiben, anrühren, fassen'. Immerhin brauchen nicht beide Substantiva alt zu sein, und es ist anzunehmen, daß das eine aus dem anderen durch Anschluß an ein Verbum entstanden ist. $\mathrm{Daß}$ Vermischungen von $\check{c} e p$ - und cép- stattgefunden haben, ist aus den von Berneker angeführten Worten mit klruss. $\check{c} i p$ - neben solchen mit ćip- (aus cép-) und čep- zu ersehen; denn klruss. čip-, das lautlich nur auf ein im Jrslavischen unmögliches * čèp- zurückzuführen wäre (urslav. *čip- hätte zu klruss. čyp- geführt), ist nur als Kontaminationsbildung verständlich. Wieweit slav. čep- auf einem vorslav. *kep- (in lit. atkémpu (wohl eigentlich -kễmpu dial. für -kempù) at-kèpti 'abfallen, sich ablösen', lett. k'ept 'haften, mit den Klauen anpacken')'), wieweit es auf einer Lautnachahmung beruht, ist kaum zu entscheiden; jedenfalls müssen bei einer Untersuchung dieser Frage die gleichbedeutenden von Berneker s. v. capajo, čapajo und čsparr behandelten Sippen mitberücksichtigt werden; merkwürdigerweiśe machen gerade die am wenigsten zu capio, cépi stimmenden

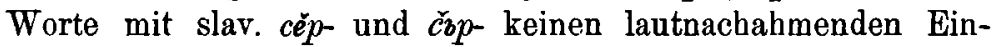
druck; und cap- und čp- könnten neben cap-, obgleich räumlich weiter verbreitet, als cép- und $\check{c} \bar{p} p$-, viel eher erst auf slavischem Boden enstanden sein ${ }^{2}$ ).

1) Vielleicht können wir balt. kep- und das gleichbedeutende kerin lit. at-kérti, lett. $k^{\prime}$ ert (IF. 22, 316 ff., 340) mit der im Baltischen, besonders im Litauischen, zu beobachtenden Tendenz, eine sekundäre $e$-Stufe zu schaffen (unten fodio, pinus und Fn., valeo) in Verbindung bringen oder (des Slavischen wegen) in ihnen Ausgangspunkte dieser Tendenz sehen.

2) Walde setzt die Wurzel von capio als *qap- an. Mir erscheint

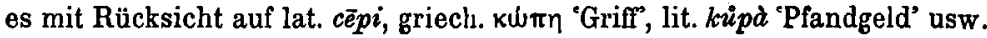


carpo. - Die Zugehörigkeit von abg. čr zur Sippe von carpo wird von Berneker s. v. črpo durch Bedeutungsparallelen gestützt; ebenda, wie auch s. v. $\check{c}$ rrvo, wird die eventuelle Zugehörigkeit eines russ.-dial. čerpz 'Sichel' (neben serpb und dial. črvz) erwogen. - Lett. zirpe 'Sichel' hält Leskien Nom. 269 für ein estnisches Lehnwort. - Neben lett. kräpju krāpt 'stehlen, betrügen' wäre auch lit. krópti 'stehlen' (Leskien Abl. 376; das Präsens scheint nicht belegt zu sein) anzuführen; s. auch unten creper. - Sehr erwägenswert ist auch die $\mathrm{Zu}$ gehörigkeit von ksl. črèpz 'Scherbe', preuß. kerpetis 'Schädel' usw. zu unserer Sippe, vgl. Berneker s. v. čerpb.

cattus. - Der bei Miklosich Lex. Pal. und Sreznerskij Mat. als Stichwort angeführte Nom. Sing. M. kotelb 'felis' ist eine unbegründete Konstruktion aus den obliquen Kasus, und Berneker s. v. koto 2. hat vollständig recht, daß er die ebenfalls bei Miklosich a. a. $O$. stehende durch rectius fortasse eingeleitete Femininform kotelja gewählt hat, denn der Dat. Plur. koteljamı im selben Satze wie pzsomz 'den Hunden', wo also die alte Form für den Dat. Plur. M. noch gebraucht wird, deutet in Ermangelung von Gegenbeweisen durchaus nur auf die femininische Flexion des Wortes hin. Noch weniger berechtigt ist Waldes dem grammatischen Geschlecht zuliebe konstrnierte Bedeutungsangabe 'Kater'. In der gesprochenen Sprache dürfte das Wort 'Katze' (so Berneker) ohne Rücksicht auf das Geschlecht bezeichnet haben; in den beiden von Sreznerskij angeführten Sätzen dient

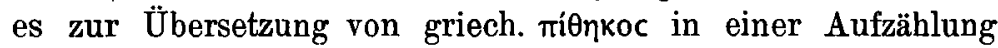
von allgemeinen, das Geschlecht nicht berïcksichtigenden, Gattungsnamen für verschiedene Tiere. Ohne Zweifel ist die Übersetzung ungenau, indem der Name eines exotischen Tieres durch den Ausdruck für ein den Slaven bekanntes Tier ersetzt wurde; indessen ist anzunehmen, daß der Übersetzer seine Auswahl unter ebenfalls nur allgemeinen Gattungsnamen getroffen hat. caveo. - Der Infinitiv čćc ('hören') ist in dieser Gestalt bloß weißrussisch richtig; klruss. lautet er čúty, serb. caùti; lies

ratsamer ${ }^{*} q \bar{e} p$ - und ${ }^{*} q \delta p$ - als die Hochstufen anzusehen und die in den einzelnen Sprachen $-a$ - in der Wurzelsilbe enthaltenden Formen auf die

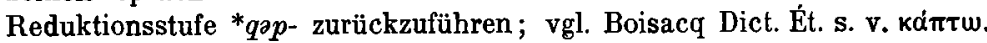
Ai. kapat̄ 'zwei Handvoll' könnte dann (sekundäres ?) *qop-enthalten, das sich zu griech. $k u ́ u \eta$ so verhält, wie balt. kep- zu lat. cēpi. Wegen der Ablautsverhältnisse der scheinbaren Parallelwurzel *ghab-, die vielleicht auf Nachahmung unserer Wurzel beruhen, s. unten habeo Fn. 
Berichtigungen u. Ergänzungen zu Waldes Lat. Etym. Wörterbuch. 197

mit Akzent nslov. čúti, serb. čúvati ('hüten'). - Ksl. štutiti 'fühlen' ist mit abg. cuti 'fühlen' nicht rerwandt; aus serb. ćutiti ds. ist zu ersehen, daß der Anlaut št- nicht auf sk- (dann würde auch serb. št- stehen), sondern auf $t j$ - zurückgeht. Eine Nebenform ksl. čutiti scheint nicht zu existieren; Miklosich Et. Wb. s. v. tjut- hat diese Form wohl fälschlich aus sloven. čútiti erschlossen, dessen $\check{c}$ - aber nach Ausweis des serb. $c$ - gleichfalls auf $t j$ zurückgeht. Sollte sich ein čutiti in einer russ.-ksl. Quelle noch finden, so würde die normale russische Lautgestait des im Kirchenslavischen als št- erscheinenden Anlauts vorliegen; bei nicht russischer Überlieferung könnte an Anlehnung an čuti gedacht werden. Jedenfalls sind hier bei Walde beide Formen čutiti und štutiti zu streichen.

-ce. - Statt lit. dial. szẽ (so betont bei KLD s. v. szẽn) ist besser die normalere Form szẽn anzuführen, und zwar schon, um einer etwaigen falschen Auffassung des Lesers, daß szẽ mit lat. -ce identisch sei, vorzubeugen. Beide Formen szẽn und szẽ sind vom Stamme szia- (*ikio-) aus gebildet, nicht von dem im Baltischen nicht belegten Stamme * $\hat{k}_{e-} \mid \hat{k} o-$, und das $-e-$ ist als aus - $a$ - entstanden anzusehen. Wenn es auch nicht undenkbar ist, daß szẽ und szẽn zwei verschiedene Bildungen vom selben Stamme seien, so ist es doch wahrscheinlicher, in szẽ eine jüngere Sandhidoublette von szẽn zu sehen; wegen ähnlicher Sandhierscheinungen bei Adverbien vgl. Doritsch Beiträge $\S 32,66$, 97, 127, 159, 190, 235, 279, 306.

cippus. - Abg. sz-cěpiti 'spalten' (bessere Schreibung als scèpiti) enthält die Präposition sz- und weist nicht auf einen ursprünglichen Anlaut $s q-;$ vgl. Berneker s. v. cép'o 1.

cĩvis. - Das, wie es scheint, nur éin Mal, und zwar aus dem 17. Jahrhundert überlieferte russ.-ksl. sěmı 'persona' ist vorsichtshalber besser fortzulassen oder wenigstens als unsicher zu bezeichnen. - Die Bedeutungsangabe 'gütig; mild' für ksl. posivo 'Tavoûproc, callidus, sagax, benignus' ist ungenügend. Der Bedeutungsumfang des Adjektivs und seiner Ableitungen ist ein ziemlich großer; die bei Sreznerskij Mat. für posivъ sowie für das abgeleitete posivbnz angeführten russischen Synonyma lassen sich etwa durch 'fähig, geeignet, passend, nützlich, bestimmt für etwas, überzeugend, geneigt zu etwas' wiedergeben. Das 'benignus', das Miklosich Lex. Pal. neben anderen Adjektiven bietet, will zu den übrigen Bedeutungen nicht recht passen; 
vielleicht liegt da eine nur in einem singulären Satzzusammenhange entstandene scheinbare Bedeutungsverschiebung vor, die wir nicht abstrahieren dürfen. Der etymologische Zusammenhang mit der Sippe von lat. civis erscheint unter diesen Umständen mehr als zweifelhaft.

clādēs. - Wegen russ. kladú 'verschneide' s. eine andere bei der geringen Ausdehnung des Wortes fast wahrscheinlichere Eventualität bei Berneker s. v. klado 2. Keltischen Ursprung vermutet Schachmatov Archiv sl. Ph. 33, 90, was wenig einleuchtend erscheint. Für ksl. kladivo 'Hammer' ziehe ich die Zurückführung auf *qold- und Beziehung auf ein Präs. *qoldō ror; anders Berneker s. v. - Die Bedeutungsangabe 'schlagen' für abg. kolja klati ist ungenau. Das Verbum bedeutet 'stechen, schlachten', wovon ersteres rom slavischen Standpunkt aus als Bedeutungszentrum, letzteres als Spezialisierung davon aufzufassen ist; gemeinslavisch tritt auch eine dritte Bedeutung 'spalten' scharf hervor, die ebenfalls für das Sprachgefühl eine $\nabla$ erengerung von 'stechen' ist. Wenn 'schlagen' die ursprüngliche Bedeutung gewesen sein sollte, so ist sie jedenfalls für das slavische Sprachempfinden ganz verdunkelt worden. Aus Bernekers Ausführungen s. v. kol'o, wo auch die einzelsprachlichen Bedeutungsangaben zu vergleichen sind, geht klar hervor, daß die Gesamtbedeutung des slavischen Verbums von den Bedeutungen der idg. Wurzel *qolä- (Bernekers Ansatz * qelā- ist kaum gerechtfertigt) 'schlagen' durchaus verschieden ist. Im Falle der Anerkennung des etymologischen Zusammenhanges mit dieser Wurzel würde es sich also um eine schon in vorhistorischer Zeit fertig vollzogene Bedeutungsverschiebung durch den Einfluß etymologisch unverwandter Worte handeln. Für diesen Vorgang ist Waldes Satz: "doch ist nur in abg. klati in der Bedeutung 'stechen"..... ein ursprünglich verschiedenes Wort eingeflossen" nicht bezeichnend. Es besteht eben kein semasiologischer, sondern nur ein lautlicher Zusammenhang mit der Sippe des 'Schlagens'. Übrigens scheint mir Bernekers (a. a. O.) Skepsis gegen einen Zusammenhang von klati mit der Sippe von lit. skeliu skélti 'spalten', aisl. skitia 'trennen, scheiden' nur insofern vollauf gerechtfertigt, als lautliche Urverwandtschaft von *qolā- "schlagen" mit *sqel- 'spalten' unbedingt abzulehnen ist. Indessen kann der induzierende Faktor für die semasiologische Umwandlung von 
slav. *kol-, den Berneker ja in außerhalb der Sippe *qola- stehenden Worten sucht, gerade in der Sippe *sqel- enthalten sein, die den slav. Worten der Bedeutung nach näher steht, als irgend eine andere. Und wenn kymr. cola, col 'Spitze, Ähre', nhd. hulst 'Stechpalme' usw. ein uridg. *gel- 'stechen' repräsentieren, dann glaube ich kaum, daß wir diese Wurzel für etwas ganz Selbständiges zu halten brauchen, da sie sehr wohl die gesuchte $s$-lose Nebenform von *sgel- sein kann, auf deren Nichtvorhandensein Bernekor aufmerksam macht. Übrigens führt Walde s. v. scalpo ein zu *sqel- gehöriges ai. kálä 'kleinster Teil' an, das ebenfalls kein $s$ - enthält. Weiteres zu den besprochenen Sippen s. auch unten s. v. scalpo.

clango. - Lett. klad/êt 'gackern' ist mit - $d /$ - und nicht mit - $d s-$ zu schreiben. $\mathrm{Zu}$ den Worten mit Ablautsentgleisung kann der Übersichtlichkeit halber lett. klëgāt 'schreien' zugefügt werden.

claudus. - Wegen ksl. kljuditi ' $\lambda \hat{\gamma} \gamma \in \imath \nu$, ó $\mu \lambda \lambda \epsilon i v$, deridere' vgl. jetzt Berneker s. v. $k t^{\prime} u d z$, der seine frühere Ansicht aufgegeben hat. Wegen russ. koldy'ka 'lahmer, hinkender Mensch', koldykats 'hinken', kólča 'Hinkender' (bei Walde alle drei unakzentuiert) vgl. Berneker s. v. krbltajo.

clīno. - Das lettische Wort für 'aulehnen, stützen' lautet slënu slët, nicht slinu slit, was auf falscher Lesung von Bielensteins slinu slit (-i-graphisch für Leskiens $-\dot{e}$-) beruht. - Zu lit. szlelti 'lehnen' bietet Szyrwid Dict. 308a das interessante alte Präsens prißteiu (lies $-j u$ ) s. v. przystosuje (accomodo, ... apto, transfero), prifißteiu s. v. przytulam sie (applico me); dazu ebenda auch das Verbalabstraktum prifißteimas (lies-jimas) s.v. przytulenie, das auf ein Präteritum *-szteiau (lies -jau) schließen läßt. Ein prifißtejmas findet sich auch in Jass. pam. 2. 342. 21. Aus den unten s. v. lìbo näher anzuführenden Gründen können wir das $\beta$ te- nicht als szlë-, sondern nur als szle- oder szlé- auffassen; in unserem Falle dürfte - $\beta$ teiu als dialektische Entsprechung eines urlitauischen ${ }^{*}$ szleju anzusehen sein, das dem ai. šráyati "lehnt, legt an' gleich ist; vgl. auch lat. clémens aus * k̂leiemeno-s Part. Präs. Pass. und cliens aus *ileients- Part. Präs. Akt. (Walde s. v.); das Präteritum ist demnach als *szlejau anzusetzen. Die jetzigen Formen szlëjù szlëjãu enthalten das aus dem Infinitivstamme übernommene nur vor konsonantisch auslautenden Endungen lautlich entwickelte $-\dot{e}$ - aus $-e i$ - und sind nicht etwa 
auf uridg. *k̂klei-i- zurückzuführen. Gleichartige Fälle werden unten s. v. frio und lïbo besprochen.

clueo. - Sloven. slüt M. (so betont) 'Verdacht, Ahnung' ist seiner Vereinzelung und des Genus wegen kaum ein altes Wort, sondern wohl ein Postrerbale zu slütim slititi 'ahnen', das seinerseits allerdings wohl ein Denominativ ist. Als slavisches Wort mit -t- Formans wäre in erster Linie serb. slutìm slútiti 'áhnen' zu erwähnen.

columba. - Lies golubój (russ.) statt golubýj. - Lit. gelumbẻ bedeutet nicht 'blaues Tuch', sondern überhaupt 'Tuch', was natürlich nicht die Möglichkeit einer ehemaligen engeren Bedeutung ausschließt. Wegen der allein vorliegenden allgemeinen Bedeutung ist auf die Wörterbücher zu verweisen. Daß (schon) zu Szyrwids Zeiten eine Beziehung zur Farbe nicht (mehr) gefühlt wurde, ist klar ersichtlich daraus, daß Dict. 65a zur Übersetzung von poln. tazur, sukno 'pannus caeruleus' nicht gietumbe $e^{1}$ ) allein, sondern gietumbe melina (mélynas 'blau') gewählt worden ist; vgl. auch $130 \mathrm{~b}$ gietumbe burnatina arba melina als Wiedergabe von poln. granat 'purpura violacea aut caerulea'. Dagegen dienen getumbe (sic!)'), gietumbes (so IV, $303 \mathrm{a} ; \mathrm{V}$ fälschlich -bas) darimas, getumbinis (sic!) und gietumbinikas auf S. 356 und 357 zur Wiedergabe von sukno 'pannus', sukiennictwo 'lanificium', sukienny 'panneus' und sukiennik 'lanarius, lanificus'; andere Stellen für das Wort s. S. 6b (bis) und $90 \mathrm{a}$ s. v. barwa, barwica, kir.

confūto in den Nachträgen. - Bei Erwähnung von lit. baudžiù baüsti 'strafen, züchtigen' hätte die früher ganz allgemein angenommene Verbindung dieses Wortes mit bundiu bùsti 'erwachen' usw. nicht verschwiegen werden dürfen, vgl. mit der Bedeutung 'mit Worten strafen', d. h. 'zurechtweisen' got. anabiudan 'befehlen, anordnen', ai. bōdháyati 'erweckt, belehrt, teilt mit', ir. ro-bud 'Verwarnung', s. Berneker s. v. bl'udo, $b u d ' o$, bzd'o; vgl. insbesondere lit. bauslỹs 'Befehl' (Juškevič, geschrieben -y's), lett. bauslis 'Gebot', bausliba 'Gesetz' mit mhd, bot, aisl. bod 'Gebot'. Was aber ganz besonders die alte $\mathrm{Zu}$ -

1) Nach $k$ - und $g$ - schreibt Szyrwid in der Regel -ie- für - $e$ - und $-\dot{e}$-, wo $-i$ - das Palatalitätszeichen des Gutturals ist; nur ab und zu fehlt in der Schrift das - $i$-. Einen anderen Fall, wo $-i e$ - als ' $e$ - zu lesen ist, s. unten s. v. piget; sonst pflegt Szyrwid $-e$ - und $-\dot{e}$ - unterschiedslos durch $-e-$ und $-\bar{e}$ - durch $-i e-\mathrm{zu}$ bezeichnen. 
sammenstellung befürwortet, ist der Umstand, daß baũsti bei Juškevič a. a. $O$. einen weiteren Bedeutungsumfang hat, als wir ihn aus der Literatursprache kennen; als Bedeutungen werden angegeben: 1) 'schrecken, drohen, bedrohen'; 2) 'antreiben, anzeigen' (vgl. russ. po-buditz ds. zu buditz 'wecken'); 3) refl. 'beabsichtigen'. Hierbei sei noch bemerkt, daß für das im Litauischen spärlich belegte baudyti $=$ abg. buditi 'wecken' (Leskien Abl. 294) sich neuerdings ein weiterer Beleg gefunden hat, vgl. den Infinitiv baudýt zweimal bei Doritsch Beiträge S. 35, Z. 11 u. 13. Beachtenswert ist, daß das Wort als Synonym von vektuót (literar. vektüti) 'wachen' (S. 34, Z. 25, 26, 36 usw.) gebraucht wird, was auch Doritsch $\$ 59$ Veranlassung gegeben hat, es als 'bewachen' zu übersetzen. Es liegt hier also im Gegensatze zum Slavischen und Arischen (s. oben) nicht kausativische, sondern iterativische, Anwendung vor.

cōnīveo. - Da ksl. poniča ponicati 'oculos demittere', wie aus dem Infinitiv mit $-c$ - zu ersehen ist, das formale Iterativ zu poniknąti 'pronum esse' ist, wäre besser die Wortstellung zu ändern; auch wäre die Angabe des für Iterativa charakteristischen Infinitios wichtiger, als diejenige des mehrdeutigen Präsens.

crābro. - Das von Zubatý Rocznik Slawistyczny II, $4 \mathrm{f}$. als archaischer Nominativ auf uridg. $-\bar{e}$ zu en-Stämmen angesehene russ.-ksl. šrša 'Wespe' (neben sonstigem saršenz), das ich IF. Anz. 28, 36 anders zu erklären versucht habe, ist jetzt nach Leskiens Ausführungen in IF. 28, $137 \mathrm{f}$. als zu unsicher beglaubigte Form überbaupt zu streichen.

cremo. - Zu cremāre 'verbrennen' passen gut in Form und Bedeutung ksl. kremy, kremens 'silex', kremykb 'Feuerstein', lett. krams 'Feuerstein'; anders über diese Berneker s. v. In den einzelnen slavischen Sprachen wechseln die Bedeutungen 'Kieselstein' und 'Feuerstein', und aus dem Slavischen selbst ist nicht zu ersehen, welche Bedeutung die ältere war, sodaß wir hier für die Etymologie freien Spielraum haben, aber das lettische Wort, das nach Berneker kaum entlehnt sein kann, spricht für die Ursprünglichkeit der Bedeutung 'Feuerstein'. Diese Verhältnisse vergleichen sich denen der von Berneker s. v. krešo kresati behandelten Sippe, wo die Bedeutungen 'Feuer schlagen' und 'schlagen' überhaupt nebeneinander stehen, und wo auch Berneker Anknüpfung an lit. krósnis 'Ofen', kársztas 
'heiß’ für möglich hält. Natürlich kann kremy, wenn es zu cremāre gehört, nicht mit der auf die Vorstellung des 'Schneidens' zurückgehenden Sippe von ksl. pokroms 'margo panni', abg. kromè 'draußen' (Berneker s. v. kroma) verwandt sein; doch besteht ja auch keine solche semasiologische Beziehung zwischen kremy und pokromb, die eine Trennung erschweren würde.

creper. - Lit. krópti bedeutet nicht 'trügen, betrügen', sondern 'stehlen', lett. kräpt kommt in beiden Bedeutungen vor, s. auch oben carpo.

cruentus. - Es ist zwar nicht unwahrscheinlich, daß lit. krùvinas, abg. krzvъnz 'blutig' dasselbe $n$-Element enthält wie lat. cruentus, avest. xrvant- 'grauenhaft, grausig'; indessen ist die Gleichung cruentus = lit. krùvintas etwas gewagt, da letzteres das reguläre Partizipjum zu krùvinu krìvinti 'blutig machen' ist, während das lateinische und das avestische Wort den Eindruck einer Sekundärbildung macben; daß das Verbum erst zum Partizipium hinzugebildet sei, ist in Anbetracht der großen Produktivität der lit. Verba auf -inu, deren Grundlage jedenfalls schon vorbaltisch ist, kaum anzunehmen.

dē. - Das litauische Verbalpräfix $d a$ - dürfte aus russ.poln. do- entlehnt sein, vgl. Leskien Nom. 457. Dafür spricht vor allem der Umstand, daß dieses Präfix im Russisch-Litauischen ungleich häufiger ist, als im Preußisch-Litauischen, wo in der Literatursprache durchaus $p a$ - herrscht, vgl. Doritsch Beiträge $\S 264,331$. Sehr instruktiv für die Verhältnisse des Präfixes in älterer Zeit ist es, daß es bei Szyrwid Dict. fast nur zur Übersetzung von poln. do- in Komposita dient; rgl. auf S. 41 bis 45: daaugu s. v. dorastam; dadirbu s. v. dokonywam, dorabiam; daduomi s. v. dodaje; daeydineiu s.v. dochodze; dakatbu, dafikatbu. ko s. v. domawiam czego; dateydimas s. v. dozwolenie; daraßau s. v. dopisuje; daficiupineiu s. v. domacać sie; dafidirbu s. v. dorabiam sie; dafweriu s. v. doważam; daßoku s. v. doskakuje; dawerdu s. v. dovarzam; dawiadamas s. v. dowodny; vgl. $175 \mathrm{~b}$ nedaaugis $\mathrm{s}$. v. niedorosty. Bei den nicht reflexiven Worten gibt es nur 6ine Ausnahme: daduomi 161 b s. v. nadqzam komu 'sufficio'; von Reflexivverben mit $d a / i$ - finde ich noch 14 neben polnischen Entsprechungen mit do- gegenüber 6 Fällen ohne solche Entsprechungen. - Lett. $d a$ - wird nach Ulmann Lettisch-Deutsches Wörterbuch nur in den Grenzgegenden mit dem russischen Sprachgebiete gebraucht, ist also auch der Entlehnung verdächtig. 
Berichtigungen u. Ergänzungen zu Waldes Lat. Etym. Wörterbuch. 203

defendo. - Petrs (BB. 21, 213) angeblich "schlagen" bedeutendes russ. ugodito ist sicherlich kein anderes Wort als ugodits 'treffen, abpassen', das meist in freundlichen Sinne 'gefällig sein' gebraucht wird, vgl. aber auch ugoditı kudá 'wohin geraten, kommen, irgendwo sein', sowie solche nicht besonders häufige Wendungen wie ugodits čems vo čto "mit etwas (einer Kugel) etwas treffen (einen Baum), in etwas (jemanden ins Auge), wo es sich um ein Treffen im feindlichen Sinne handelt. Zur Etymologie vgl. Berneker s. v. godz; das Bedeutungszentrum der ganzen Sippe ist treffen, und die älteste Bedeutung dürfte etwa 'abpassen, die rechte Zeit abtreffen' gewesen sein, woraus sich auch die Bedeutung 'irgend etwas zu treffen suchen', d. b. 'zielen' entwickeln konnte. Petrs verkehrte Etymologie dürfte auf einer inißverständlichen Auffassung des in den russischen Wörterbüchern beliebten Beispielsatzes: vo grudb on̋ strëlój ugodilo 'in die Brust traf er mit dem Pfeil' beruhen; wenigstens zweifle ich stark daran, daß das Wort jemals 'schlagen' ohne die im Vordergrunde stehende Beziehung zum 'Treffen, Zielen' bedeuten kann. Es ist bedauerlich, daß Berneker, der a. a. 0 . Petrs Irrtum in bezug auf čech. hoditi 'werfen', das letzterer ebenfalls mit lit. gadinti 'beschädigen' usw. verbindet, aufgeklärt hat, es unterlassen hat, bei ugoditb die falsche Auffassung zu erwähnen, denn es ist nur allzunatürlich, daß ein unbefangener Leser auch beim aufmerksamen Lesen infolge der unrichtigen Bedeutungsangabe nicht darauf kommt, sein Wort mit dem Bernekerschen $\mathrm{zu}$ identifizieren.

dens. - Statt lit. dantótas 'gezähnt' muß es heißen dantütas resp. vorsichtshalber besser ohne Akzent dantitas. Nesselmanns (126a) dantotas dürfte eine falsche Wiedergabe von Szyrwids Dict. zweimaligem duntuotas (-unt- lautgesetzlich aus -ant-) sein; vgl. 169 a duntuotas s. v. narzynany 'serratus, multifidus, denticulatus', 98b ratas duntuotas s. v. kotko abo koto zablkowate jako u zegarów, we mtynach 'tympinum dentatum'. Auch Juškevič bietet ein dantütas. Das literarische Adjektiv ist dantýtas, das vielleicht das Part. Perf. Pass. zu dantyjù dantýti 'zahnen, Zähne bekommen' ist. Fin historischer Zusammenhang zwischen den baltischen $t$-Bildungen und lat. dentātus dürfte kaum bestehen.

derbiōsus. - Das Präsens dirù zu lit. dìrti 'schinden' ist zu streichen, da wir über die finiten Formen dieses Verbums nicht genügend unterrichtet sind, vgl. Leskien Abl. $323 \mathrm{f}$. Das 
diru bei KLD[ stammt aus Nesselmanns (143b) dirru, dessen -rr- indessen seiner Schreibgewohnheit nach ebensogut ein gesprochenes $-\dot{r}$ - reflektieren kann (ähnlich groju für Szyrwids grioiu, s. unten graculus), sodaß wir die Form besser als *diriu ansetzen könnten; denn letzterer Präsenstypus ist der normalere bei den auf Liquida auslautenden Wurzeln, vgl. Leskien Abl. 386f. Außerdem können wir, wenn wir Nesselmanns Quellen nicht kennen, nicht entscheiden, welche von den in einem Averbo stehenden Formen er gehört resp. gelesen, und welche er konstruiert hat; und seine Konstruktionen können falsch sein. Im vorliegenden Falle stimmt sein Präteritum dirrau, das nur als *dirau gelesen werden kann (-rr-bezeichnet wie - $l l$ - in szillus, villu (s. oben caleo und unten villis) die Kürze des Vokals, und *diriau wäre eine ungewöhnliche Form) nicht zum Präsens: wir würden entweder *deru $*$ dirau oder *diru resp. *diriu *dyriau (könnte bei Nesselmann *dyrau geschrieben werden) erwarten; eine der beiden Formen muß also falsch sein. Wie Kelchs dyru dyrau 'steche Rasen $\mathrm{ab}^{\text {' }} \mathrm{zu}$ lesen ist, ist auch unklar. Aus moderner Zeit bietet Juškevič derù dýriau dìrti 'schinden, hauen' und daneben déru (vielleicht Schreibfehler für *dériu = literar. *deriù) dériau dérti; auch hier bestehen zwischen den einzelnen Formen Inkongruenzen, und wir können an ihrer Richtigkeit zweifeln.

dissipo. - Einen Infinitiv ksl. stpati 'fundere', rastpati 'dissipare' (Walde fälschlich -pere) kann ich nicht finden. Das Primärverbum lautet abg. szpq suti 'schütten, streuen'; ein $\bar{a}$-Stamm ist nur das Iterativ sypati 'schütten', rasypati 'ausstreuen', das bei Walde auch angeführt ist. Ein alter Stamm *szpa- 'schütten, streuen' scheint im Slavischen überhaupt nicht belegt zu sein; das seltene apoln. ospac scheint eine Neubildung zu sein und kann in seiner Isoliertheit nicht zur Konstruktion eines urslav. *szpati Veranlassung geben. Vorhanden ist nur ein sopati, Präs. szplją 'schlafen', das mit sopq nichts zu tun hat. Es wäre ja verlockend, das Iterativ sypati auf ein primäres *szpa-, entsprechend lit. supa ũ Prät. 'wiegte, schaukelte', lat. supāre 'werfen' zurückzuführen, vgl. Arch. sl. Ph. 32, 333; doch sind bekanntlich derartige Iterative auch zu solchen Verben gebildet worden, wo kein alter $\bar{a}$-Stamm mit kurzem Wurzelvokal vorhanden war (Beispiele a. a. O. 329ff.); außerdem ist speziell bei sypati auch vorslavische Entstehung möglich (a. a. O. 330). - 
Berichtigungen u. Ergänzungen zu Waldes Lat. Etym. Wörterbuch. 205

Lies ošibaja sẹ (abg.) statt ošibq sę. Die hergehörigen nicht akzentuierten russischen Worte lauten mit Akzent šibátz, šçbkij, ošibátosja.

diū. - Lit. dabartanas ist in dabartinas ('jetzig') zu ändern; wegen Nebenformen s. Leskien Nom. 407.

dōlium. - Das hergehörige slavische Nomen, das nur spärlich und zwar in älterer Zeit nur in mbg. und russ. Überlieferung belegt ist, ist in normalisierter ksl. Gestalt $d b l y$, Gen. dzlzve zu schreiben, also mit Vokal zwischen $d$ - und $-l$-; die belegten Formen s. bei Berneker s. v. dbly. Der bei Walde an zweiter Stelle stehende Nom. Sing. delzva beruht wohl auf falscher Auffassung des -e- in bulg. délva (bei Walde ohne Akzent) und im belegten russ.-ksl. delvi aus ${ }^{*} d z l b v i$, Lok. Sing. und Nom. Plur. zu doly; ein Nom. Sing. auf $-a$ ist in älterer Zeit weder belegt noch auch aus den belegten Kasus zu erschließen.

dōnicum. - Ein russ. kudano ist mir unbekannt; wenn es vorhanden ist, ist es jedenfalls eine junge Zusammenrückung von kudd 'wohin' mit einer Partikel -no, deren unmittelbare Gleichsetzung mit lat. -ne in quandone sehr fraglich ist. Wegen der ebenfalls problematischen Wortgleichung quando $=k u d a ́$ s. unten quando.

edo. - Lies jadb (abg. 'Speise') statt jadz.

èmungo. - Es heißt im Lettischen nicht mükt, sondern mukt (Präs. mukku aus *munku), und die Bedeutung ist besser als 'sich abstreifen, in einen Sumpf einsinken, fliehen' anzugeben. Übrigens ist auch ein lit. mùkti intrs. 'entwischen, eilen' belegt, vgl. Leskien Abl. 303. - Von den angeführten slavischen Worten ist smyčati zu verbessern in smycati ('schleppen, ziehen') und mučati in smučati ("kriechen').

eo. - Abg. jadq jachati ist im allgemeinen ebenso wie das Iterativ ksl. jazditi nicht durch 'reiten' sondern durch 'fahren' zu übersetzen, s. Berneker s. v. jado und jaždżo, wo für 'reiten' der Ausdruck ksl. jazditi na konji '.... . auf dem Pferd' angeführt wird; doch dürfte in Fällen, wo die Situation einen Zweifel ansschließt, der Zusatz auch fortbleiben könnon. Daß in den modernen südslarischen Sprachen auch beim alleinstehenden Verbum die Bedeutung 'reiten' überwiegt, dürfte auf einer jüngeren Spezialisierung aus einer allgemeineren Vorstellung beruhen. Das slavische Sprachgefühl kennt nämlich keine prinzipielle Scheidung der Begriffe 'fahren' und 'reiten'; 
gemeinslav. *jachati, *jěchati, *jazditi, *jèzditi bezeichnen in Gegensatze zu iti 'gehen' jede Art der Fortbewegung vermittelst eines Fahrzeuges oder eines Tieres; 'fahren' und 'reiten' sind nur Spezialvorstellungen eines allgemeineren Begriffes, den wir im Deutschen nicht einheitlich ausdrücken können. Das Polnische und Russische stehen dem Altbulgarischen und wohl auch dem Urslavischen sehr nahe. Poln. jechac, russ. jëchatb bezeichnen für sich allein in der Regel 'fahren' und werden auch dann gebraucht, wenn es einem darauf ankommt, auf die bestimmte art der Fortbewegung hinzuweisen; um 'reiten' auszudrücken, gebraucht man im allgemeinen die adverbiellen Zusätze poln. konno 'zu Pferde', poln. wierzchem, russ. verchómz (Instr. Sing. zu wierzch, verchъ 'Gipfel, das Oben', zu übersetzen etwa durch) 'rittlings, zu Pferde'. Bulg. jáham bedeutet in der Regel 'reite', vgl. aber auch den Satz ciijáto kolá jáha, néja pèsen pée 'wessen Wagen man fährt, dessen Lied man singt.' Die Spezialisierung zu 'reiten' scheint im Nomen agentis ksl. jazdbcb, altruss. jězdécz, poln. jeździec 'Reiter' schon gemeinslavischen Ursprungs zu sein; bei derartigen Verbalnomina ist es ja häufig, daß sie nicht den vollen Bedeutungsumfang des Verbums zum Ausdruck bringen. Der slavische weite Bedeutungsumfang der Wurzelform $j a-, j e ̨-$ 'fahren, reiten' stammt wohl aus der Ursprache; lit. jöti 'reiten' dürfte auf einer vom Slavischen unabhängigen Verengerung des Begriffes beruhen.

fābala. - Lit. bóju bóti hat mit der Sippe von fäbula nichts $\mathrm{zu}$ tun und ist überhaupt kein Verbum des 'Redens', wie aus Kurschats ungeschickter Bedeutungsangabe geschlossen werden könnte. Es bedeutet eigentlich, was auch Kurschat selbst hinzufügt, 'worauf Rücksicht nehmen, worauf achten'; das negierte Verbum kann allerdings im Deutschen durch 'nicht danach fragen' in Sinne von 'kein Gewicht darauf legen' übersetzt werden, aber in einem positiven Satze dürfte die Übersetzung von boti durch 'fragen' kaum möglich sein. Kurschat hat sich also durch einen ganz vereinzelten Fall der deutschen Ausdrucksweise verführen lassen, ein ungeeignetes deutsches Wort an erster Stelle hinzuschreiben, wodurch die Etymologen verwirrt werden mußten. Das Verbum ist nach Leskien Nom. 457 eine Abstraktion aus den scheinbaren Komposita atbóti und daboti 'worauf achten', die ihrerseits Lituanisierungen des poln.weißruss. $d b a c$, klruss. dbáty ds. (mit Vermeidung der unbequemen 
Anlautsgruppe $d b$-) sind. Leider hat Berneker es unterlassen, das Fehlen von boti in seiner Sippe bajo 1. durch einen Hinweis auf Leskien oder besser auf sein Stichwort taba ( $d b$ - aus tob-, s. Berneker s. v. dybajo), wo er wahrscheinlich das lit. Wort zu erwähnen beabsichtigt, zu motivieren, so daß aus seiner Darstellung der Sippe *bha- nicht ohne weiteres auf die Unrichtigkeit von Waldes Etymologie geschlossen werden kann. Wegen der notwendigen Verbesserung von balija in balbji (-liji) (abg.) s. unten fascinum.

facio. - Statt abg. dètz 'Tat' stände besser: abg. -dètz in blago-dètb 'xáplc, Gnade, Dank'. Wenn in der späteren Literatur ein Simplex vorkommen sollte, so dürfte es auf künstlicher Abstraktion beruhen; zum Kompositum vgl. Berneker s. v. dètz.

fallo. - Lies balamutio (russ.) statt balamutz und bulwāns (lett.) statt bulvans (wegen der Länge s. oben augur); die zugehörigen serb.-sloven. Formen lauten akzentuiert serb. bàlvan, sloven. balvân, bolvân (Berneker s. v. balvanz).

famēs. - Poln. chęc, čech. chut' sind keine Verba, sondern femininische Substantiva in der Bedeutung 'Lust, Wille, Neigung', vgl. Berneker s. v. chot'o.

farcio. - Wegen lit. brukì brùkti 'einzwängen, drängen', ksl. brutz 'Nagel, Keil' vgl. IF. 28, 147 f. Lies b'́rkam (bulg.) statt brkkam.

fascinum. - Es lautet abg. im Nom. Sing. balbji (resp. jünger auch baliji), vgl. Berneker s. v. und wegen der Flexion solcher Stämme Leskien Gramm. abg. Spr. 117.

fastîdium. - Wenn lit. bódžiư 'ekle mich', ai. bỉbhatsatē 'empfindet Ekel' mit lat. foedus 'ekelhaft, garstig', lit. baisùs 'greulich, abscheulich' usw. verwandt sind, dann kann ein lat. gleichfalls verwandtes * fasti-s nur auf *bhadh-ti-s, resp. bhadh-s-ti-s, nicht aber auf *bhadh(s)ti-s, zurückgeführt werden; da bei zugehörigen Worten diese Ablautstufe sonst zu fehlen scheint, ist die von Walde auch ohnehin befürwortete Trennung des lat. fastídium von den übrigen Worten vorzuziehen.

fel. - Neben abg. żlıč́ und dem seltenen żlztz 'Galle' gibt es auch die Form zlă̌̀ (Meillet Etudes 265), vgl. auch bulg. zlz'čka neben żlz'čka 'Galle, Wut, Zichorie'. Es sind also im Slavischen, falls es sich nicht um Dissimilation des $-z$ - gegen das $-\check{c}$ - handelt, Reimworte von den beiden Wurzeln ${ }^{*} g\left({ }^{*}\right)$ hel- und ${ }^{*}$ ghel- vorhanden. Das lettische Wort für 'gelb' ist am besten dreltdins oder 
auch $d$ /eltäns, $d$ /eltềns zu schreiben, vgl. Bielenstein Lett. Spr.I, 280, Leskien Nom. 386. Die Form auf $-\bar{a} n s$ ist die für ein etymologisches Werk wichtigste, vgl. lit. geltónas 'gelb'; ähnliches s. v. augur. ferio. - Wegen russ. burávz (nicht -vz), burávlo 'Bohrer', die keinesfalls mit lat. foräre, ahd. borōn 'bohren' urverwandt sein können, vgl. Berneker s. v. bur. - Russ. brónja (bei Walde ohne Akzent) 'Brünne' ist dasselbe Wort wie russ.-ksl. brznja und ein germanisches Lehnwort, s. Berneker s. v. brznia. [Anders Iljinskij Praslavjanskoje bronja 'pancyrb', Něžinz 1911, S. 1-8. K.-N.] - Als normales lit. Präsens zu bárti 'schelten, streiten' ist nicht bariù sondern barù anzuführen. Nur letztere Form findet sich bei KLD, Juškevic und Szyrwid Dict. (55a, $66 \mathrm{a}, 350 \mathrm{a}, 354 \mathrm{~b}, 357 \mathrm{~b}$ : baru, baruofi refl. und barus Part. Präs. Akt. = barās). Waldes bariù stammt wohl aus Leskien Abl. 372, 417, der beide Formen bietet; dessen Quelle aber ist laut brieflicher Mitteilung Schleichers Lesebuch, wo im Glossar barù steht mit dem Zusatz in den Büchern meist bariù. Es handelt sich also, je nachdem, wie wir den Ausdruck 'Bücher' auffassen, entweder um eine in alten Texten bezeugte veraltete resp. dialektische Bildung oder um eine (vielleicht falsche) Form bei den von Schleicher benutzten Grammatikern oder Lexikographen. Jedenfalls gibt auch Leskien heute der Form barù den Vorzug. Es orscheint mir nicht ausgeschlossen, daß Schleichers bariù im letzten Grunde auf einer Grammatikerkonstruktion in Anlehnung an lett. baru 'schelte', (daneben jüngeres baru in den Dialekten, die auch buru, duru, kuru für sonstiges buru 'zaubere', duru 'steche', kuru 'heize' haben), abg. borja 'kämpfe, streite' beruht, was auch bei Schleichers lakiù (aus Scheicher auch bei Leskien Abl. 375) für sonstiges lakì 'lecke' neben abg. ločq ds. der Fall sein kann; dieselbe Entstehung vermutet Leskien jetzt auch (brieflich) für seine kaliù 'schmiede' und maliù 'mahle' (Abl. 335, $375,410)$, die sonst kalù und malì lauten, neben lett. kal'u, mal'u, abg. kolja 'steche, schlachte', melja 'mahle'. Die Übereinstimmmung des Lettischen und Slavischen spricht nicht unter allen Umständen für die Priorität der io- Bildung. Im Litauischen ist bei diesen Worten der Typus mali (= got. mala, lat. molo), im Lettischen und Slavischen derjenige von lit. ariù, lett. aru, abg. orja. 'pflüge' (= got. arja) produktiv geworden, und wir können nicht bei jedem einzelnen Wort die ursprüngliche 
Berichtigungen u. Ergänzungen zu Waldes Lat. Etỳm. Wörterbuch. 209

Bildungsweise feststellen. Bei unserem Worte ist allerdings mit Rücksicht auf lat. ferio der io-Bildung der Vorzug zu geben, vgl. auch ahd. berjan, aisl. beria, das aber auch ein ursprüngliches Iterativ *bhoreino repräsentieren könnte. Jedenfalls darf das etwas zweifelhafte lit. bariù nur dann dem lett. baŕu gleichgesetzt werden, wenn es sich in guten alten Quellen auffinden läßt. [Aus modernen Dialekten erklärt Doritsch bariù für die ihm geläufigere Form. K.-N.]

fertum. - Wegen russ. brága vgl. Berneker s. v.

fiber. - Über die verschiedenen Formen des litauischen Bibernamens orientiert Leskien Nom. 434, der an der Richtigkeit des $-\dot{e}$ - in Kurschats bẽbrus, bẻbrùs zweifelt, weil Kurschats von ihm selbst angegebene Quelle - Mielcke - nur -e- (-é-) hat; auch Nesselmann, der für $\dot{e}$ in der Regel $\tilde{e}$ schreibt (z. B. in der Infinitivendung -etti, s. unten fodio; $\tilde{e}$ ist bei ihm gleichzeitig das Zeichen für $\dot{e}$, s. unten leo), hat in seinem bébrus offenbar kein $-\dot{e}$ - gosehen. Wegen ebenfalls unmotivierter $-\dot{e}$ - bei KLD[ s. unten s. v. pecu und vetus. Wenn auch als die normale lit. Aussprache bebr- anzusehen sein dürfte (also auch bebrìnis in bebrinis zu ändern), so scheint dialektisch dennoch auch ein bébr- vorzukommen, vgl. das bébras (vielleicht für *bebras) bei Juškevič. Als lettisch kenne ich nur bebrs, Gen. bebra, aber kein bébris, vgl. Ulmann Lett.-Dtsch. Wtb., auch Leskien a. a. O. - Statt des konstruierten abg. bebro wären einige moderne slavische Formen anzuführen, die übrigens vorwiegend auf *bobrz zurückgehen und die Existenz eines voreinzelsprachlichen *bebrz fraglich erscheinen lassen, da die bei Berneker s. v. bebro (demnach also ungeeignetes Stichwort); bobro; bobrz aufgeführten Beispiele mit $-e$ - altes $-\checkmark$ - enthalten oder sonst sekundär entwickelt sein können. - Ksl. (? s. unten) brunatonz (nicht - $a-$ !) adj. 'kuavíuv, caeruleus, fuscus' (die falsche Bedeutungsangabe 'Braunschimmel' bei Walde beruht wohl auf Petrs BB. 21, 208 poln. brunatny (kon') 'braun(-schimmel)', das wörtlich als 'braun(es Pferd)' zu übersetzen ist) stammt bei Miklosich Lex. Pal. aus einer mir nicht zugänglichen Beschreibung slavischer Handschriften. Es ist jedenfalls ein seltenes Wort, und die Möglichkeit, daß es aus dem Westslavischen (cech. brunatný, poln. brunatny 'braun') in eine späte kirchenslavische Quelle hineingeschmuggelt ist, ist nicht ausgeschlossen. Jedenfalls kann die allgemein geltende überaus plausible Annahme einer Ent- 
lehnung des Wortes aus dem Germanischen oder Romanischen durch sein einmaliges Vorkommen in einer kyrillisch geschriebenen Quelle nicht entkräftet werden. Vgl. Berneker s. v. brun, der leider ksl. brunatznъ überhaupt nicht erwähnt. Wenn wir auch darin eine Bestätigung unserer $\mathbf{Z}$ weifel an der Berechtigung dieses Wortes sehen können, so wären doch, da es nun einmal im Lex. Pal. steht und von dort übernommen wird, ein Hinweis auf seine Unsicherheit und womöglich auch eine Erklärung wünschenswert gewesen. - Berneker a. a. 0 . hält auch sloven. brûn (nicht bruny) 'braun, rötlich, falb' samt serb. brun 'dunkelbrann, schwärzlich', ěech. bruny 'schwarz' usw. (zuzufügen wäre noch russ. dial. brimyj 'rot') für eine germanische resp. italienische Entlehnung, woran zu zweifeln ich keinen Grund finden kann. In den meisten slavischen Sprachen ist das Wort nur dialektisch oder doch nur neben anderen häufigeren Worten gebräuchlich. Außerdem ist auch die Ablautstufe idg. *bhrou- sonst nirgends belegt; wegen der von Berneker s. v. bronz ohne genügenden Grund als mit mhd. brun usw. urverwandt angesehenen russ. brunětz, brynètz (= bronètz) 'reifen vom Hafer' vgl. vielmehr IF. $28,144 \mathrm{f}$.

fidēlia. - Von den slavischen Formen sind nach Berneker s. v. bzdbrí zu korrigieren : bedeñ (nslov.) in bədànj, bódnarb (klruss.) in bodnar, bondar; und statt bóndarb (russ.) stände besser bóndarb.

finis. - Neben abg. $u$-bojz M. '甲óvoc' ist auch das Simplex ksl.-gemslav. bojb M. 'Kampf' vorhanden, das in erster Linie erwähnt zu werden verdiente. - Lies dŷgsnis (lit.) statt dýgsnis.

flaccus. - Lies ml'ity, ml'a (klruss.) statt ml'ity, ml'a; bláhij (wruss.) statt blagij; mlédan (sloven.) statt mlêden; mulk'is (lett.) statt mulkis. - Das von Miklosich Et. Wb. erwähnte mlachavo (im Kirchenslavischen schreibt man jetzt $-c h$ - und nicht - $h$-) 'schwach' scheint in der kirchenslavischen Literatur nicht belegt zu sein; wenigstens fehlt es im Lex. Pal., wo nur ein mlochavbstvo 'infirmitas' (mit -o-) steht. Vielleicht stammt aber dieses $\mathrm{Ab}$ straktum, wie sicher das kroatische Adjektiv mlohav, aus einer glagolitisch geschriebenen kroatischen Quelle, sodaß wir ein ksl. *mlochavb daraus nicht erschließen dürfen. Ein mlahav führt Miklosich aus dem älteren sog. Neuslovenischen an; vielleicht hat er auch sein ksl. (Miklosich altsloven.) mlachavo aus diesem hergeleitet. 
Berichtigungen u. Ergänzungen zu Waldes Lat. Etym. Wörterbuch. 211

flāgito. - Die Ausdrucksweise: “. . . . . abg. blago 'gut, erwünscht' (dazu Denominativ poln. btagać 'flehen, besänftigen' ... . . ." ist nicht glücklich gewählt. Denn poln. btagac, das mit polnischen Mitteln kaum zu erklären ist (es heißt btogi. 'glücklich, behaglich' mit -o-; - $a$ - wäre nur in einem jungen Iterativ verständlich, doch fehlt hier ein geeignetes Grundverbum für ein solches), steht trotz semasiologischer Schwierigkeiten in Verdacht aus čech. blahati 'segnen, selig sein' entlehnt zu sein (Berneker s. v. bolgb), und auch dieses ist wohl nur eine indirekte Ableitung rom Adjektiv (etwa von čech. alt bláha 'Seligkeit'?). Die morphologischen Beziehungen der einzelnen Worte zu einander sind schwierig. - Lies bláhij (wruss.) statt blagij.

flagro. - Ein Simplex brězgb 'Dämmerung' ist nach Berneker s. v. brěskio weder für das Altbulgarisehe, noch auch für das Urslavische, mit Sicherheit anzunehmen; es wäre besser abg. pro-brězgo anzuführen und darauf aufmerksam zu machen, $\mathrm{da} B$ in den modernen Sprachen neben *brězgo auch die (nach Berneker ältere) Form brěskı vorkommt. - Lies bligstu (lit.) statt bligstù (Leskien Abl. 290). - Das altbulgarische Primärverbum für 'glänzen', das unter den hergehörigen Verben an erster Stelle erwähnt zu werden verdient, heißt nach Berneker (s. v. blaska) blbšta blıštati; das Iterativ dazu abg. bliscati se, ksl. auch bliskati se (nicht reflexiv scheint dieses kirchenslavisch nicht vorzukommen, anders in den modernen Sprachen). - Lit. blyszkiu 'funkle' ist vorsichtshalber besser unbetont zu lassen, wie es in Kurschats Quelle, Nesselmann 341 b, steht.

flāvus. - Lies geltas (lit.) statt geltas; wegen der Schreibung von lett. $d$ feltăns usw. 'gelb' s. oben fel. - Statt oder vor lit. żlti 'grau werden', das offenbar ein Denominativ ist, ist das diesem zugrunde liegende żilas 'grau' zu erwähnen. - Unter den Worten für 'Gold' ist auch lett. felts 'Gold' zu nennen. Merkwürdigerweise fehlt dieses lettische Wort sowohl in Leskiens Nomina und Ablaut, als auch bei Meillet Etudes 298, doch glaube ich trotzdem aus lautlichen Ursachen, daß es nicht aus dem Slavischen entlehnt sein kann.

fodio. - Zu lit. bedù 'grabe' lautet der Infinitiv nicht bedéti, wie Nesselmann 324b (geschrieben -eti) mit einem Fragezeichen und nach ihm KLD[ (fälschlich geschrieben -eti) angibt, sondern bèsti. In Nesselmanns Quelle, Szyrwid Dict. 104a, steht 
$k a / u$, bedu s. v. kopam, kopie 'fodio, abdita terrae scrutor' und kafeias, kaftoias, bedeias, kuris ka/a, beda ku s. v. kopacz 'fossor'. Dieses bedeias (lies *bedejas) ist aber nicht, wie Nesselmann angenommen zu haben scheint, zu zerlegen in den Stamm *bedéund das Formans -jas, sondern -éjas ist ein produktives Formans zur Bildung von Nomina agentis gerade von konsonantisch auslautenden Verbalstämmen, vgl. auch oben das Synonym kafeias (kasejjas) zu kasì kàsti 'graben'. Von einem *bedèti wäre vielmehr die Ableitung *bedétojas zu erwarten, vgl. Leskien Nom. $329 \mathrm{f}$. Auch Juškevič hat bedù bèsti 'stechen' = badýti, $\tilde{z}$-bedu í-bèsti 'hineinstecken' (s. v. $i$-smergti), wobei die von den sonstigen Belegstellen abweichende Bedeutung zu beachten ist. - Was die baltische Ablautstufe *bed- anbetrifft, so legt kymr. bedd 'Grab' usw. die Vermutung nahe, daß es sich um eine Vermischung zweier Sippen *bhedh-1*bhodh- und *bhodh- handelt, von denen die eine 'graben', die andere 'stechen' bedeutet hat. Wenn das keltische - - - sich durch germanische Entlehnung oder jüngere Lautprozesse erklären ließe, wäre m. E. die Annahme einer sekundären $e$-Stufe im Baltischen vorzuziehen (s. oben capio und unten pinus Fn.); denn die vortreffliche Parallele lat. fodio fōdi und abg. bodq baš spricht doch dafür, daß die o-Stufe auch dem Primärverbum ursprünglich zukam, und bei einer Scheidung in zwei Wurzeln bliebe es unklar, wie die einzelnen Worte unter dieselben zu verteilen wären.

foria. - Lies driskam (nbg.) statt driskati und drístati (čech.) statt dristati. Im Serbischen ist neben drickkati, das eine bei Schallworten nicht ungewöhnliche Umbildung zu sein scheint, auch die Form driskati vorbanden. Um Mißverständnisse zu vermeiden (man könnte an ein urslav. ${ }^{*} d r i d$-, *drid'- entsprechend germ. drit- denken, vgl. serb. vóckati 'herumführen, ductare’ zu vòdim vòditi 'führen'), wäre es praktischer, drićkati, obgleich es die häufiger gebrauchte Form ist, garnicht oder doch wenigstens erst an zweiter Stelle zu erwähnen.

formus. - Lies zeravo (ksl.) statt żeravo.

frāgor. - Lies brāfchu (lett.) statt brafchu.

frīgeo. - Neben lett. strëg'ele 'Eiszapfen' (mit $-g$ '- zu schreiben) kommen auch die Formen streg'ele, strég'ele vor, so daß es fast natüricher erscheint, - $e-$ auf $-e n-$, statt auf -ei-, zurückzuführen, und die Zugehörigkeit der baltisch-slavischen 
Berichtigungen u. Ergänzungen zu Waldes Lat. Etym. Wörterbuch. 213

Worte zur i-Reihe zweifelhaft wird. - Lies sréz (nslov.) statt srěž́, śrzeź (poln.) statt śrzež und srẻn (nslov.) statt srèn.

frio. - Zu lit. grëjù grêti 'die Sahne von der Milch bogenförmig abschöpfen' führt Juškevič als Nebenform auch das žemaitische Präsens grejù an, das, wie die s. v. clinno und lïbo besprochenen alten Parallelen zeigen, eine ältere nur dialektisch erhaltene Bildung gegenüber dem gemeinlitauischen grëjù darstellt.

fugio. - In betreff von gemslav. bljušč 'Efeu' ist neuerdings Trautmanns (Die altpreußischen Sprachdenkmäler 312) Verbindung mit bleusky Fem. (Vok. 286; wäre lit. *bliauskè) 'Schilf' sebr beachtenswert. Bisher ist allerdings das Wort als blensky gelesen worden, und es müßte noch untersucht werden, welche von den beiden Lesungen paläographisch die bessere ist.

fui. - Lit. būkla, büklè 'Heimat, Wohnstätte' sind besser unakzentuiert zu lassen. Kurschat hat die Worte aus der mündlichen Rede nicht gekannt; daher ist auf seine Akzentuation kein Verlaß. Und bei derartigen Worten ist es immer besser, keine Akzente zu setzen, da die Gefahr vorliegt, daß sie zur Stütze von Akzenttheorien verwendet werden könnten, was natürlich fehlerhaft wäre. Die Länge kann man hier, trotzdem sie literarisch nicht festgelegt ist, wohl für sicher halten, denn die noch als Ableitungen gefühlten Bildungen von buiti 'sein" pflegen sonst langes $-\bar{u}$ - zu haben (bitas 'Haus' ist für das Sprachgefühl als ein isoliertes Wort zu betrachten), vgl. auch pabuklas, pabriklé bei Leskien Nom. $496 \mathrm{f}$. (die Schreibung būklas a. a. O. ist literarisch nicht beglaubigt), über deren Akzentqualität man jedoch im Zweifel sein kann.

fūlîgo. - Lit. dülis 'Räucherwaren zum Forttreiben der Bienen' ist besser nur in der unakzentuierten Form zu schreiben; die Schreibung $d \bar{u} l y s$ scheint auf dem aus Mielcke stammenden dulys bei KLD zu beruhen, doch kann man Mielckesche Schreibungen für die Feststellung der Akzentuation nur mit $\nabla$ orsicht verwenden. Akzentuiert finde ich das Wort nur bei Juškevič als dúlis M. (Bedeutung 'Nebel' und 'Räucherholz'), was wegen diulke 'Stäubchen', dúmai 'Rauch' ansprechend erscheint; doch schreibt Juškevič in Teil I ( $a-d$ inkl.) regelmäßig den Akut auch für den Zirkumflex, und seine Hochtonstelle weicht oft 
von der literarischen $a^{1}{ }^{1}$ ). Vgl. auch oben capio Fn. und unten rapio.

fũmus. - Es besteht eigentlich kein Grund zur Annahme, daß abg.-gemslav. dunqti 'spirare', was lautlich (vgl. Arch. sl. $\mathrm{Ph}$. $35,55 \mathrm{ff}$.) allerdings möglich wäre $\left.{ }^{2}\right)$, zu der durch -s- erweiterten Wurzelform in abg. ducho 'spiritus' usw. gehöre; es ist vielmehr natürlicher, es auf die reich belegte unerweiterte Wurzelform zu beziehen. Praktisch betrachtet ist, wie aus Berneker s. v. dujo zu ersehen ist, dunq das Perfektivpräsens zum imperfektiven gemslav. *duja *duti (russ. dúju dutz, serb. dùjèm dùti, osorb. duju duć usw.). Beide Verba machen den Eindruck von Primärverben, deren Präsentia sich nur in der Ablautstufe von ai. dhǔnóti,

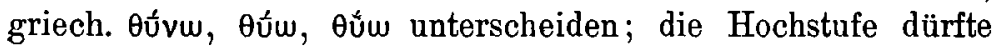
auf Grund von solchen Bildungen wie ai. dhavişyati Fut. verallgemeinert worden sein. Wenn man an der Hochstufe eines primären Nasalpräsens Anstoß nimmt, dann allerdings bleibt kaum etwas anderes übrig, als dunq auf ein ideelles (im Sinne von Arch. sl. Ph. $35,57) * d u c h n q$ zurückzuführen und für eine indirekte Ableitung von duchb als Perfektiv zum denominativen duchati Imperf. aufzufassen (direkte Ableitung von $d u c h$ s erscheint für die frühe Zeit, wo die ideelle Lautgruppe -chn- noch intakt war, ausgeschlossen, da die Produktivität denominativer $n q$-Bildungen jüngeren Datums sein dürfte); indessen ist die Trennung von *duja unnatürlich, und man müßte dann annehmen, zu duna wäre zunächst nach dem Muster von stana stati 'sich stellen' der Infinitiv *duti und dann zu diesem das Präsens *duja zugebildet worden. Eine Beanstandung von urslav. *dunq hat m. E. nur dann einen Zweck, wenn man auch urslav. *duja *duti zu beseitigen strebt. Jeder einzelne der anzunehmenden analogischen Vorgänge wäre zwar einfach; ihre Gesamtheit aber würde eine fast ununterbrochene Folge von schnell aufeinander folgenden Umbildungen voraussetzen, die teilweise

1) In Teil II ( $e-i$ inkl.), wo der Akut und der Zirkumflex unterschieden werden, und überhaupt die Bearbeitung des Stoffes weit kritischer ist, können wir solche Worte wie iszmánkyti, imencziù (unten māceria und mamphur), die zur literarischen Tonqualität der Sippen stimmen, in der Regel ohne Kautelen mit Akzent schreiben.

2) Anders Meillet Études 130; doch gibt es keine Fälle, wo -chvor Nasalen und Liquiden nicht auf Restitution oder auf dem Ausfall eines - $\delta$ - beruhen kann; wegen des letzteren Falles s. die bei Berneker s. v. bystrz wegen vichro zitierten Stellen. 
Berichtigungen u. Ergänzungen zu Waldes Lat. Etym. Wörterbuch. 215

wohl auch auf chronologische Schwierigkeiten stoßen würden. Wir halten also dung lieber dem Augenscheine folgend, für eine bloß durch den Ablaut differenzierte Entsprechung von griech. $\theta$ úvw.

fủnus. - Die im ersten Absatze erwähnten slavischen Worte lauten akzentuiert: žurýty, żurbá (klruss.) und żuríc sja (wruss.) - Lies źuvimas (lit.) statt żumimus.

galbus. - Lies hotúbyj (klruss.) statt hotubij.

gannio. - Das nur bei Miklosich Et. Wb., nicht aber Lex. Pal. und bei Sreznerskij Materialy, belegte ksl. gagnati 'murmeln' ist besser zu streichen; aus den modernen Sprachen kenne ich diese Verbalbildung des Wortes im Polnischen (gegnac 'schnattern') und im Bulgarischen (gz'gna 'näsele, stottere'; letzteres fehlt bei Berneker s. v. goginio). Die Form gagnati (besser vielleicht gq.gznati) kann eher stehen bleiben, trotzdem das Wort nur in russischer Überlieferung in der Lautgestalt gugnati belegt ist, vgl. S. 186 und unten grunda.

genius. - Zu streichen ist die Form kznegr neben abg. kanęz 'Fürst'; ihr Fehlen im Lex. Pal. macht es sehr wahrscheinlich, daß Miklosich sie im Et. Wb. nur als gemeinsames Grundwort zu kznęzb und konegynji 'Fürstin' konstruiert hat; auch bei Berneker s. v. konęd'ź fehlt sie.

gero. - Statt des, wie es scheint, nur éin Mal im Altrussischen belegten $\tilde{z}$ esto wäre besser das abg. und in mehreren modernen slavischen Sprachen gebräuchliche żestokz hart, grausam' anzuführen, vielleicht der sinnlicheren Bedeutung wegen daneben auch ksl. żestok 'hart, spröde' = russ. žëstkij ds. Vielleicht ist der aruss. Akk. Sing. Fem. żestu bei Sreznevskij Materialy, aus dem allein ein žesto erschlossen wird, bloB ein Schreibfehler für žestku $\mathrm{zu}$ żest(z)kz.

glëba. - Poln. gleba 'Erdscholle’ hält Berneker s. v. gleba für ein lateinisches Lehnwort. Eine Vereinigung des polnischen Wortes als *gléba mit russ. glýba ds. unter den Grundformen ${ }^{*} g l e(u) b \bar{a},{ }^{*} g l \bar{u} b \bar{a}$ erscheint wegen der Isoliertheit beider slavischer Worte unwahrscheinlich.

glomus. - Ein slovenisches glub 'Strunk' gibt es nicht; nsl. glub bei Petr BB. 21, 212 ist wohl eine Verwechslung mit nsorb. gtub 'Strunk', beruhend auf der Abkürzung ns. bei Miklosich Et. Wb. Dieses Wort, das übrigens im Slovenischen *glōb lauten 
müßte, scheint nur westslavisch belegt zu sein, vgl. Berneker s. v. globb, wo eine Zurechtstellung von Petr aber unterbliehen ist. graculus. - Lies im Litauischen grioju grioti statt gróju gróti. Die litauischen Wörterbücher führen das Wort allerdings als groju groti 'krächzen, schelten, schmähen' an. Aber Szyrwid Dict. kennt nur grioiu $110 \mathrm{~b}$ (bis: s. v. kraczz 'crocito, cornicor' und kracze na kogo 'urgeo conviciis, maledictis, succlamo'), dazu auch das Verbalabstraktum grioimas 111 a (s. v. krakanie 'crocatio, crocitus'). Aus grioiu haben die älteren Lexikographen mit bekannter Vernachlässigung der Palatalität groju gemacht (andere Beispiele s. v. derbiōsus Fn. und minus). Daß Szyrwid ibre Quelle gewesen ist, ist aus der genau übereinstimmenden Angabe der übertragenen Bedeutung zu ersehen; beachtenswert ist dabei, daß Nesselmann, genau wie Szyrwid, diese übertragene Bedeutung nur bein Präsens, nicht aber beim Verbalabstraktum (grojimas), anführt; überhaupt entspricht es seiner Praxis, Verbalabstrakta nur da aufzunehmen, wo seine Quellen sie bieten. KLD[ hat groju aus Nesselmann abgeschrieben, ohne die Richtigkeit des Wortes nachzuprüfen, was ihm in diesem Falle dadurch erschwert war, daß Nesselmann seine Quelle nicht angibt.

gradior. - Statt gridiju (lit. dial. 'gehe, wandere') empfiehlt es sich, die normalisierte Präsensform gridyju (Juškevič: gridiju gridyti) zu schreiben, da wir nicht jede phonetische Schreibung übernehmen können. Die Isoliertheit dieses Wortes erscheint mir übrigens bedenklich, und ich vermute Entlehnung aus dem Germanischen (got. grips 'Schritt, Stufe').

grunda. - Ksl. grẹd 'Balken' ist ein seltenes aus altrussischer Überlieferung (grjadb) stammendes Wort; statt dessen wäre besser das Feminimum gręda (eigentlich aruss. grjada, doch kann -e-geschrieben werden, S. oben S.186 und s. v. gannio) als häufigeres gemeinslavisches Wort anzuführen, vgl. Berneker s. v. gręda. - Die Bedeutungsangabe von lit. granda (Betonung unbekannt) beruht wohl auf Verwechslung mit gràndai Nom. Plur. M. "Latten auf dem Deckbalken des Stalles" (Leskien Abl. 328; die eigentümliche dialektische Akzentuierung wäre bei Walde vielleicht besser unbezeichnet zu lassen); granda F. bedeutet in den Leskien Nom. 208 vorgelegenen Quellen 'Stockwerk'; nach KLD[ aus Nesselmann 271 a-b ist es (auch) ein Synonym von grindis $\mathrm{F}$, das gewöhnlich 'Dielenbrett' und bei Ness. a. a. $O$. auch 'Gebrücke, Steinpflaster' bedeutet. 
gula. - Ein russ. golto 'Schlund' scheint nicht zu existieren; das golto bei Miklosisch Et. Wb. dürfte auf einem Druckfehler beruhen. Die Wörterbücher bieten zu glotátb 'schlucken' nur das normale, übrigens nicht häufige, Postverbal glotz das Schlucken, Schluck (als allgemein gebräuchliches Wort bekannt ist mir nur glotokro 'Schluck'), Gurgel, Schlund, Trunkenbold, Vielfraß'. Außerdem gibt es noch dial. koltátz 'verschlucken', koltókr 'Schluck', die aber mit glotáto nichts zu tun haben, vgl. Berneker s. v. glato (kein geeignetes Stichwort, da das Substantiv jünger sein dürfte, als das Verbum gemsl. *glbtati), wo das angebliche golto nicht erwähnt ist.

habeo. - Daß Walde von den Reflexen des gemslav. *gabati gerade die weißrussische und slovakische Form (letztere schreibt sich haba ) herausgreift, mag wegen der gut erhaltenen ursprünglichen Bedeutung seine Berechtigung haben, erweckt aber den falschen Eindruck, als ob das Wort in den anderen Sprachen überhaupt nicht vorhanden sei. Die Angaben müßten an der Hand von Bernekers Artikel gabajo vervollständigt resp. modifiziert werden. - Abg. gobino 'fruges', ksl. gobiznz 'reichlich' sind entlehnt aus got. gabei 'Reichtum', gabigs, gabeigs 'reich', s. Berneker s. v. gobino und gobbd'ź; ; statt des seltenen gobiznz (besser wohl gobizbnz) könnte eines der vielfachen Worte mit gobbz- (Berneker a. a. O.; auch ein gobbzbnz 'abundans' ist belegt) genannt werden. - Ksl. chabiti se "sich enthalten" scheint mir trotz Berneker s. v. chab'o 2. sehr gut ein germanisches Lehnwort sein zu können; aus der Bedeutung 'sich enthalten' konnte sich 'sich entfernen' entwickeln, woraus russ. ochábito trans. 'entfernen, beseitigen' abstrahiert ist. Auch die Bedeutungen von Bernekers Sippe chab'o 3. scheinen mir nicht unvereinbar zu sein; doch müßte das Nähere noch untersucht werden. ${ }^{1}$ )

hallus. - Poln. ogot bedeutet 'Gesamtheit, Allgemeinheit'; es kommt hauptsächlich nur in den adverbiellen Redensarten ogótem, $w$ ogóle 'im allgemeinen' vor; 'allgemein' heißt ogólny adj.; ein Substantiv 'der Allgemeine' scheint nicht zu existieren.

1) Wegen des Vokalismus von ahd. gëban 'geben' vgl. das Verhältnis von lett. Kept, lit. at-kepti zu capio, cēpi. Auch in der Sippe von habeo ist die $\bar{e}$-Stufe belegt in lit. apgébau 'habe gebracht' (Leskien Nom. 387). Trotzdem erscheint es mir möglich, daß habeo altes - $a$ - und nicht -a- enthält, denn die Ablautstufen *gheb-, ${ }^{*} g h \bar{e} b$ - können unursprünglich und durch Einfluß der Sippe von capio entstanden sein; vgl. auch oben capio Fn. 
Zur Etymologie s. Berneker s. $\nabla$. gulo und Rozwadowski in Język polski I (1913) Maiheft, S. 139 ff.

haud. - Wegen baltisch-slavischer Worte, die an air. gāu, gō 'Unrichtiges, Lüge' in Laut und Bedeutung anklingen, aber schwer zu vereinigen sind, vgl. KZ. 44, 156 ff. und unten s. v. vafer und vola.

hērēs. - Statt des als Simplex seltenen ksl. jazdz 'das Fahren, die Fahrt' wäre besser ksl.-gemslav. jazda (jězda) zu nennen, vgl. Berneker s. v. jaźdźg, wo aber die ksl. Simplizia feblen.

horior. - Lit. gèrètis 'Wohlbehagen empfinden' wird von Leskien Abl. 327 wohl mit Recht zu lit. gêras 'gut' gestellt (giriù giřti 'loben' und Ableitungen dürften aber besser fernbleiben), das bei Juškevič Slovarj auch in der Bedeutung 'üppig lebend, üppig' angeführt wird; vgl. auch ebenda géris M. 'Güte, GenuB', ferner géris 'Gut' Auszra 1884, 307 Nr. 41, géris = lùstas, ráskaziuus, etwa 'Wollust, Üppigkeit', Juškevič Li ètùviszkos dájnos (3. Teile Kazan 1880-1882) 1226. 9. Russ. zárkij (bei Walde ohne Akzent), 'begierig, lüstern'1) und źáritz 'Lust erwecken, reizen' (mir in ähnlicher Bedeutung unbekannt, vielleicht auf einem Mißverständnis beruhend) sind identisch mit žárkij 'heiß', žáritb 'erhitzen, braten, schmoren' (zur Sippe von lat. formus); zur Bedeutung vgl. z. B. poln. gorgcy "heiß, begierig', lit. gãras 'Dampf', Juškevič auch 'sehnlicher Wunsch'; gobroti 'sehnlich entbrennen'; nhd. entbrennen für etwas, inbrunst. - Lit. zar ras, żertas 'Scherz' stammen zunächst aus poln. zart, apoln. żert ds., die allerdings ihrerseits deutsche Lehnworte sind. hospes. - Wegen ačech. hospota s. Berneker s. v. gospodz.

humulus. - Da das bei Miklosich Lex. Pal. stehende chmèlı (-è-graphisch für -e-) 'lupulus' aus einem russischen Buche des 17. Jh. stammt, kann man es nicht als altksl. Form ansehen, und es wäre besser, das Wort aus einigen modernen Sprachen anzuführen; die Formen s. bei Berneker s. v. chrmel'z. Übrigens wäre fürs Ksl. chrm- statt $\mathrm{chm}$ - zu schreiben.

ibex. - S. o. s. v. aper.

in. - Die litauische Präpositon $\bar{z}, \bar{z}$ 'in' kommt dialektisch noch in der älteren Lantgestalt in vor, vgl. bei Doritsch Bei-

1) [Genauer 'hitzig, heftig (vom Streit); leidenschaftlich, begehrlich (von den Organen des Menschen, z. B. von den Augen, nicht vom Menschen selbst)'. K.-N.] 
Berichtigungen u. Ergänzungen zu Waldes Lat. Etym. Wörterbuch. 219

träge S. 65, Z. 4 in tạs dravès 'in die Löcher', S. 67. Z. 4 in dángu 'in den Himmel', S. 69, Z. 11 in savo póny 'zu seinem Herrn', S. 70, Z. 11, 22 in $j i$ 'bei ihm, zu ihm', S. 72, Z. 32 in kartuives 'zum Galgen'; ebenda wird in den $\S \S 219,264$, 331, 333 auch die Aussprache $n$ erwähnt, die sich vor und nach beliebigen Lauten zu finden scheint, vgl. z. B. S. 72, Z. 18 at'ája n kaváli 'ging zum Schmied', S. 73, Z. 31 ánas n pánu 'jener .... zum Herrn'. Die Form in steckt auch in dem dialektisch sehr weit verbreiteten $i \tilde{n} g$ 'in' aus $i n+g i$; vgl. darüber Kurschat Gramm. Litt. Spr. 391. Als Präfix scheint in noch weit verbreiteter zu sein, denn als Präposition, vgl. bei Juškevič die Nebenformen in-áugti, in-eiti usw. s. v. $i$-augti, $i$-eiti und auch sonst vor vokalisch anlautenden Worten. Aus älterer Zeit siebe Beispiele für in-, im- vor Dentalen und Labialen bei Szyrwid Punktay Sakimu S. XXXIXf.; vor $k$ - vgl. aus Szyrwid Dict. 265 b inkatu 'schlage ein, stoße ein' s. v. pobijam; 169 a inktoiu 'instruo' s. v. naścielam; 164 a inkrauiu 'impono, indo, ingenero' s. v. naktadam. Doch kann vor allen Lauten auch die Form $i$ - (geschrieben $i$-) stehen. Als selbständige Präposition wird $121 \mathrm{~b}$ s. v. $k u$ die Form ing angeführt, die auch in den passim vorkommenden Sätzen figuriert.

inquam. - Es gibt im Litauischen außer sekù 'folge'= lat. sequor auch ein zu sakaũ sakýti 'sagen' gehöriges seku sekti 'sagen'= griech. évvé $\pi \omega$ 'sage an, erwähne' usw. Vgl. bei Szyrwid Dict. 5a das Präsens leku s. v. baje, bajki powiadam 'fabulor, fabulam narro' in der Wendung rekmi (Akk. Sing. zu sekmé 'Fabel, Märchen') (eku = lekmi fakau, niekus katbu, wo feku nur als Synonym von fakau aufgefaßt werden kann'). Den Infinitiv und das Verbalabstraktum bietet Juškevič, vgl. s. v. ászokeis (geschrieben ïš-) den Satz sẽnis jiszokeis bemóka pãsakas sèkti 'der Greis kann ab und zu Märchen erzählen' und s. v. jaunimas ('Jugendgesellschaft') die Wendung dèl sekimo pãsakū 'wegen des Erzählens von Märchen'. In der Literatur kommt das Wort, (Leskien mündlich) auch sonst vor. Szyrwid Dict. bietet auch ein - reku 'zeige', das wohl eine ältere Bedeutungsvariante von feku 'sage' ist, entsprechend ksl. sočiti 'anzeigen', vgl. 45a prifeku ku kami = prifektinay (Adv. eines Verbaladjektivs) parodziu s. v. dowodze 'probo, convinco, arguo'; ebenda dawiadamas dayktas, prifekimas (zu lesen wohl -kamas und Part. Präs. Pass. als Attribut

1) [Vgl. jetzt W. Schulze KZ. 45, 288. - K.-N.] 
zu dayktas 'Ding') s. v. dowodny 'eridens, authenticus'; daza gehört ebenda das Substantiv prifeka = parodimas s. v. dowód "argumentum, ratio, probatio, documentum". Am genauesten läßt sich die Bedeutung dieses pri-feku als 'zeige in Worten, beweise' präzisieren. Es ist möglich, daß sich diese Bedeutung nur in diesem finen Kompositum erhalten hat; an eine jüngere Bedeutungsentwicklung, hervorgerufen durch ein etwaiges deiktisches Element im Präfix pri-, zu denken, ist kaum vorzuziehen. - An got. saikun 'sehen' erinnert die Verwendung von baltisch sek-, sak-zur Affektbezeichnung; siehe darüber sowie über die wahrscheinlich sekundäre Bedeutung 'folgen' in slav. sok-unten s. v. sequor. - Nbulg. posóka soll nicht 'Wunderzeichen' bedenten sondern nur, wie es die Wörterbücher angeben, 'Richtung'.

interus. - Lies atroba (ksl.) statt atrova.

labo. - Bei der Beurteilung von lett. dial. lābuitës (nicht -ötës) 'schleichen' ist Vorsicht angebracht. Das Wort ist trotz des unklaren -b-kaum von lawĩtës, läwĩtés, l'āwètës 'umherschleichen, lauern, sich heimlich bestreben' zu trennen. Aus Ulmanns Beispielen zu diesen Worten ist zu ersehen, daß es beim Schleichen nicht sowohl auf die Gleitbewegung, als auf das heimliche Erreichen eines Zieles, ankommt, sodaß Entlehnung aus russ. lovitb 'fangen' sehr wahrscheinlich erscheint; auch nhd. lauern und lavieren mögen hineingespielt haben. - Lit. slopstu 'werde schwach', das in der Kurschatschen Sprache nicht rorkommt, ist besser unakzentuiert zu lassen; die eigentliche Bedeutung des Wortes ist wohl 'ersticke' intrs., vgl. Leskien Abl. 377.

lacer. - Abg. lačą lạciti 'trennen' gehört zu abg. lękq lęšti 'biegen' (s. u.s. v. lacertus und lacio), zu dem es das formale Iterativ ist, so daß es dem lett. liuzit iter. 'biegen', lit. lankýti 'besuchen' genau entspricht. Die alte Bedeutung findet sich noch in čech. loučiti se 'sich beugen, sich neigen', sloven. lóčiti 'biegen', vgl. auch russ. oblučito 'umbiegen, um etwas herumbiegen, mit einem bogenförmigen Aufsatze versehen', das kaum ein jüngeres Denominativ ist, da ein geeignetes Nomen fehlt. Bei sloven. slóčiti 'krumm biegen, krümmen' ist eher denominativer Ursprung möglich zu slōk 'krumm'. Die Bedeutung 'trennen' beruht wohl auf Abstraktion aus den Komposita raz-lqaciti 'zertrennen' ursprünglich 'auseinanderbiegen', und otb-lqciti 'abtrennen', ursprünglich 'abbiegen'; ähnlich ist aus *sb-ląciti (ksl. nicht belegt, vgl. aber das Iterativ sb-ląčati sowie 
Berichtigungen u. Ergänzungen zu Waldes Lat. Etym. Wörterbuch. 221

¿ech. sloučti, poln. ztaczyc) 'verbinden, vereinigen”, ursprünglich 'zusammenbiegen', das Simplex sloven. ločiti, čech. loučiti, poln. tączyć 'verbinden, vereinigen' abstrahiert worden $\left.{ }^{1}\right)$. - Wegen poln. tach, russ. lóchma (so betont; láchma scheint selten zu sein) 'Fetzen' usw. vgl. jetzt Berneker s. v. lachъ.

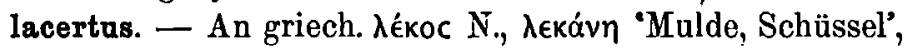

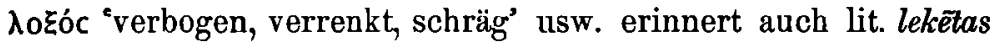
'kleine Winde zum Drehen von Stricken', lekets 'kleine hölzerne Rinne, wie man sie in einen Baum steckt, um dessen Saft zu gewinnen; Zäpfchen im Halse (Leskien Nom. 570)'. Daneben findet sich auch die Form lenkétas 'Haspelstock', die offenbar auf Anlehnung an lenkiù 'biege', auch 'haspele', beruht. - Abg. sz-ląkb, slakb 'krumm' erweist keine mit sl-oder skl-anlantende Wurzel für 'biegen, krümmen', da höchstwahrscheinlich die etymologisch richtigere Schreibung diejenige mit sol-, und das Wort ein Kompositum mit der Präposition sz- ist, vgl. Miklosich Lex. Pal. und Et. Wb. s. v. lenk-1, sowie Leskien Glossar zum Handbuch. - Für abg. lęko lešti 'biegen', lit. lenkiù leñkti ds. ist sehr ansprechend Bernekers (s. v. lęko) Verbindung mit alb. l'engór 'biegsam', ahd. chrumbelingūn 'in krummer Richtung' usw.; dieses *lenq-, zu dem ev. auch lat. lanx 'Schüssel' gehören könnte, ist vielleicht eine schon uridg. Nebenform von *leq-. Die Grundbedeutung war vielleicht 'spannen', aus der sich unmittelbar die gleich unten s. v. lacio zu besprechenden Bedeutungen der Sippe 'fangen, Fallen stellen, bestricken' usw. entwickelt haben können.

lacio. - Solange die problematischen Zusammenhänge einerseits von ital. ${ }^{*} l a q^{\varkappa}$ - oder ${ }^{*} l a q-$ (so, wenn laqueus suffixales -u-enthält) 'bestricken, belisten' mit uridg. *ớ 'ě́q- 'biegen', anderseits letzterer Wurzel mit balt.-slav. *lenk- 'biegen' (s. oben lacertus) nicht erwiesen sind, schwebt auch die von Walde angenommene Wurzelverwandtschaft von lacio 'locke', laqueus 'Strick' mit abg. lęca lecati 'fangen, bestricken' und mit dessen ron Walde angeführten baltisch-slavischen Verwandten in der Luft, denn diese können, was Walde entgangen ist, von abg. lekkq, lit. lenkiù 'biege' nicht getrennt werden, vgl. Berneker s. v. lęko. Aber auch in dem Falle, daß die obigen Beziehungen alle fest-

1) [Vgl. jetzt zu diesem und zu den beiden folgenden Abschnitten

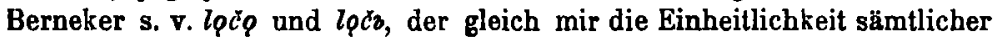
slavischer loc- und lok- enthaltenden Worte vertritt. K.-N.] 
ständen, und wir Wurzelverwandtschaft zwischen den lateinischen und den baltisch-slavischen Worten anerkennen müßten, würde Waldes Darstellung einen falschen Eindruck von den Tatsachen erwecken; es würden eben nur auf baltisch-slavischem Boden ähnliche Bedeutungswandlungen bei der nasalierten Wurzelform vorliegen, wie im Italischen bei der unnasalierten Form, nicht aber könnten wir ital. *laq- und balt.-slav. *lenk- auf eine gemeinsame jüngere Bedeutungsvariante der Wurzel zurückführen. Die in ksl. polę̌r 'laqueus', lett. lenza 'Strick' vorliegende Bedeutung scheint allerdings wegen aisl. lengia F. 'Riemen' (Berneker a. a. O.) schon vorbaltisch-slavisch zu sein, dagegen dürften die slavischen Bedeutungen 'betrügen, schrecken' (ebenda) jüngeren Ursprungs sein. Eine monographische Darstellung der Sippe in semasiologischer Beziebung wäre für das Slavische eine dankenswerte Aufgabe; die Zusammenstellung bei Berneker genügt noch nicht, um über alle Punkte Klarheit zu gewinnen. Lett. lenkt 'auflauern, nachspüren' hat historisch mit den gleichbedeutenden wurzelverwandten Worten im Slavischen nichts zu tun; dieses als Simplex kaum gebräuchliche Wort ist aus dem Kompositum ap-lenkt 'einkreisen, den Aufenthalt eines Wildes durch Umgehen nach den Spuren im Winter bestimmen', ursprünglich wohl 'Bogen beschreiben, bogenförmig um etwas herumgehen' abstrahiert worden. - Von slav. lẹk- zu trennen ist čech. lákati 'locken', dessen -á- wegen osorb. takac, nsorb. takaś "lauern' = urslav. - $a$ - sein muß (bei Entlehnung wäre im Sorbischen schwerlich $t$ - eingetreten); eine Etymologie des Wortes s. bei Berneker s. v. lajo 2.

laevus. - Zuzufügen ist aus Berneker s. v. lëvo lit. isalaivóti 'Biegungen machen'; auch könnte erwähnt werden, daß Berneker selbst seine frühere Ansicht aufgegeben hat. Lett. l'auns (nicht l'auns) bedeutet eigentlich 'böse, übel, unrecht', vgl. die Redensart par l'aunu nemt 'übel nehmen' und die Ableitungen l'aunigs 'ärgerlich, erzürnt', l'aunưtés 'sich ereifern, übel nehmen, schmollen". In solchen Verbindungen wie l'auna puse "schlechte Seite, verkehrte Seite' kann man zwar das Wort durch 'link' übersetzen, doch bedeutet es nicht 'link' in bezug auf die Richtung, wofür kreiss (zu lit. kreĩvas 'schief', s. Berneker s. v. krivz) gebraucht wird; und es fehlt jeglicher Grund zur Annahme, daß dieses die ursprünglichste Bedeutung gewesen sei. Lit. liaunas (fehlt bei Walde) bedeutet außer 'böse' auch 'biegsam, lose', vgl. Leskien 
Nom. 355, der als Grundbedentung 'losgelassen, lose, zügellos' vorschlägt und Zusammenhang mit lit. liáuti 'aufhören', lett. l'aut 'zulassen, erlauben' (Grundbedeutung 'lassen') vernutet. Aber auch in der Sippe von lat. luo 'löse', die von Walde (s. v. luo) mit dem baltischen Verbum nicht verbunden wird, gibt es Worte mit zu liaunas passenden Bedeutungen, vgl. etwa got. laus 'los, leer, eitel, nichtig', ahd. los auch 'mutwillig'; außerdem könnte man auch an Verwandtschaft mit abg. ljuto ' $\chi \alpha \lambda \in \pi$ óc,

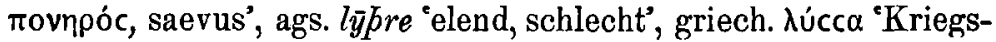
wut, Raserei, Leidenschaft' usw. (Walde s. v. lìber) denken; hierher vielleicht auch lit. liũtas 'Löwe', das aber eher ein slavisches Lehnwort ist, vgl. Fraenkel IF. 22, 399 mit Literatur. Jedenfalls macht lit. liaunas, lett. l'auns durchaus den Eindruck, ein echt baltisches Wort zu sein. Aus lit. deszinas 'dexter' (vgl. Leskien Nom. 399, Juškevič, auch KLD[ s. v. deszinasis) hätte nur -inas, nicht aber -nas, als Formans zur Weiterbildung eines entlehnten *lèvas oder *lëras abstrahiert werden können; wir hätten also *levinas oder *lëvinas (wegen $-\dot{e}-$ und $-\ddot{e}-$ s. unten membrum) zu erwarten. Bei einer Weiterwanderung ins Lettische, wo eine Entsprechung von deszinas und deszinẽ 'rechte Hand' fehlt, und wo auch das Formans -ina-s nicht lebendig ist, wäre so ein Wort vielleicht analogisch weiter verändert worden, aber schwerlich hätte l'auns daraus entstehen können. Die Existenz von lit. liaunas, das Walde nicht kennt, macht vollends seine Vermutung einer Entlelınung aus slav. lèvo unmöglich.

lāma. - Statt lóma (lit.) ist lomà (so KLD[ und nach ihm Leskien Abl. 216) oder noch besser unakzentuiert loma zu schreiben. - Ksl. loms 'sumpfiger Ort' von lomiti 'brechen' zu trennen, erscheint mir unnatürlich, da wir in nhd. bruch "feuchte Wiese' zu brechen (von einigen Forschern allerdings bezweifelt) eine schöne Parallele baben, auf die schon Miklosich Vergl. Gramm. II, 26 aufmerksam gemacht hat, vgl. auch Walde s. v. frango. - Lies lāwa (lett.) statt lāva.

lāmentum. - Lies lāt (lett.) statt lāti.

langueo, levis. - Lit. lingüti (lingóti) "sich wiegen, schaukeln, schwanken" wird von Berneker s. v. legajo nicht zu langueo, sondern zu levis, gestellt. Zu einer der beiden Wurzeln *lengoder *lengh- dürfte m. E. trotz Berneker a. a. O. auch russ. ljagáto ('legati) 'schlagen, hauen', refl. 'mit den Hinterfüßen ausschlagen', 
otljagátı 'durch Schwenken ermüden, beschädigen' gehören. Keinenfalls kann ljagátb als Stütze für die von vielen Forschern angenommene lautgesetzliche Entwicklung von vorslav. in + Kons. in slav. $e+$ Kons. gelten; der Zusammenhang mit poln. dial. ligać 'ausschlagen, mit dem Fuß stoßen', 厄ech. alt lihati 'bewegen', lit. láigyti 'wild umherlaufen' usw., den Berneker vertritt, schwebt schon deshalb in der Luft, weil ein nasaliertes *ling- nicht belegt $z$ u sein scheint (das von Walde s. v. lado angeführte air. lingim 'springe' hat Walde selbst s. v. levis richtiger (wegen des Präteritums leblaing) auf *lengh- zurückgeführt), während zur e-Reihe gehörige Worte in ähnlichen Bedeutungen mannigfach vorhanden sind; o-stufige Verwandte von lit. lingriti s. bei Leskien Abl. 334 .

lanio. - Der Vereinigung von lat. lanio 'zerfleische' mit abg. lomiti 'brechen' stellt sich die Schwierigkeit entgegen, daß slav. lom- wegen der von Walde nicht erwähnten baltischslavischen Ablautstufen lem-, lém- altes -o- haben muß; lanio müßte dann in seinem - $a$ - den Reflex eines Schwundstufenvokals haben, nicht, wie Walde annimmt, altes - $a$-. Im Preußischen kommt der Infinitiv des zugehörigen Primärverbums außer als limtwey, limbtwey (im Lettischen heißt es l'imt mit $l^{\prime}$-) auch in der Gestalt lembtwey vor (alle diese Formen im vierten Gebot); dazu gehört noch die $3^{\text {te }}$ Optativi lemlai, die auch bei Leskien Abl. 333 steht. Da hier die Bedeutungsangabe fehlt, und die Form unmittelbar hinter lit. lémti 'als Schicksal bestimmen' steht, mag Walde es in der Bedeutung zu diesem gezogen haben; es bedeutet aber 'brechen', vgl. Berneker Pr. Spr. 227. Die $\bar{e}$-Stufe liegt m. E. in serb. lijemäm lijemati 'schlagen, pertundere' vor, das ursprünglich das Iterativ zu einem dem preuß. lembtucey entsprechenden Verbum gewesen sein dürfte; auch das $-\bar{i}$ - in preuß. limauts $3^{\text {te }}$ Prät. könnte auf $-\bar{e}$ - zurückgehen. Mit $-e-v g l$. noch ksl. lemešı M. 'Pflug', lett. lemesis 'Pflugschar' bei Berneker s.v. Interessant ist das von Berneker nicht erwähnte bulg. laméz 'Pflugschar' neben leméź ds. An alten Ablaut innerbalb desselben Wortes kann man kaum denken; aber sekundärer Anlehnung an die Ablautstufe von abg. prè-lamati ' $k \lambda \hat{\alpha} v$, frangere' steht die Schwierigkeit entgegen, daB im Bulgarischen ein lamin geeigneter Bedeutung feblt. Wenn auch nicht alle hier genannten Worte und Formen mit Sicherheit zu lomiti gehören, so dürfte doch die Existenz von *lěm- 'brechen' erwiesen sein, 
und lit. lümas 'lahm' kann als echt litauisches Wort auf uridg. *lōmo-s zurückgehen. Weiterhin stehen auch der Anknüpfung an lit. lémti 'als Schicksal bestimmen' keine lautlichen Bedenken entgegen; eine vermittelnde Bedeutung liegt etwa in lit. aplamìnti 'geschmeidig machen' vor. Auch könnte man vielleicht bulg. lémav 'schwer beweglich (von Menschen), faul' mit heranziehen, ursprünglich etwa 'durch anhaltenden Druck geknickt, zusammengebrochen'. - [Vgl. jetzt auch Berneker s. v. lomz. K.-N.]

lappa. - Lies sloven. lopuih, serb. lòpüh (Gen. lopúha) statt slov. serb. lopuh; lies lapuichr (russ.) statt lapuchr.

lāridum. - Lies lojo (ksl.) statt loj. - Statt der jüngeren (iterativischen) Form des Infinitivs lijati ist besser die ältere (primäre) Form lbjati (abg.) zu schreiben.

latro. - Lies jestr (abg.) statt jestb.

lentus. - Poln. dial. tet (nicht let) im Satze jak tẹt goty (Miklosich Et. Wb. s. v. lontü) bedeutet 'Gerte' und nicht 'abgeschälte Rinde' ('wie eine kahle Gerte'). - Lies tutjé (klruss.) statt lute und lutje (russ.) statt lutje. - Lit. KLD[ linta (besser ohne Akzent) ist ein germanisches (oder slavisches) Lehnwort, s. Berneker s. v. lentijb.

leo. - Das lit. (bloß dialektische) Wort für 'Löwe' ist nicht lëvas, sondern levas, liavas zu schreiben; wegen des letztgenannten vgl. KLD[ s. v., wo jedoch der Akzent zu streichen ist, und Doritsch Beiträge $\S 56,220$. Das lëvas bei KLD[ beruht auf Nesselmanns (359 b) lêvas, dessen $-\tilde{e}-$ jedoch eine willkürliche Wiedergabe von Szyrwids - $e$ - (in der Regel ist Nesselmanns $-\tilde{e}-$ als $-\dot{e}$ - oder $-\ddot{e}-$ zu lesen) zu sein scheint, denn aus der Wabl der Ableitungen geht hervor, daß Nesselmanns Quelle Szyrwid war. Bei Szyrwid Dict. findet sich lewas 132 a s. v. lew, Gen. Sing. lewo (so 329 a s. v. ryk lwi 'rugitus leonis' und IV 104 a s. v. lwi 'leoninus'; an dieser Stelle steht V 138 b fälschlich tewo); lewaytis, lewitis (lies -aitis, -ytis) 138a s. v. lwiatko ‘junger Löwe'; lewee IV 104a (lies leve; V 138b fälschlich lewec, vgl. ebenda IV lutee (lies liüté), V lutce) s. v. lwica 'lea, leaena'. Nur éin Mal findet sich die Schreibung liew-, nämlich V 138b in liewinis s. v. lwi 'leoninus', doch bietet auch hier die 4. Auflage (104a) lewinis. Wir können nicht daran zweifeln, daß Szyrwid nicht $l \dot{e}$-, sondern $l e-(l ' e-)$ gesprochen hat. Diese Lautgruppe ist zwar in seinem Dialekt infolge des lautlichen Überganges von

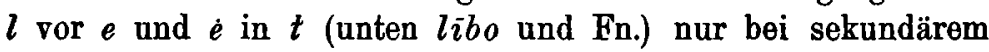


Ursprunge möglich (der sicherste Fall ist -ley (lies -lei) aus -l'ai in der Nominalflexion, s. Beispiele bei Garbe Punktay Sakimu S. XXXVIIf.), ist aber in Lehnworten durchaus normal (Garbe S. XXXIIIf.). Nesselmann scheint fälschlich Szyrwids Schreibungen le und lie für gleichwertig angesehen zu haben; auf Grund einer ähnlichen Erwägung, als ob le- eine nachlässige Schreibung für te-sei, was hin und her zutrifft (unten $l i \bar{b}$ o und $l i s$ ), mag der Bearbeiter der 5. Auflage zu seinem liewinis gekommen sein. Wir können aber nicht annehmen, daß Szyrwid sich hier regelmäßig verschrieben hat, da sonst derartige Nachlässigkeiten bei ihm im Verhältnis zu der regulären Schreibung bei weitem in der Minderzahl sind; außerdem spricht für die Aussprache levas (l'evas) die aus anderen Dialekten bekannte Form liavas (auch Szyrwid Punktay Sakimu bietet neben lewas, lewicia 113, 12. 24 die Form lawu (lies l'avu, vgl. unten minus Fn.), denn nur $e$ und 'a wechseln, nicht aber $\ddot{e}$ und 'a. - Das literarische lit. Wort für 'Löwe' lautet liũtas, das mit leo und seiner Sippe kaum zu vereinigen ist; zur Etymologie s. oben laevus.

lētum. - Kurschats graphische Nebenform lésas zu lit. lésas 'mager' ist zu streichen, da sie nur auf der bei ihm bekannten Verwechslung von $\dot{e}$ und $\dot{E}$ beruht. Leskien Abl. 278 und Nom. 597 bietet nur lésas, wie auch Szyrwid Dict. nur liefas $(27 \mathrm{~b}, 101 \mathrm{a})$, liefibe, liefinu (27 b) und lieftu ('macresco, tabesco' 33 b) schreibt (lies lësas, lësybè usw., vgl. unten $l \bar{z} b o$ und Fn.). - Dieselbe Labialerweiterung wie in ksl. libiı 'gracilis', ags. lēf 'schwach' liegt auch in lit. láibas 'schlank', lébas 'mager" vor, vgl. Berneker s. v. Es könnten übrigens wegen der ursprünglicheren Bedeutung 'schwach, mager' auch russ. dial. libivyj, čech. alt libivý miterwähnt werden, denn bei Kenntnis bloß der Bedeutung 'gracilis' will einem die Etymologie nicht recht glaubhaft erscheinen, und es empfiehlt sich inmer, die Bedeutungsentwicklung, wo es angeht, einigermaßen deutlich darzustellen.

levis. - S. oben langueo.

liber. - Statt aruss. ljudins muß es heißen abg. ljudinz.

líbo. - Das Präsens des literar. lit. Verbums léju léjjau léti 'gießen' wird bei Szyrwid nicht wie der Infinitiv und das Part. Perf. Pass. mit dem zu erwartenden lie- geschrieben (ein -lieiu in abweichender Bedeutung s. unten s. v. lino), sondern 
in der Regel teiu, eine Form, die wir nur als *leju oder *lëju in literarische Gestalt umsetzen können ${ }^{1}$ ), womit auch das als žemaitisch bezeichnete $\tilde{z}$-leiu bei Juškevič (s. v. $\dot{z}$-lét $i$; -e- kann in unbetonter Silbe verkürztes $-\dot{e}$ - sein, vgl. das žemaitische Präteritum $i$-ejáu für sonstiges $i$-ëja ũ bei Juškevič s. v. $\boldsymbol{i}$-eĩti, "hineingehen') übereinstimmt. Als Präteritum bei Szyrwid läßt sich aus den Verbalsubstantiven teimas Nomen act. und teieias Nom. ag. (lies -jimas und -jëjas, vgl literar. lëjimas und lëjëjas) die Form *teiau, d. i. *lejau oder *lejau, erschließen. Belege für Szyrwids Schreibung im Verbum und in den Verbalnomina bietet Garbe in seiner Ausgabe der Punktay Sakimu S. XIII und XXXVIIIf.; vgl. außerdem noch aus dem Dict. iteiu $167 \mathrm{~b}$, ażufiteia $431 \mathrm{~b}$, iż/iteia $324 \mathrm{a}$, teieias $104 \mathrm{a}$, iżteieias $117 \mathrm{a}$, lieta Nom. F. 128b, iżlietas $324 \mathrm{a}$, nulietas $411 \mathrm{~b}$. Als Schreibfehler kommt einige wenige Male sowohl für te-, als auch für lie-, auch $l e$ - vor. Besonders instruktiv sind im Dict. leimas $129 \mathrm{a}$ und $i z$ /ileia $321 \mathrm{~b}$, die in der 4 . Aufl. 105 a und 270 a richtig teimas und $i z$ fiteia lauten; vgl. sonst noch nuletas Dict. 428a, nuletus Punktay 105, 18. Wir haben also $-\dot{e}$ - nur vor konsonantisch anlautender Endung, wo es lautgesetzlich eingetreten ist; vor vokalisch anlautender Endung jedoch ist hier, wie in *szleju und grejù (oben clīno und frio) sowie in abg. lëjä 'gieß日' das ursprüngliche -ễi- erbalten geblieben ${ }^{2}$ ); die Neubildungen léju,

1) In Szyrwids Dialekt wird $l$ vor $e$ und $\dot{e}$ lautgesetzlich zu $t$, bleibt aber vor $\vec{e}$ erhalten: in der Schrift haben wir also, da $e$ und $\dot{e}$ unterschiedslos -e- geschrieben werden, nur zwischen -te- (Beispiele bei Garbe Punktay Sakimu S. XXXV) und lie (Beispiele s. v. $l \bar{e} t u m$ und $l \bar{\imath} s$; $-i e-$ ist außer in den s. v. columba und piget besprochenen Fällen stets nur als $-\bar{e}-\mathrm{zu}$ lesen) zu unterscheiden.

2) Garbe a. a. O. S. XXXVIII ist die Ratio der Differenz der Schreibungen te- und lie- bei diesem Worte entgangen. Seine Auffassung, daB teiu, teieias usw. Schreibfehler für zu erwartende *leiu, *leieias usw. seien, verbietet sich nicht nur durch ihre außerordentliche Häufigkeit, sondern vor allem dadurch, daß wir ein *leiu mit dem Lautwert * $l e j u$ nur als Schreibfehler für *lieiu ansehen könnten. Es ist merkwürdig, daß Garbe, der Szyrwids Graphik sonst auch in bezug auf die $l$ - und $e$-Laute richtig beurteilt, dennoch für $l e ̄-$ die Schreibung $l e$ - für richtig hält (allerdings nicht konsequent, vgl. S. XVIII Fn. 1, wo liep/na dem lep/nos vorgezogen wird). Er scheint die Lautgruppe $l \ddot{e}$ - fälschlich als erweichtes $l+e$-Laut aufzufassen (S. XXXVII gegenüber XXXV), was auf Verwechslung des im unechten Diphthong $\ddot{e}$ (ie) enthaltenen $i$ mit dem Palatalitätszeichen $i$ beruht; nur letzteres wird bei Szyrwid in der Regel nicht geschrieben (wegen Szyrwids $l a-, l u$ - usw. für Kurschats lia-, liu- s. unten minus, vilis, volo; wegen le 
salejù usw. vergleichen sich dem lit. pláuju zu pláuti 'spülen" gegenüber abg. plovq 'schwimme, schiffe'. Die Betonungsdifferenz von léju léti und szlejjù szlếti, grëjiù grêti spricht dafür, daß teiu als genaue Entsprechung von abg. lěja auf ${ }^{*} l_{e}^{e} \dot{i} \bar{o}$ zurückgeht; das lett. Präteritum lëju hat dann altes $-\bar{e}$-, das in slēju usw. analogisch fortgewuchert hat. Eine Gleichung ${ }^{*} l e j u=$ abg. laja ist nicht vorzuziehen, da letzteres höchstwahrscheinlich als ideelles *liio aufzufassen ist, denn die slav. Verba, die überhaupt in den einzelnen Formen Ablaut zeigen, pflegen im Präsens Tiefstufe zu haben, die allerdings in vielen Fällen urslavische Neubildung sein dürfte.

lino. - An lat. lino 'beschmiere, bestreiche' erinnert in der Bedeutung außer den unten s. v. lis zu besprechenden Worten noch lit. laistaũ laistÿti 'verkleben, verschmieren, verwerfen', das auch in der Betonung von láistau láistyti, Iterativ zu léti ds., abweicht und daher aus zwiefachen Gründen nicht mit diesem identisch zu sein braucht. Zu laistýti, gibt Szyrwid Dict. 200 a das Primärverbum aplieiu (lies -lëju) als Synonym von aptayftau s. v. obmazuje 'circumlino, circumlinio, oblino'; beachtenswert ist hier das jüngere io-Präsens gegenüber dem in Szyrwids teiv 'gieße' (oben s. v. $l i z b$ ) noch erhaltenen alten o-Präsens, was auf dem Bedürfnis, das semasiologisch Verschiedene auch formal zu differenzieren, beruht. Ein drittes Präsens ist Szyrwids Dict. 54 a lienu (vgl. memelisch lënu KLD[ 'gieße') s. v. formuje, ksztattuje 'formo, fingo aliquid e cera, argilla usw., figuro'; indessen

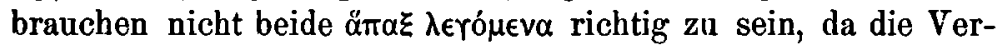
schreibung von $-i$ - für $-n$ - und umgekehrt leicht verständlich ist. Die Bedeutung 'forme, bilde' weist eher, als 'schmiere', auf internen litauischen Bedeutungswandel aus 'gießen' hin, vgl. als Mittelstufe die bei Juškevič stehenden iszlỹdinti eeine Figur gießen' und žem. lŷti, lè̃ti (-êi- lautlich aus -ë-) 'Glocken, Kerzen gießen' (Stichwort išlỹdinti).

lĩnum. - Wegen lit. linta 'Zierband' s. oben lentus.

lis. - Die Form leteti (lit.) ist zu streichen. Die Richtigkeit der Schreibung letteti rechtfertigt sich durch folgende Formen

im Lautwert $l^{\prime} e$ s. oben $l_{e o}$ ). Speziell beim Wort lét $i$ hat Garbe zwar S. XIII richtig beobachtet, daß die Schreibung -e- sich häufiger findet, als -ie-; doch ist seine Konstruktion eines ${ }^{*}$ let $i=* l^{\prime}$ et $i$ falsch, da die ins Gewicht fallenden Belege mit - $e$ - ohne $-i$ - nicht $l$-sondern berechtigtes $t$ - enthalten, wie wir gesehen haben. 
bei Szyrwid Dict.: lieciu (d. i. lëcziu) 163a s. v. nagabam kogo und nelieftas (Part. Prät. Pass.) 177 a s. v. nienagabniony; leteimas 163 a s. v. nagabanie dürfte also für lieteimas und nicht für ein *teteimas verschrieben sein (wegen lie-, te-, le- bei Szyrwid s. oben lîbo und Fn., vgl. auch leo). Es gibt, wie wir aus obigen Formen sehen, einen Infinitiv lësti und einen Infinitiv lëteti; zu welchem das Präsens lëcziu gehört, läßt sich nicht ausmachen. Aus anderen Quellen vgl. dasiléczu dasilésti mit Hinweis auf ein Simplex lésti bei Juškevič (Betonung nicht gesichert, s. oben fülìgo), sowie ein lësti und eine 3. Präs. prilěczia bei Leskien Abl. 278, wo auch ein ablautendes lett. laitit 'streichen' (hin und her mit der Hand) angeführt wird. Die Worte gehören vielleicht mit Wurzelerweiterung zu lat. lino 'beschmiere, bestreiche'.

līveo. - Sloven. slîv, fem. sliva 'zwetschkenblau' dürfte eine Rückbildung aus sloven. sliva 'Zwetschke, Pflaume' sein; lit. slyvà 'Pflaume' halte ich für ein slav. Lehnwort.

locus. - Das in seiner intransitiven Geltung ganz isolierte serb. utòliti 'still werden' ist, da es ohne Kommentar befremdend wirkt und leicht zu falschen Vorstellungen über die slavische Morphologie fübren könnte, besser fortzulassen. Wenn Walde das serbische Wort semasiologisch besonders interessant findet, dann wäre ein Hinweis darauf angebracht, daß das Kompositum in den anderen Sprachen und das Simplex auch im Serbischen bloß transitiv ist, etwa in der Form, daß der Satz hieße "...... gemslav. toliti, utoliti 'besänftigen, beruhigen, stillen (Durst, Hunger)', serb. utòliti 'still werden' (neben tòliti 'besänftigen') .....”. Übrigens bedeutet serb. utoliti in erster Linie nicht 'schweigsam werden', sondern 'ruhig werden'; so wäre derselbe semasiologische Effekt auch allein durch eine vollständigere Bedeutungsangabe von gemslav. toliti, utoliti erzielt.

lolium. - Von den angeführten slavischen Worten lies in richtiger Schreibung mit Akzent: serb. ljûlj 'lolium', klruss. ljutó̌nyk 'Nachtkerze', nslov. ljúljčen 'betäubt', serb. ljúljati 'einwiegen', russ. ljülbka 'Wiege', klruss. tel'ijaty 'wiegen'; wegen der gebräuchlichen serbischen Worte mit lel- s. Berneker s. v. lelëjo.

lūceo. - Preuß. laukit bedeutet 'suchen', nicht 'sehen'. Wegen wahrscheinlich verwandter Worte s. unten pollüceo. Lies lükati (sloven. 'spähen, gucken') statt lukati.

māceria. - Lies máčkam (bulg.) statt mačkam. - Neben lit. minkyti 'kneten' bietet Juškevič auch ein ablautendes mánkau 
mánkyti (= germ. *mangjan 'mengen'; abg. mąciti ist wohl ein Denominativ zu maka 'Qual') und mánkinti. Die Bedeutung des Simplex mánkyti, das vorläufig nur unter iszmánkyti erwähnt ist, läßt sich aus den Komposita nicht ganz genau ersohließen (etwa 'rühren, wühlen'?); letztere haben einen ziemlich weiten Bedeutungsumfang, wobei zu erwähnen ist, daß ihre russischen und polnischen Bedeutungsangaben teilweise mehrdeutig sind und sich daher schwer präzise verdeutschen lassen. Vgl. $\boldsymbol{i}$-si-mánkyti 'sich hineindrängen, sich hineinzwängen' (ij-simánkè vaĩkas kur añkszta 'es zwängte sich der Knabe hinein, wo es eng war'); iszmánkyti mit dem Beispiele su kójomis kêli iszmánkyti etwa 'mit den Füßen den Weg aufrühren (ausmischen, auswühlen)', isz-si-mánkinti (auch -kyti) 1. 'sich (durch Herumwälzen) beschmutzen (sich auswälzen)'; 2. etwa "herauskriechen (aus einem Sumpf, aus einer schmutzigen Grube)' mit

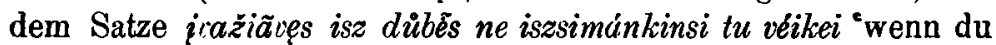
hineingefahren bist, wirst du dich nicht leicht aus der Grube herausarbeiten (dich nicht ... herauswälzen, ... herauswühlen)'. maior. - Neben abg. Vladi-mèr wäre auch Vladi-mirz zu erwähnen; diese Gestalt des zweiten Kompositionsgliedes ist die in den modernen Sprachen vorherrschende.

mãlus. - Lies mostorája (russ.) statt mostavaja.

mamphur. - Zu lett. mente 'Rührschaufel' und dessen bei Walde fehlender litanischer Entsprechung meñté 'Spatel, Schulterblatt' (Leskien Nom. 266) bietet Juškevič auch das Primärverbum $i$-mencziù $\boldsymbol{i}$-mêst $i$ (phonetisch für seinen Dialekt geschrieben $\boldsymbol{i}$-meñsti) 'einrühren (Mehl)', das dem abg. meta męsti 'mischen, verwirren', ai. mánthati, máthati usw. 'schüttelt, rührt, quirlt' entspricht. Eine Weiterbildung dieses Verbums steckt vielleicht auch in lett. mentēt 'mit der Schaufel rühren', das gewöhnlich wohl als Denominativ von mente angesehen wird, aber auch auf dem alten Präteritalstamm menté- in lit. menczia ũ (vgl. das altbulgarische Imperfektum mętè-achz) beruhen kann, wie ich es Arch. sl. $\mathrm{Ph} .32,328 \mathrm{Fn}$. für die lettischen Transitiva (Kausativa usw.) auf -êt neben lit. Verben auf $-y t i$, -inti vorausgesetzt habe; mentēt würde sich dann zu mencziañ genau so verhalten wie lett. d/esēt 'löschen', püdèt 'faulen machen' zu den litauischen Präterita gesia ũ púdžiau ${ }^{1}$ ). Vgl. auch lett. wer (ēt unten s. v.

1) Auf alte $\bar{e}$-Präterita gehen vielleicht auch zurück lit. tekéti 'laufen'

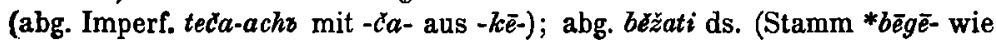


vergo. Natürlich braucht nicht für jedes einzelne lettische Transitivverbum auf -et diese Entstehung vorausgesetzt zu werden: gab es erst eine Reihe solcher Transitiva, dann konnte die $\bar{e}$-Bildung auch weiter um sich greifen und sich auch auf Denominativa erstrecken; jedenfalls aber handelt es sich hier nicht, wie es oft den Anschein hat, um alte io-Verba von femininen $\bar{e}$-Stämmen als Parallele zu der gleichartigen Bildung von $\bar{a}$-Stämmen. - Ein dem slavischen Iterativ mątiti (zu mẹsti) entsprechendes Verbum scheint im Litauischen nicht zu existieren, denn das bei Juškevič stehende isz-si-mañtyju isz-si-mañtyti 'sich herauswinden' macht den Eindruck, auf poln. macić 'trüben, verwirren' $\mathrm{zu}$ beruhen, und zwar als scherzhafte Übersetzung eines ideellen poln. wymacic sie (es scheint in dieser Verwendung nicht zu existieren), etwa, als wenn in einem zweisprachig polnisch-deutschen Gebiet in der Bedeutung 'sich herauswinden, sich herauswirren' ein sich *herausmontieren gebraucht würde. - Neben ksl. motati se 'agitari', klruss. motáty (so betont) 'schütteln' würde es sich empfehlen der Bedeutungsmannigfaltigkeit wegen auch russ. motáto "haspeln, aufwickeln, aufwinden, spulen, schütteln, wackeln; verschwenden, vertun" anzuführen; die Bedeutungen 'haspeln, aufwickeln' dürften. der Grundbedeutung am nächsten kommen.

mannus. - Wegen der Akzentuation von aruss. komons s. oben caballus.

membrum. - Preuß. mensā und lett. mësa 'Fleisch' sind höchstwahrscheinlich aus poln. mięso und russ. mjáso ds. entlehnt. Ein sicher russisches Lehnwort ist m. E. lit. mèsà 'Fleisch'; als Reflex einer uridg. nasallosen Form müßte es *mésa lauten. Bestätigt wird meine Annahme einer Entlehnung durch die Form miesōs (entsprechend lett. mësa) Gen. Sing. bei Doritsch Beiträge S. 4, Z. 33 aus einer Mundart, die bei echt litauischen Worten in der Regel $-\dot{e}$ - und $-\dot{\varepsilon}$ - auseinanderhält. Gute Parallelen sind die gleichfalls aus solchen Mundarten stammenden apsiryédi ebenda S. 6, Z. 25 und apsiriéde S. 39, Z. 12 neben apréde S. 25, Z. 35 (3. prät. literar. -rêdé) zu rédañ rédýti 'bekleiden' aus russ. rjadito 'putzen, ankleiden'; zu diesem Wort vgl. auch aus Szyrwid Dict. 355 a irieditas s. v. strojny 'graphicus, graphice exornatus'

im lett. Prät. bèd/u); abg. pitetti 'nähren' zum Präs. ${ }^{*}$ pitg in pitoms adj. 'gemästet'; vellęti 'wissen' zum Prăs. věms, vedde, und želęti 'wünschen',

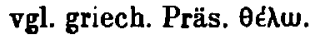


neben ireditay (lies -ytas, -ytai) adv. ebenda s. v. strojno (gescbrieben stroyny, stroyno) und neben redau $62 \mathrm{~b}, 354 \mathrm{~b}, 376 \mathrm{~b}$ (das Wort mésà und Ableitungen gibt Szyrwid als me/a 104a, $149 \mathrm{~b}$, mefinis $149 \mathrm{~b}$, me/inikas $75 \mathrm{a}, 331 \mathrm{a}$ usw.).

memini. - Der Infinitiv zù lit. menù 'erwähne' lautet nicht menéti, sondern minéti. Das altlitauische Präsens miniu (besser ohne Akzent) gehört nicht zu miñti 'gedenken', wie man aus Waldes Wortstellung schließen könnte, sondern als regelmäßigere Form zu minéti. Vgl. bei Szyrwid Dict. miniu 'admoneo, adhortor' $167 \mathrm{a}$, 'nomino, appello nomine' $147 \mathrm{a}$, mini 3. Präs. dazu 167 a, minetoias 'monitor, adhortator' 167 a, 'nominator' $147 \mathrm{a}$, paminet 'erwähnen' $423 \mathrm{~b}$. Daß diese Formen eng zusammengehören, ist außer aus der Bedeutung auch aus der Präsensflexion (3. Sing. -i, nicht $-i a$ ) zu ersehen. Übrigens läßt sich bei Szyrwid die Bedeutungsscheidung zwischen diesem Verbum und den Formen des literar. menù miñti nicht ganz reinlich durchführen. Vgl. einerseits das Verbaladjektiv minetinas 'memorabilis' 240a als Synonym der regelmäßigen atmintinas, atmenamas, anderseits die auf den Infinitiv miñti weisenden minimas 'admonitio, hortatio' $167 \mathrm{a}$, praminimas 'denominatio" 172b sowie das Präsens pramenu 'appello, cognomino' $172 \mathrm{~b}$. Das Simplex menù ist bei Szyrwid nur reflexiv und in einer merkwürdigen Bedeutung belegt, vgl. menuo/i to intelligo in hac re vel hanc rem' $456 \mathrm{a}$, kuris menafi 'peritus' 2 a (s. v. anatomik), menu/is (= literar. -qsis) kokio daykto 'magister' $152 \mathrm{~b}$.

mens. - Leskien Nom. 542 vermutet, daß lit. menta 'Geist, Seele' ein von Dowkont nach dem lat. mens gemachtes Wort zu menù miñti 'gedenken' sei.

merda. - Lit. smárié, smarstas 'Gestank' gehören zu smirdéti 'stinken' und sind an der Stelle, wo sie stehen, zu streichen. Ob man smarsas, smarstvas, smarste 'Fett' von dieser Sippe trennen kann, erscheint mir trotz der verlockenden Zusammenstellung mit ahd. smero 'Schmeer, Fett' usw. fraglich. Bei Nesselmann $487 \mathrm{~b}$ sind die Worte erläutert durch 'Fett, mit dem man Speisen abmacht, bes. schlechteres Abmachsel. Besseres heißt uždaras' (KLD ìżdaras 'Abmachsel, Speisewürze'). Vgl. auch Leskien Nom. 551, der smarsté 'schlechtes Fett' durch den Zusatz 'eigentlich schlechtriechendes, Gestank' erläutert.

mico. - Lies miknuś (nsorb.) statt miknus. - Russ. 
Berichtigungen u. Ergänzungen zu Waldes Lat. Etym. Wörterbuch. 233

migáto (so betont) 'blinzeln' ist als normales Iterativ zu abg. mognąti ds. besser nach den altbulgarischen Worten zu nennen.

minus. - Das litauische Wort für 'Kleinigkeit' lautet nicht mailus, sondern mailius, wie es auch Leskien Nom. 320 schreibt. Die Schreibung mailus bei KLD[ aus Ness. 388 a ist eine ungenaue Wiedergabe von Szyrwids (Dict. 46 a s. v. drobiazg 'minuties') mailus, das aber seiner Orthographie zufolge nur als *mail'us gelesen werden kann ${ }^{1}$ ).

misceo. - Zu lit. maiszaũ maiszýti 'mischen', sumisztù sumiszañ sumiszti 'in Verwirrung geraten' findet sich in der litauischen Literatur auch ein primäres transitives Verbum mësziu mèszti 'mischen'. Vgl. Szyrwid Dict. $359 \mathrm{~b}$ mieśiu midu s. v. syce miod 'coquo hydromeli, mulsum'; Palangos Juze (Wilna 1863) 11.20 sumijsztas $(\ddot{j}=\ddot{e})$ unduo 'gemischtes Wasser'; Auszra 1883. 2661. 34 miesziu, ebenda 30 atmieszti; Juškevič iszmësziù iszmẽsati (geschrieben išm-) 'verdünnen' (z. B. mẽdu su vandenimì 'Honig mit Wasser') und s. v. iszleszinti (geschrieben $i s ̌ l-$ ) auch atmẽsati ds. Dieses Verbum ist interessant durch die Ablautstufe (ideelles idg. ${ }^{*} m e i s \hat{k}$ ), die bei dieser Sippe weder von Leskien Abl. $278 \mathrm{f}$., noch auch von Walde (hier nur im Griechischen ein ideelles *meizg- erwähnt) angeführt wird. Vielleicht liegt sekundärer litauischer Ablaut vor; s. wegen dieser Erscheinung unten pinus Fn.

mōlës. - Sollte lett. mal'îtës (mit -l'-) 'sich dringend bemühen' nicht eher mit malt, lit. málti 'mahlen' zusammenhängen? Vgl. refl. maltés 'für sich mahlen, sich aneinanderreiben, zerreiben, sich irgendwo herumbewegen'. Zu erinnern wäre der Bedeutung wegen an nhd. sich aufreiben. - Lett. muldinät 'andern keine Ruhe lassen' ist kaum von muldèt 'herumirren, phantasieren, sich viel Mühe und Arbeit (d. h. Unruhe) machen' zu trennen; Bedeutungszentrum 'unruhig sein oder machen'. - Russ. májato (so betont) trans. 'plagen, erschöpfen, ermüden' samt majá 'schwere Arbeit, Qual, Plage' steht im Slavischen in der Bedeutung isoliert. Ich möchte es trotz der

1) Da Szyrwid die l-Laute nach polnischem Muster schreibt, so sind seine $l a, l o, l u$ als $l^{\prime} a, l^{\prime} o, l^{\prime} u$ zu lesen und in Kurschats Orthographie durch lia, lio, lik wiederzugeben; indessen haben Nesselmann und seine Vorgänger fülschlich jedes $l$ und $t$ bei Szyrwid unterschiedslos durch $l$ wiedergegeben. Gute Beispiele s. unten s. v. villis und volo, vgl. auch oben caleo. 
semasiologischen Differenz für identisch halten mit abg. mają majati 'winken', bulg. mája 'verzögere, verlangsame', refl. 'zaudere, verspäte; zerbreche mir den Kopf'; glaváta mi se máe 'werde schwindlig'. Das Bedeutungszentrum dürfte sein "heftig hin und her resp. in die Runde bewegen, durch unruhige (vgl. nhd. beunruhigen = quälen, plagen) Bewegung aus dem Gleichgewicht bringen'. Auf 'schwingen' geht zurück russ. májatnikz 'Pendel, Perpendikel'. Interessant sind auch die verschiedenen Bedeutungsnuancen von russ. májačito 1) trs. "in der Luft hin und her bewegen, Zeichen geben, betrügen', 2) intrs. 'schimmern, sich in der Welt herumtreiben, sich kümmerlich durchhelfen; zaudern, zögern'. Es handelt sich im Russ. und Bulg. um verschiedene Resultate eines übertriebenen 'Winkens, Drehens oder Schwingens'; vgl. die Parallele bulg. vortjá se 'drehe mich; zögere, zaudere'. mollis. - Lies mláto (sloven.) und mótot (klruss.) statt mlato, molot. - Das in den litauischen Wörterbüchern häufig verzeichnete und von den Etymologen oft verwertete lit. mildus 'fromm' existiert nicht und hat seine scheinbare Existenz nur einem Druckfehler bei Szyrwid zu verdanken 1). Bei Ness. 379 a und bei KLD[ stehen mildus 'fromm, gottergeben' und mildybè 'Frömmigkeit' mit dem Hinweis auf Szyrwid Dict. als Quelle. Bei Szyrwid aber ist ein mildus überhaupt nicht vorhanden, und ein mildibe findet sich nur in der 5. Aufl. $160 \mathrm{~b}$ (s. v. nabozienstwo 'pietas, devotio in Deum, cultus') als Druckfehler für das in der 4. Auflage $122 \mathrm{~b}$ stehende maldibe. Das Adjektiv mildus, das aus dem vorgefundenen fehlerhaften Abstraktum mildybe methodisch richtig erschlossen ist, muß also zugleich mit diesem fallen. Das Abstraktum maldybe (rgl, auch bei Szyrwid Punktay Sakimu 84, 6 den Gen. Sing. maldibes) gehört zu maldañ maldýti Iter. 'bitten', maldà 'Gebet', und zwar dürfte es abgeleitet sein von einem Adjektiv *maldus 'dem Gebet ergeben, fromm', das zwar nicht belegt (Szyrwids Dict. $177 \mathrm{~b}$ ne maldus Diewuy s. v. nienaboziny 'irreligiosus' wird durch das dativische Objekt als Part. Präs. Akt. = liter. maldąs gekennzeichnet) ist, aber, da Adjektiva auf -us sehr produktiv sind, obne Schwierigkeit vorausgesetzt werden darf (vgl. auch das gleichfalls aus

1) Wenn es vorhanden wäre, könnte es von meldžiù 'bitte, bete" nicht getrennt werden; dadurch würde ohne weiteres die Verbindung

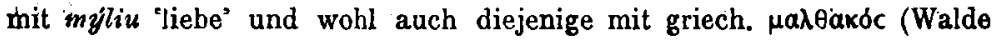
$\mu \mathrm{d} \lambda \theta$ aкоc) 'weich, zart usw.' hinfällig werded. 
Berichtigungen u. Ergänzungen zu Waldes Lat. Etym. Wörterbuch. $23 \check{5}$

Szyrwid stammende maldingas 'fromm' bei KLD[). Wie wir sehen, ist zu lit. meldżiù melsti, Iter. maldyti "bitten, beten' eine Ablautsstufe mild- in der jetzigen Bedeutung der Sippe nicht vorhanden. Es gibt aber ein dialektisches mildingas, das etwa 'freundlich' bedeutet, vgl. bei Doritsch Beiträge S. 65, Z. 29 mildíngai práše 'er fragte freundlich'. Es fragt sich nun, ob dieses ganz vereinzelte Wort echt litauisch oder eine Entlehnung aus nhd. mild ist. In ersterem Falle wäre daran zu erinnern, daß malda $\tilde{u}$ bei Szyrwid Dict. (matdau) in den der modernen Literatursprache fremden (wohl älteren) Bedeutungen 'placo; lenio, mitigo (15b s. v. btagam), delinio, mulceo (128b s. v. tagodze), inhibeo fletum ( $370 \mathrm{~b}$ s. v. tule $)^{\prime}$ belegt ist. Wir hätten dann also doch eine Tiefstufe zu diesem Verbum, die allerdings sekundären Ursprungs sein könnte, sodaß sie für die Ursprünglichkeit der litanischen Verbindung meld-, mald- gegenüber slav. modl- in poln. modlic 'beten', modta 'Gebet' nicht in Betracht kommt. Wohl aber sprechen Szyrwids Bedeutungen 'placo, lenio' usw. und das belegte Primärverbum meldżiu m. E. gegen eine etwaige Herleitung der litauischen Sippe aus dem Polnischen. molo. - Lies auf der vorletzten Zeile malù (lit.) statt malu. musca. - Lett. muscha 'Fliege' hat kurzes -u-.

nāvus. - Lett. finät par kio (nicht $k o$ ) 'für etwas sorgen' dürfte durch einzelsprachliche Bedeutungsverschiebung aus finät 'wissen' entstanden sein; vgl. russ. zavédats čĕmz 'etwas verwalten, überwachen, einer Sache vorstehen', vëdomstvo 'Verwaltungsbezirk, Kompetenz' zu vếdato 'wissen', vëdomyj 'kund, bekannt', auch 'subordiniert'; umgekehrt nhd. eine sache beherrschen, einer sache mächtig sein. Die Bedeutungsverwandtschaft der $\mathrm{Be}-$ griffe 'wissen' und 'sorgen, sich kümmern' zeigt sich auch in den negativen Ausdrücken von jemandem nichts wissen wollen $=$ sich um jemanden nicht kümmern und bulg. ne iskam da znája $z a$ négo 'ich will nichts von ihm wissen'. - Übrigens scheint Walde, wenn er an die Vereinigung von lat. nävus mit nosco denkt, eine ähnliche Bedeutungsentwicklung für die Ursprache anzunehmen.

nidor. - Besser als lett. knëst 'jucken', dessen konsonantischer Stammauslaut -t- ist (vgl. die 3. Präs. knésch und das Deverbativ knëtêt 'jucken'), wäre hier knëdët 'nieten' anzuführen. In der Bedeutung 'jucken' nennt Ulmann Lett.-Dt. Wtb. ein knidet, das sonst 'kriechen, sich bewegen, keimen' bedeutet und 
wohl auf Vermischung mit kniudët "jucken, kitzeln' beruht. Lies knüsit (lett.) statt knosīt.

nōs. - Abg. ny ist Akk. Plur. und bedeutet 'uns'.

novem. - Die Kardinalzahl 'neun' lautet abg. nur devętz, nicht auch devetz. Bei den Ordinalzahlen sind zwar die bestimmten Formen auf $-y j b$ in der Sprache gebräuchlicher, als die unbestimmten auf $-r$; da es aber üblich ist, abg. Adjektiva in der unbestimmten Form anzuführen, wäre hier besser devętb statt devętyjz zu schreiben, zumal Walde bei den übrigen Ordinalzahlen diese Praxis befolgt hat; s. auch unten septem.

oculus. - Woher hat Walde lit. uiksauti ansehen, ausspionieren'? Ist die Bedeutung 'ansehen' genau angegeben? Ich vermute Zusammenhang mit den von Leskien Nom. 595 angeführten oksai (richtiger wohl ikssai) "kundschaftende Bienen', lett. úgstìt 'schnüffeln' usw., die mit 'eingeschobenem' Guttural zu lit. üdžiu üsti 'riechen' (Walde s. v. ōdor) gehören; üksauti würde dann eigentlich '(aus)schnüffeln' bedeuten. - [Vgl. jetzt Leskien IF. 32, 205 ff. K.-N.] s. v. elëjb.

olea. - Lies olëjb (ksl.) statt olëj. Weiteres s. bei Berneker

opìmus. - Wegen abg. pitèti, pitati 'nähren, füttern' s. unten pāsco. - Nahe verwandt mit ai. páyatē 'schwillt, strotzt', pipyniş̧i 'strotzend, milchreich' sind lit. pa-pijusi kárvè 'Kuh, die beim Melken die Milch nicht zurückhält' (KLD $\mathrm{s}$. v. pìjusi), žêmé isz-pijusi '(durch Wasser) aufgeweichte Erde'(Juškevič, Stichwort $i s ̌$-pýt $i$, doch werden andere Verbalformen nicht belegt), pýdau pýdyti 'eine Kuh zum Milchen reizen', vgl. zu diesem

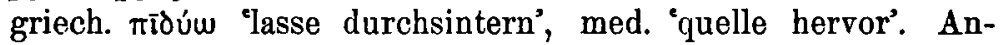
sprechend ist Leskiens (Abl. 280) Heranziehung ron lit. pénas 'Milch' (also als 'beim Melken hervorquellende Flüssigkeit' aufzufassen) und (fragend) von lit. péva 'Wiese'. Zu ersterem, das bei dieser Auffassung nit abg. piti 'trinken' nur in entfernter Weise wurzelverwandt sein kann, vgl. nnorw. fèl ${ }^{\circ} \mathrm{Rahm}$, dickgemachte Milch'; zu pếva verhält sich in der Bedeutung ai. $p \bar{i}-v a-h$ 'Fett, Speck', griech. mîv 'Fett' usw. wie russ. żirz 'Fett' zu abg. žir 'Weide, Weidefutter'; wegen des wohl sekundären -ë- (ror dem $\underline{u}$-Formans ist sonst nur die Ablautstufe $p \bar{i}$-belegt) sowie über die Assoziation zwischen péva und pëmũ 'Hirt's. unten pinnus. Daß péva zur Sippe von pëmũ (s. unten päsco und Fn.) gehört, ist mir unwahrscheinlich, da es im Formans gar zu gut zu ai. piva- $h$ usw. stimmt. 
opĩnor. - Bei der Etymologie dieses Wortes sind die sehr interessanten Ausführungen von Rozwadowski im Rocznik Slawistyczny II, 99. 103 zu berücksichtigen.

ornus. - Berneker s. v. asens und asika dürfte recht haben, daß nur russ. jásenb, serb. jàsēn usw. (nicht abg.) 'Esche' zu lat. ornus 'wilde Bergesche' gehört, dagegen bulg. jasika, serb. jàsika 'Zitterpappel, Espe' (nicht abg.) samt klruss. osýka, čech.poln. osika, altpoln. und poln.-dial. osa usw. mit ahd. aspa, lett. apsa 'Espe' usw. verwandt ist, was schon aus morphologischen Gründen einleuchtet. Doch das in der zweiten Gruppe nur südslavisch belegte $j a$ - möchte ich nicht, wie Berneker tut, auf 'Anlantsdehnung', sondern auf Vermischung mit erstgenannter Sippe, die ursprüngliche Länge hat, zurückführen. Bei Walde muß unter diesen Umständen jasika fortbleiben. Aber auch bei Berneker scheint mir eine Änderung in der Darstellung geboten. Als Stichwort für die zweite Gruppe möchte ich nämlich osa vorschlagen (südslavisch jasika, das natürlich unter diesem untergebracht werden müßte, könnte außerdem s. v. asenı mit Hinweis auf osa kurz erwähnt werden). Als Stichworte eignen sich m. E., wo Auswahl vorbanden ist, doch nur Worte mit normalem, möglichst altertümlichem, Aussehen, nicht aber solche, die eine unorganische Veränderung aufzuweisen haben. palam. - Russ. pólyj (so betont) bedeutet nicht nur 'offen, frei, unbedeckt, hohl, leer', sondern auch 'ausgetreten aus den Ufern' (vom Wasser). In dieser Bedeutung erinnert es an lit. am̃palas 'Aufwasser auf dem Eise', lett. pal'i Plur. 'Überschwemmung', ufpĭles 'Aufwasser auf dem Eise', atpiles 'Moraststellen, die im Winter nicht zufrieren', die kaum von lit. pilù pilti 'gießen, schütten', lett. pilt 'voll werden' (s. unten pēluis und $p l e o$ ) getrennt werden können, vgl. Leskien Nom. 172. Eine gute Bedeutungsparallele zum Verhältnis von am̃palas zu pilti ist poln. wylew wody zamarzty 'Aufwasser auf dem Eise', wörtlich 'Ausguß gefrorenen Wassers' (Juškevič s. v. ámpatas) zu poln. lać, abg. lsjati 'gießen'. Es bleibt noch zu fragen, ob im russischen Adjektiv zwei verschiedene Worte zusammengeflossen sind, oder ob die eine Bedeutung aus der anderen herleitbar ist; im letzteren Falle wäre der Zusammenhang mit abg. polje 'Feld' unwabrscheinlich.

palea. - Im Russischen werden plevá, plená 'Häutchen' etymologisch unrichtig mit $-e$ - statt mit $-\dot{e}$ - geschrieben. Wegen lit. pilù 'schütte's. unten pleo. 
palleo. - Zu den Worten in der Bedeutung 'altersgrau' gehören wohl auch lit. peléju peléti intrs. 'schimmeln', pelésiai M. Plur. 'Schimmel', ksl. plësnb F. ds. Da pelesiai nicht -szsondern -s- hat, können wir auch in plěsnı altes -s- vermuten; aber lit. pálszas 'fahl', von dem ich ksl. pelest 'grau' nur ungern trennen würde, kann nur $-\hat{k}$ - enthalten und ließe sich nur bei dem etwas gekünstelten Ansatz ${ }^{*}$ pols- $\hat{k} o-s$ in nähere Beziehung zu pelèsiai und einem ital. *palso-s bringen.

pannus. - Abg. ponjava 'Umhang, Kleid', opona 'Vorhang' können m. E. nicht unmittelbar mit lat. pannus 'Stück Tuch, Lappen' verbunden werden, da es unnatürlich wäre, in den slavischen Worten nicht die o-Stufe zu abg. ponq peti 'spannen' zu sehen; insbesondere sieht opona durchaus wie ein ursprüngliches Verbalnomen aus. Wir können also nur mit einer entfernten Wurzelverwandtschaft zwischen dem lateinischen und den slavischen Worten rechnen.

pariës. - Ksl. tvorz 'habitus corporis' (Walde 'forma, creatura') ist als ein in Form und Bedeutung uninteressantes, hauptsächlich aus jüngeren Quellen belegtes Wort und vermutliches Postverbale besser zu streichen. Semasiologisch resp. formal bemerkenswerter sind abg. zatvoriti 'verschließen, einschließen', tvar'b 'Schöpfung, Geschöpf', tvrzdz 'fest', alle drei gemeinslavisch. Die vorhandenen Nomina mit tvor- in der Wurzelsilbe sind ksl. meist wenig gebräuchlich und sind in der Bedeutung durchaus vom Verbum tvoriti 'schaffen, machen' und dessen Konposita abhängig.

pāsco. - Bei Erwähnung von abg. pasq 'weide, hüte' erübrigt sich der Hinweis auf lat. specio, s. unten specio. Lies pastyro (abg.) statt pastyro. - In bezug auf die Etymologie von lit. pếtūs Plur. 'Mittagessen, Mittag', abg. pitèti, pitati 'füttern, ernähren', ai. pitu- $h$ 'Saft, Nahrung' usw. herrscht bei Walde Unklarheit, indem er sowohl ihre Verbindung mit * $p \vec{a}$ - 'weiden, nähren, essen', als auch mit * $p \bar{\imath}$ - 'strotzen, hervorquellen' (s. v. opīmus und pinus) anerkennt, ohne jedoch die beiden Sippen zu vereinigen oder auch die Möglichkeit einer Vermischung derselben zu erwähnen. M. E. kommen wir mit einem *pät-1)

1) Wegen lit. pët-s. unten s. v. pīnus. Mit der Quantitätsdifferenz von ai. pitúh̆ und lat. pītuita, ai. pĩvah 'Fet1, Speck' usw. hängt wohl auch die Betonungsdifferenz von lit. pêtus und péva 'Wiese', pénas 'Milch' zusammen; übrigens paßt auch lit. pëmũ 'Hirt' in der Betonung nicht zum Langdiphthong in ai. pāyuih 'hütend', griech. $\pi$ wu 'Herde'. Es haben also offenbar Vermischungen von schweren und leichten Basen stattgefunden. 
Berichtigungen u. Ergänzungen zu Waldes Lat. Etym. Wörterbuch. 239

'hervorquellen, saftreich sein' für alle Bedeutungen der von Walde genannten Worte aus (beachtenswert ist der auch zum Litanischen stimmende $u$ - (tu-) Stamm idg. $\left.{ }^{*} p \tilde{t} t u-\right)$, womit auch die Notwendigkeit, die Wurzel von $p \bar{a} s c o$ als ${ }^{*} p \bar{a}(i-)$ anzusetzen, entfällt. Anders würden sich die Ablautrerbältnisse gestalten, wenn wir trotz Waldes Widerspruch passco mit griech. $\pi \hat{\omega} u$

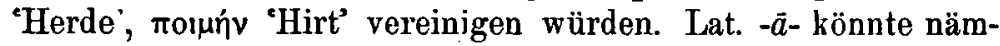
lich unter Umständen auf Qualitätsangleichung von $-\overline{\boldsymbol{o}}$ - an die Reduktionsstufe $p a$ - aus ${ }^{*} p a$ - beruhen, eventuell auch in nasalinfizierten Formen aus -an- lautlich entstanden sein. Semasiologisch kann ich keinen prinzipiellen Unterschied zwischen den Sippen sehen; nur ist der Bedeutungsumfang bei * $p \bar{a}$ - größer, als bei *poi-. Für die Grundbedeutung halte ich bei *pā- nicht etwa 'essen' oder 'füttern', sondern 'Vieh büten' resp. auch 'weiden, grasen' (vom Vieh als agens). Die eine dieser beiden Bedeutungen hat sich durch die beiden gemeinsame Vorstellung 'auf der Weide sein' aus der anderen entwickelt. Von 'hüten' kommen wir unmittelbar zu 'füttern' und von 'grasen' zu 'fressen'. Die weitere semasiologische Entwicklung des Begriffes 'hüten' nach der ethischen Seite hin s. unten s. v. specio.

pateo. - Das preußische Wort für 'Ofenschaufel', das in der sprachwissenschaftlichen Literatur als pettis bekannt ist, ist eigentlich pectis zu lesen, und bloß aus Etymologisierungsrücksichten haben Berneker und Trautmann, gestützt darauf, daß in der preußischen Schrift - $c$ - und - $t$ - verwechselt werden können, das Wort als pettis angesetzt. Ich glaube aber, daß wir diese Konjektur entbehren können, denn auch ein pertis d. h. pektis läßt sich gut etymologisieren. Das Wort, das im Vokabularium Nr. 332 unter lauter auf die Brotbereitung bezüglichen Worten steht, bezeichnet ein für die Brotbäckerei sehr wichtiges Gerät. Ich halte es für eine Entsprechung von abg. peštı F. 'Ofen', ursprünglich ein Verbalabstraktum zu peka pešti 'backen' $=$ griech. $\pi \dot{\epsilon} \psi \mathbf{i c}$, ai. pakti-h 'das Kochen, gekochtes Gericht'. Aus der Bedeutung 'das Backen' konnte natürlich sowobl 'der Backofen' (weiterhin überhaupt 'Ofen'), als auch jeglicke Art von 'Backgerät' werden; das Bedeutungszentrum des slavischen und des preußischen Wortes ist 'Backort'. Daß ein baltisches Verbum *pelti 'backen' nicht existiert, sondern statt dessen lit. kèti, lett. zept gebraucht wird, spricht nicht gegen die Existenz 
eines aus der Urzeit stammenden Substantivs *pek-ti-s, vgl. auch

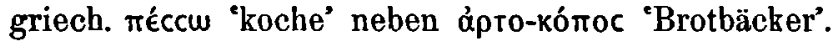

patro. - Ksl. popada popasti 'fassen' ist ein Kompositum von pada pasti 'fallen', woran keiner, der in einer modernen slavischen Sprache einigermaßen Sprachgefühl hat, zweifeln kann; vgl. z. B. russ. popásto na myslb 'auf einen Gedanken verfallen', dial. popásto kogó 'jemanden antreffen, erwischen', eigentlich 'auf jemanden fallen, jemanden anfallen'. Ähnlich ist ja auch im Deutschen der Ausdruck auf etwas verfallen bedeutungsähnlich den Ausdrücken etwas erfassen, begreifen.

pecu. - Aus welchem Grunde Kurschat das ihm aus der gesprochenen Sprache nicht bekannte altlit. pekus 'Vieh' nit -eschreibt, ist nicht zu ersehen; die von Leskien Nom. 240 angeführten Quellen scheinen keine Anhaltspunkte dafür zu bieten, und auch Nesselmann 282 a schreibt das Wort mit -e-, was höchstwahrscheinlich richtig ist. Für -e- spricht auch die Schreibung -ck- in preuß. pecku 'Vieh'. Ähnliche Fälle siehe s. v. fiber und vetus.

pēdo. - Das slovenische Wort für 'pedere’ ist pazdéti zu schreiben statt pezdéti, wobei das -ə- die Grundform *pzzdèti (Brugmanns im Grundriß I2, $512{ }^{*}$ pezdéti ist also unerwiesen) erweist, und die klruss. Formen $b z d^{\prime}$ ity, pezd'ity statt $b z d^{\prime}$ 'ity, pezd'ity. Bei der Beurteilung der Frage, ob lit. bezdéti ein slavisches Lehnwort ist, sind die im Vokalismus abweichenden bizdas 'podex', bizdżius 'Stänker' samt Ableitungen und das auf ein Verbalnomen mit -t-Suffix rom Stamme bizd- zurückzuführende bisteleti 'pedere' (alle drei aus Juškevič, bizdžius auch bei KLD[ and Leskien Nom. 322) zu berücksichtigen, und es ist auch zu beachten, daß auch im Lettischen ein befdet vorkommt, und daß ein klruss. *bezd'ity resp. großruss. *bezdèttb nicht vorhanden ist, daß also lit.-lett. - $e$ - entweder ein jüngerer Einschubvokal sein oder auf einer Vermischung beider kleinrussischer Formen beruhen müßte. Durch die Entlehnung erklärt sich nur das $b$ einfach, die Erklärung des Vokalwechsels aber müßten wir jedenfalls auf baltischem Boden suchen; und wenn wir für einen Teil der Worte eine echt baltische Grundlage annehmen wollten, so kämen wir doch ohne Kontaminationen zwischen einheimischen und entlehnten Worten nicht aus, die kaum weniger kompliziert sind, als die analogischen Umwandlungen usw., mit denen wir rechnen müssen, wenn wir die ganze Sippe 
für aus der Ursprache ererbt halten. Ich halte bezdù bezdéti für echt baltisch, und zwar für eine Vermischung eines dem lat. $p \bar{e} d o$ entsprechenden urbalt. *pezdi und eines Infinitivstammes *bzdé-; es ist möglich, aber kaum zu beweisen, daß

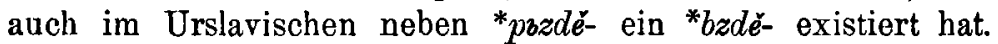
Lit. bizd- kann entweder lautlich aus ${ }^{*} b z d$ - oder analogisch aus ${ }^{*}$ pizd- hervorgegangen sein; letzteres ist wegen der Existenz von slav. ${ }^{*} p b z$ - wahrscheinlicher. Übrigens könnten wir sogar ein urbalt. ${ }^{*} b z d \bar{e}-$ entbehren und den stimmhaften Anlaut durch Herübernahme des stimmhaften Inlauts erklären, wie es bei derartigen Worten ja vorkommt. - Gegen slavische Entlehnung spricht auch der Umstand, daß ein bizd- in anderen Bedeutungen vorkommt, das, wenn wir die Echtheit von bizdas usw. anerkennen wollen, sehr wohl durch Bedeutungsverschiebung aus der Sippe von pēdo hervorgegangen sein kann. Vgl. su-bizdo 'geriet in Aufregung, Verwirrung KLD[, wo aber als Präsens fälschlich *bizdu statt eines zu erwartenden *bistu erschlossen worden ist; bizdžius (außer als 'Stänker' auch gebraucht als Schimpfwort in der Bedeutung) 'dicker, schwerfällig gehender Mensch', vgl. Leskien Abl. 321; ferner mit dem Bedeutungszentrum etwa 'müßig umhergehen' aus Juškevič: bizdu Interj. zur Bezeichnung des 'Gehens ohne Zweck', bizdùlis 'müßiger Mensch', bizdinti 'gehen' mit dem Beispiel ans bizdina, ant subinès rankàs susidéjes 'er geht mit auf dem Hintern zusanmengelegten Händen umher', wo man statt subinès auch bizdo Gen. Sing. gebrauchen könnte; ähnlich bizdinét $i$ 'mit hervorgestrecktem Hinteren einhergehen: Hierher gehört wohl auch die auf einen Infinitiv *bisti (zu su-bizdo s. oben) weisende Interjektion bistu(m) in bìstu-pabàstu, bìstum-pabàstum "bei unablässigem Herumwirtschaften in unwichtigen häuslichen Verrichtungen', vgl. Leskien IF. 13, 186. Das pahàstu(m) erinnert an bastã̃ bastýti 'stoßen', das zu badýti ds. gehört, vgl. zur Bedeutung nhd. sich (müßig) herumstoßen; an Wurzelverwandtschaft mit bistu(m) ist also kaum zu denken. Ein slavisches $b b z d$ - (mit analogischem $b$ - oder mit eingeschobenem -b-) in ähnlicher Bedeutung scheint in sloven. bazdám bazdáti 'pfuschen' noch vorzuliegen und dürfte auch vorauszusetzen sein in sloven. bazniti bazniti 'stupfen, stoßen' mit lautlichem Schwund des $-d$ - vor $-n$ - und in deu aus diesem Verbum abstrahierten sloven. bazâm bazáti 'stupfen, stochern', serb. bãzām bázati 'ambulare' (anklingend, aber unklar, auch 
bàsām bàsati 'daherschlendern'); Bedeutungszentrum etwa 'sich unnütz machen'.

pējero. - Lies gnesti (abg.) statt gnetiti.

pēluis. - Ksl. polø, ispolz 'Schöpfgefäß', sloven. pòt Gen. póla 'Schöpfschaufel" erinnern zunächst an lit. pilta 'Schöpfschaufel', piltuvas 'Schöpfeimer, Pumpe', piltavas 'Trichter' ( $\nabla \mathrm{gl}$. Leskien Nom. 543, 566), die zu pilù pilti 'gießen, schütten' gehören. Eventuell kann Wurzelverwandtschaft mit lat. péluis bestehen; vgl. die unteu s. v. pleo vorgetragene Etymologie von pllti. Sloven. poljem plati "haurire' (Miklosich Lex. Pal. s. v. polz) dürfte wegen des Vokalismus ein uraltes Denominativ sein, vgl. zur Bildung lit. grindżiù grizsti 'den Fußboden mit Brettern belegen, dielen' zu grindis F. 'Dielenbrett', Plur. 'Diele'. Sloven. pòt 'Futterschwinge', póljem pláti '1) in wallende, wogende Bewegung versetzen, 2) schwingen, 3) in Bowegung sein' sind vielleicht nit obigen Worten identisch. Weitere wahrscheinlich verwandte baltisch-slavische Worte mit der gleichen Vokalstufe wie pols s. oben s. v. palam.

pēnis. - Von den hier angeführten čechischen Worten

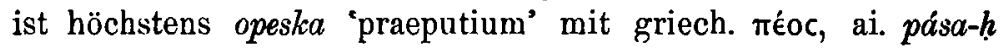
'penis' usw. verwandt; doch ist mir wegen der Isoliertheit im Slavischen auch dieses Wort verdächtig, wenn ich es auch nicht anders erklären kann. Das Adverb pesky 'schändlich, schamlos' ist der Instr. Plur. von peský 'hündisch, hundsföttisch" zu pes = abg. pass 'Hund', vgl. abg. passsky Adv. 'canum more'. Čech. opeslý 'schändlich, schamlos' beruht wohl auf einer nicht ganz klaren analog. Umbildung aus opsely ds., ursprgl. "hündisch geworden', Verbaladj. (*opžé-lz) zu einem Verbum auf -èti (poln.psieć 'schlechter werden', russ. psëts 'nach Hunden zu stinken anfangen'), gehört also gleichfalls zu pes. Čech. péchový 'Hengst' fehlt bei Kott Slovnik ceského jazyka. Vermutlich ist entweder die Form oder die Bedeutungsangabe ungenau, denn der Form nach ist das Wort ein possessives Adjektiv. Entweder also hat das Grundwort (etwa *pěchı?) 'Hengst' bedeutet, oder es ist ein verselbständlichtes Atrribut $\mathrm{zu}$ einem 'Hengst' bedeutenden Substantiv. In jedem Falle ist ein Zusanmenhang mit ěech. péchovati 'stampfen' (Walde s. v.pinso) wahrscheinlich; weniger naheliegend würde oin Zusammenhang mit abg. pěšz Adj. 'zu Fuß’, čech. pěš, pěchý ds. sein. Čech. pěchúr 'uterus' ist mir unbekannt; bei Kott (a. a. O.) gibt es nur ein péchúr 'Fußgang, Fußgänger' zu abg. 
pěšs (s. oben). Wenn die Bedeutungsangabe richtig ist, könnte vielleicht an Verwandtschaft mit abg. pizda 'vulva' oder mit lit. pis̀u pisti 'coire', lat. pinso 'stampfe' gedacht werden, so daß eventuell ein Zusammenhang mit obigem pěchový bestände; anderseits erinnert das Wort auch an ksl. pěchyro M. 'bulla'. Doch werden wir besser bei diesen beiden Worten, bevor ihren Quellen nachgespürt worden ist, ein non liquet konstatieren. Jedenfalls dürfen wir nicht vergessen, daß uridg. * pēs- im Slavischen *pěs- ergeben müßte, und daß wir, solange andere Erklärungsmöglichkeiten vorliegen, nicht ohne weiteres berechtigt sind, ein sekundäres -ch- anzunehmen.

pertica. - Lies prêkla (sloven.) statt prèkla und prićc,

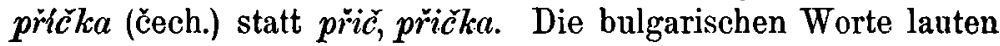
prěčka 'Querstange, Hindernis' und pričcka 'Rute'.

pès. - Lies pěšs (abg.) statt pěšr.

pestis. - Ein Substantiv *estis 'das Sein' wird auch außerhalb des Indischen angenommen in preuß. astin Akk. Sing. M. 'Ding, Handlung' ( $a$ - aus $e$-, vgl. asmai 'bin'), vgl. Berneker Prouß. Spr. 281, Trautmann Die altpreuß. Sprachdenkmäler 305. Allerdings schwebt es mir vor, daß ich auch eine Ablehnung dieser Etymologie gelesen habe, doch kann ich mich nicht mehr erinnern, wo. Ob die Bedeutung im Preußischen eine konkrete oder eine abstrakte gewesen ist, läßt sich aus den drei von Trautmann zitierten Stellen nicht mit voller Sicherheit ersehen. Mit astin 'Ding' ist die Wirkung des Wassers bei der Taufe und des Essens und Trinkens beim Abendmahl bezeichnet, mit astin 'Handlung' aber die Taufe. In die ursprüngliche Bedeutung des Wortes können wir daraus keinen Einblick gewinnen. piget. - Szyrwid Dict. hat folgende litauische Worte, die mit ai. plšunah 'böse gesinnt, verräterisch, verleumderisch", pišācáh 'Dämon' laut- und bedeutungsverwandt sind. $264 \mathrm{~b}$ stehen papeśiu (lies -sziu) s. v. podszczuwam instigo, concito, incito, acuo

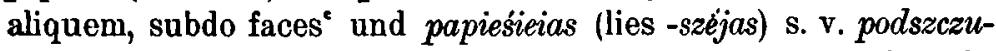
wacz 'instigator, mandator, fax accusationis', und $167 \mathrm{~b}$ steht papiecieias (lies -caejjas) s. v. naprawiacz na kogo, zdradliwy 'subornator. Es ist klar, daß zwei dieser Formen fehlerhaft sein müssen, wenn wir sie alle miteinander verbinden wollen. $\mathrm{Zu}$ nächst dürfte der Wurzelauslaut $s z(\xi)$, nicht aber $c z(c)$, gewesen sein, denn von einem Präsens *pëcziu ("pieciu) würden wir das Nomen agentis *pêtéjas ("pieteias) und nicht *pëczéjas erwarten. 
Was aber den Wurzelrokal anbetrifft, so deutet das zweimalige -ie- an ganz getrennten Stellen, zwischen denen keine Assoziation möglich ist, auf die Richtigkeit dieser Schreibung hin; wir werden also den semasiologisch möglichen Zusammenhang mit peszù pèszti 'pflücken, zupfen' ablehnen müssen ${ }^{1}$ ). Außerdem ist bei Szyrwid peszù stets, wie auch literarisch, ein o-Stamm, und es finden sich auch keine abgeleiteten Bedeutungen; vgl. $340 \mathrm{~b}$ peßu, peśimas s. v. skubie 'vello' und skubienie 'vellicatio, vulsura'; 203 a peszu ptaukus s. v. obrywam wtosy 'vello comam'; 264 a papeszu s. v. podskubuje czego 'aliquantum vello ex plumis'. Daher dürften wir papeśiu und papiećieias in papiesiu ("papésziu) und papieśieias ("papészejas) zu verbessern haben. Lautlich ist das Verbum gleich dem bekannten pësziu pëszti 'schreiben'. Wenn wir es für identisch mit diesem halten wollen, müssen wir annehmen, daß das Wort sich seit der Urzeit in zwei Bedeutungsvarianten erhalten hat, denn die eine innerhalb des Baltischen aus der anderen abzuleiten, erscheint kaum möglich. Dann hätte papieśiu eine gute Anknüpfung an ai. pišsáti "haut

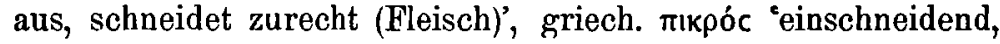
scharf, bitter, feindselig' (s. Walde s. v. pingo). Walde bestreitet, daß ai. pišuna- $h$ und pišācá- $h$ mit diesen Worten zusammenhängen; es fragt sich aber, ob nicht schon in der Ursprache eine teilweise Vermischung der Sippen des 'Feindseligseins' und des 'Ritzens, Schneidens, Malens' stattgefunden hat. Auch werden wir es unentschieden lassen müssen, zu welcher der beiden Sippen lit. papiessiu zu rechnen ist.

pingo. - Lit. pésziu pëszti 'schreiben' ist besser unbetont zu lassen. Während Juškevič ipësziù ipęszti bietet, hat Leskien Abl. 292 überall betonte Wurzelsilbe, was für Stoßton spricht. Über ein -pësziu in anderer Bedeutung, das eventuell mit diesem identisch sein kann, s. oben s. v. piget. - Lies paz̃szas (lit.) statt páiszas.

pinna. - Lies spaiglis (lett.) statt spaigilis. - Daß cech. spile 'Stecknadel', lett. spile 'Holznagel, Holzgabel' mit nhd. spille, griech.

1) Szyrwids -ie- ist in der Regel das Zeichen für -ë- und nicht für $-e$ - und $-\dot{e}-$, die $-e$ - geschrieben werden (oben $l i \bar{b} o$ und Fn.); nur nach Gutturalen (oben columba) und Zischlauten (Beispiel papiesieias) dient -ie- auch zur Bezeichnung des durch den vorhergehenden Konsonanten erweichten $-e$ - und $-\dot{e}$-, sodaß in diesem Falle die drei $e$-Laute in der Schrift nicht auseinandergehalten werden. 


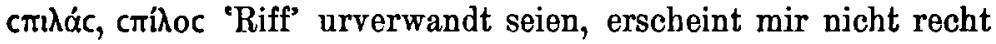
wahrscheinlich; es müßte noch untersucht werden, inwieweit Entlehnung vorliegen kann, vgl. die wegen $\check{s}$ - sicher entlehnten russ. špilı M. 'Spille, Winde, Spitze, Zapfen', špillbka 'Spitze, Spieß, Stecknadel usw.', prišspllito 'feststecken, anstecken'. Zu beachten ist auch lit. spylỹs 'Speil, Stachel, Dorn', Plur. spyliã 'Sperrute der Leinweber', das aus dem Germanischen (nhd. speil) stammen dürfte.

pinso. - Lies pésta (sloven.) statt pêsta.

pinus. - Über eine andere von Walde angenommene (wohl unrichtige) Etymologie von lit. pêtūs 'Mittag' s. oben s. v. $p \bar{a} s c o$ und Fn, wo auch über die Betonungsdifferenz zwischen pếtūs und pếnas usw. die Rede ist. Mit Ablaut zu pễtüs, abg. pitati 'füttern, nähren' usw. vgl. lit. isz-páitvéju, isz-páitvéti 'wieder zu Kräften kommen, gesund werden' (Juškevič; in der Betonung besser zu pënas stimmend) und vielleicht auch lit. pitas 'rund' (Leskien Abl. 280; anders Walde s. v. pila). Interessant ist es, daß der indogermanische Stamm ${ }^{*} p \tilde{z} t u$ - allein im Litauischen mit Diphthong in der Wurzelsilbe erscheint; äbnlich ist auch das Verhältnis von lit. pë́nas 'Milch' zu ai. pinci- $h$ 'fett, feist, dick' und von lit. péva 'Wiese' zu ai. pivah N., griech. mîv 'Fett'. Da ich an den von vielen Forschern angenommenen Lautwandel von ai (oi ) zu $\ddot{e}$ im Litauischen und Lettischen wegen der Spärlichkeit der Beispiele nicht glauben kann'1),

1) Wegen lit. vénas 'unus's. unten s. v. ūnus. - An lit. kễmas 'Dorf' neben kaimýnas 'Nachbar' eriunert lit. szeimýna 'Gesinde' neben lett. saime, abg. sembja ds. Es dürfte hier, sowie z. B. auch in lit. gễdras neben gaidrùs 'heiter' und lett. bëdêt neben baidit $=$ lit. baidy'ti 'schrecken" ein Sekundärablaut vorliegen, dessen Ratio noch zu untersuchen ist. Das - $\ddot{e}$ - (teilweise wohl noch in der älteren Gestalt $-e \underline{i}$-) ist teils für $-\tilde{z}$ ( $p \bar{e} t \bar{t} 8$ usw.), teils für baltisches -ai- (verschiedenen Ursprungs) eingetreten. Unursprünglich ist das $-\bar{e}$ - wohl auch in lett. géd $u$ 'werde inne, vermute' (KZ. $44,44 \mathrm{ff}$ ), lit. géd $u$ 'singe' (Wurzel wohl * $g \bar{o}(\boldsymbol{z})$ - oder *ga( $\boldsymbol{i})$ - wegen ai. gdyati, gāti 'singt', russ. alt gajati 'krähen', vgl. Berneker s. v. gajo) und vielleicht in lit. mësziu 'mische' (oben misceo). Da sich im Baltischen auch sonst mehrfach die e-Stufe zeigt, wo sie in den übrigen Sprachen gar nicht oder nur schwach (fast nur im Slavischen) bezeugt ist (s. oben capio und fodio und unten valeo; sonst etwa noch lit. kvepiu 'dufte' mit -e- statt $-a$ - aus -a- bei Walde s. v. vapor und męzं $\dot{u}$ "mingo" für *minźú bei Leskien Abl. 279), kann man vielleicht die Fälle mit jungem $-\vec{e}$ - (und -ei-) auf dieselbe Tendenz zurückführen, die ein junges -e- geschaffen hat. Ein Ausgangspunkt der Entwicklung kann in den 
wir aber keine Berechtigung haben, *pęzi- als Wurzel anzusetzen, vermute ich, daß alle drei Worte, die einst als Verbalnomina zu demselben Verbum *pyti 'strotzen' (oben opimus) miteinander in einem assoziativen Verhältnis gestanden haben, sekundäres $-\dot{b}-$ haben, das zunächst vielleicht im $t u$-Stamm * $p^{*} t u$ - eintrat, da in derartigen Stämmen von ursprachlicher Zeit her die e-Stufe vorherrschend war. Dasselbe gilt auch von den men-Stämmen, und so können wir auch in lit. pëmũ 'Hirt' statt *paimu $=$ griech. $\pi o u \mu \eta \dot{v}$ ds. sekundäres -ë- annehmen; zwischen pëmư und péva kann übrigens auch, obgleich keine Verwandtschaft besteht (oben opimus), schon früh eine Assoziation stattgefunden haben.

pleo. - Hierher gehört nach Leskien Abl. 359 auch lit. pilù pilti 'gießen, schütten', d. h. 'mit Flüssigkeiten, Sand und dgl. füllen'. Im Litauischen beschreibt man durch das Wort anschaulich gewisse Arten des 'Füllens', während durch lat. pleo, nhd. füllen nur die Tatsache selbst konstatiert wird. Die beim litauischen Verbum auch vorliegende Bedeutung 'aufhäufen' (z. B. 'einen Wall', vgl. pýlimas 'das Gießen, Schütten; der Wall') erinnert an armen. holem, holonem 'häufe auf, sammle auf' (baltisch-slavische Worte mit der Ablautstufe *pol- s. oben s. v. palam und péluis), vgl. auch (anders Walde s. v. populus)

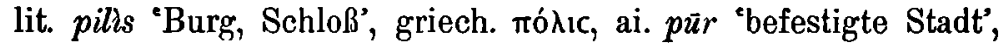
d. h. 'Aufschüttung'. Schon in der Ursprache dürften die beiden Bedeutungen 'einfüllen' und 'aufbäufen' nebeneinander bestanden haben; nicht unwahrscheinlich wäre die Grundbedeutung 'einen Wall aufschütten'. Das blasse 'füllen', das in den meisten Sprachen als Bedeutungszentrum der Sippe vorliegt, dürfte aus einer schon ursprachlichen $\mathrm{Ab}$ straktion aus einer konkreten Tätigkeitsbezeichnung entstanden sein. Im Litauischen, wo das Iterativ pìldyti 'füllen, erfüllen' und die Nomina instr. pilutis, pilusis 'Fällholz' ein Primärverbum in der Bedeutung 'füllen' voraussetzen (vgl. auch lett. pë-pilst 'es füllt sich'), liegt wohl bei pilti eine jüngere Bedeutungsspezialisierung vor, und zwischen der litauischen Bedeutung 'aufschütten' und der urindogermanischen 'einen Wall auf-

Fällen zu suchen sein, wo -e- auf Qualitätsangleichung an - $\bar{e}-$ beruht, z. B. kvepéti 'duflen' nach kvêpti 'hauchen'. Zu einer Zeit, als man *kvepji neben *kvapjü sprach, konnte man etwa auch zu einem *badú aus *bhodho 'steche, grabe' und zu einem *gajdi 'singe' (beide nicht bezeugt) ein *bedu (bedì) und *gejadu (géddu) schaffen. 
schütten' besteht wohl kaum ein unmittelbarer Zusammenhang. - Mit abweichender Ablautstufe könnte lett. peldēt hergezogen werden. Gewöhnlich bedeutet es 'schwimmen' (etwa 'sich in einem gefüllten Bassin obenauf halten'?), vgl. aber auch den Satz bei Ulmann Lett. Dtsch. Wtb. labiba peld atpakal" 'das Korn fließt zurück (aus dem Kornbehälter, weil er zu hoch aufgehäuft ist)'.

plöro. - $\mathrm{Zu}$ der in ags. flowan 'fließen' enthaltenen dehnstufigen Wurzelform gehört auch das Kausativ ksl.-gemslav. plaviti 'facere ut fluat, natet', refl. plaviti se 'navigare'. Auch abg. plavati 'schwimmen' werden wir als al te dehnstufige Form ansehen dürfen. Äußerlich sieht es zwar wie ein Iterativ zu plova pluti 'fließen, schiffen' aus; seine Anwendungen in den Einzelsprachen aber machen es wahrscheinlich, daß es schon im Urslavischen ein selbständiges, d. h. weder deverbativ noch denominativ empfundenes, Wort war; es dürfte also eher zu den Vorbildern der slavischen Iterativkategorie mit 'gedehnter' Wurzelsilbe gehören, als mit diesen gleichzeitig entstanden sein. Beachtenswert ist besonders der Umstand, daß das Verbum als Simplex ganz geläufig ist, während bei den meisten Iterativen die gelegentlichen Abstraktionen aus den Komposita ziemlich deutlich den Stempel der Unursprünglichkeit tragen. Die Ablautstufe von lit. pláuju pláuti 'spülen' liegt auch im abg. Infinitiv pluti (zu plovq s. oben) vor. Neben oder statt plytonz 'schiffend', das Walde wohl nur anführt, um ein slavisches Beispiel für die Ablautstufe uridg. * $p l \bar{u}$ - zu zeigen, könnte auch der Infinitiv russ. plytb, serb. pliti, genannt werden, der deutlich zeigt, daß diese Ablautstufe noch in Formen des Primärverbums erhalten ist.

(pluo.) - Das sehr seltene Postrerbal ksl. plavz 'Schiff' zu abg. plavati 'schwimmen, schiffen' ist besser zu streichen und eventuell durch dieses Verbum zu ersetzen (s. über dieses oben s. v. ploro); auch russ. plovo, das 'das Schwimmen, Wasserfahrzeug, Boot' bedeutet, ist kein häufig gebrauchtes Wort und ist weder semasiologisch noch formal interessant genug, um hier miterwähnt zu werden.

pollen. - Lit. pelẽné, preuß. pelanno 'Feuerherd' können m. E. schwer von abg. vosplanati 'aufflammen', plame 'Flamme', russ. pólomja, cech. plapol 'Flackern, Flamme' getrennt werden. 'Feuerherd' läßt sich natürlicher auffassen als 'Feuerort', denn 
als 'Aschenort'; und lit. pelenaĩ, lett. pelni, preuß. pelanne 'Asche' können daher kaum auf die Bedeutung 'feines Mehl, Staub und dergl.' zurückgeführt werden; sie werden vielmehr wie abg. popelz, russ. pépelz 'Asche' als 'Verbrennen, Verbranntes' aufzufassen sein. Wegen der Ablautverhältnisse vgl. IF. Anz. 28, 37.

pollūceo. - Abg. polučiti 'erhalten', russ. polučítı, serb. poluéiti ds. (also nicht bloß serbisch) ist ein Kompositum von

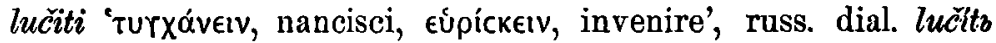
'werfen, mit dem Bogen schießen' (volksetymologisch mit lukt 'Bogen' = abg. lakb ds. verbunden), refl. impers. 'geschehen', bulg. líča 'ziele, errate', sloven. lučtti eeinen Wurf tun, schleudern', poln. tuczyć 'zielen', zu dem auch abg. sz-lučiti sę 'geschehen', lučajb, sz-lučajb 'Zufall' gehören. Das Bedeutungszentrum dieser Worte ist wohl 'zielen' mit den Bedeutungsvarianten 1. 'werfen, schleudern', 2. 'abtreffen, passen, heranreichen', vgl. russ. ulučtto 'eine günstige Zeit und Gelegenheit abpassen, abwarten; jemanden antreffen, vorfinden', dolukats 'werfen bis wohin', refl. 'reichen bis'. Ähnliche Bedeutungsverhältnisse liegen in der von Berneker s. v. godz behandelten Sippe vor, vgl. čech. hoditi 'werfen' = russ. godito dial. 'zielen', ugoditz 'treffen' (oben s. v. defendo); speziell an szlučiti se 'geschehen' erinnert bulg. pogodi se 'trifft sich, ereignet sich' zu pogodjá 'treffe ins 'Ziel'. Zur Bedeutung 'erreichen, erlangen' vgl. auch nhd. erzielen zu zielen. Entfernter Zusammenhang ron gemslav. lučiti 'zielen' mit lat. pollüceo ist möglich, wenn wir beide an die von Walde s. v. lüceo behandelte Sippe 'des Leuchtens, Sehens' anknüpfen wollen. Die Vorstufe von 'zielen' war wohl 'die Augen auf ein bestimmtes Ziel hinrichten', vgl. lett. nì-lūks 'Absicht, Ziel' zu lūkit 'schauen' und mit der Bedeutung 'hinschauen auf ein zeitliches Ziel' lit. láukti 'erwarten', dessen Kompositum su-láukti 'durch Warten erreichen' semasiologische Verwandtschaft mit abg. szlučiti se, russ. ulučitb usw. hat. Wir haben für das Slavische von der iterativischen Verwendung des uridg. *louqério auszugehen, die auch in preuß. laukit 'suchen', ai. locáyati lokáyati 'betrachtet' vorgelegen hat (das Wort konnte auch kausativisch verwendet werden, s. bei Walde s. v. lüceo). Verschieden von luciti 'zjelen', wenn auch wahrscheinlich wurzelverwandt, ist russ. lucittasja 'Strahlen werfen, strablen', das eine Ableitung von luč̀ 'Srahl' ist; dagegen lučito rýbu 
'Fische beim Kienspanfeuer, bei der Kienfackel fangen' scheint auf einer Bedeutungsassoziation von lučtto in der aus 'zielen, treffen, schießen' abstrahierten Bedeutung 'ein Tier erjagen, fangen' an lučz 'Kienfackel zum Fischen, Bündel Kienspäne' zu beruhen. - [Vgl. jetzt auch Berneker s. v. luča und lučo. K.-N.] - Lies lócíti (sloven) statt lôciti.

porrīgo in den Nach trägen. - Ein bulgar. przšav 'krätzig' scheint nicht zu existieren. Es beruht wohl auf Verwechslung mit poršiv 'Schuppen im Haare habend' (= poln. parszywy 'grindig, räudig, krätzig'). Ein ksl. praskati 'kratzen' ist mir unbekannt.

quando. - Wenn lat. $d \delta$ in quandó, dōnicum ein zu einer Post- resp. Präposition erstarrter Kasus des Pronominalstammes *do- ist, dann ist Waldes Bemerkung, daß russ. kudá 'wohin' (nicht auch 'wo') dieselben Elemente enthalte wie lat. quand $\delta$ in bezug auf das zweite Kompositionsglied nur insofern richtig, als ebenfalls ein Kasus desselben Pronomens (oder des Pronomens *dho-, vgl. das ron Walde wegen ahd. wanta bemerkte), eventuell sogar derselbe Kasus vorliegt; keinenfalls aber kann dieses russ. $-d a$ eine in präpositionalem Sinne erstarrte Form sein, ebensowenig wie das bei den $-d \ddot{e},-d u,-d \bar{z},-d y$ in abg. kaqdu, kqqdè 'woher', poln. do-kaqd 'wohin', od-kąd 'woher', kędy 'wo, wohin' (Berneker s. v. kato 7.) der Fall ist. Vielmehr spricht die Mannigfaltigkeit der Endungen dafür, daß man ihren flexivischen Charakter mindestens ebenso lange und ebenso stark gefühlt hat, wie denjenigen von $k q$-; doch könnte natürlich ein Teil der Endungen auch auf Nachahmung anderer Ortsadrerbien (vgl. etwa doma 'zu Hause', gorě 'oben') beruhen. Eine Postoder Präposition *da ist im Slavischen überhaupt nicht vorhanden und darf aus der Partikel (Konjunktion) $d a$ 'so, und, aber, daß" (Berneker s. v.) nicht gefolgert werden. Leider sind die slavischen Adverbia kqdĕ, kqadu und ihre Entsprechungen von den anderen Pronomina (tadé 'von dort', sqdu 'von hier, hierher', inqqdé 'anderswoher' usw., vgl. auch $-d b$ in ksl. otonqdo, otinquds ' $g a n z$ und gar' bei Berneker s. v. inz) nicht wörtlich übersetzbar (Beispiele bei Doritsch Jhber. des Inst. für rumän. Spr. zu Leipzig 16, $91 \mathrm{ff}$.), und die Art der Komposition ist psychologisch unklar. Vielleicht sind es überbaupt nicht Zusammensetzungen zweier Kasus, sondern Kasus von komponierten Stämmen *kqdo-, *tqdo-, *sqdo- usw. Gesetzt den Fall, die Elemente $-d \check{e},-d a$ usw. seien schon vor ihrer Verbindung 
mit ka- usw. erstarrt, so könnten sie nur selbständige Ortsresp. Richtungsadverbien mit wechselnder Bedeutung (etwa ${ }^{*} d a$ "von dort', *dě 'dort', *dz 'dorthin') gewesen sein, die sich nachher vermischt haben. Die Verbindungen mit den Akk. F. tạ, $s q, k q$ könnte man dann vielleicht übersetzen mit 'dort, ron dort usw. (mit verblaßter Deixis) in bezug auf jenen, diesen, welchen Ort'.

que. - Zuzufügen ist noch bulg. $\check{e}$ 'aber, und, daß, weil' und nach Berneker s. v. $a$ 8. auch die Anhängepartikel $-\check{c e}$ in cech. alt. $a \check{c}$, $a \check{c}$ 'wenn', poln. acz 'obgleich, obwohl', vielleicht auch das $-\check{c} e$ in russ. dial. nýnž̌e 'jetzt', nsorb. ven-ce 'draußen', das aber Berneker s. v. $-\check{c e}$ und $-k a$ mit griech. $-k \alpha,-k \alpha,-\kappa \epsilon(v)$ verbindet.

racco. - Abg. rekq rešti 'sagen' wird von Uhlenbeck Et. Wb. ai. Spr. s. v. und auch von anderen Forschern mit ai. racáyati 'ordnet, verfertigt. bildet, bereitet, macht zurecht', got. rahnjan 'rechnen', garēhns 'Stimmung, Ratschluß' verbunden. Für die Richtigkeit dieser Etymologie spricht namentlich das Substantiv abg. rokb, sb-rokb 'Termin, Frist', russ. rokb 'Termin, Schicksal', das wegen pro-reka 'prophezeie', pro-rokz 'Prophet',

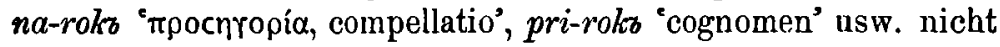
von reka zu trennen ist. Eine gute Bedeutungsparallele ist ‘ech. práviti 'sagen' neben bulg. prátja 'mache', abg. praviti 'richtig machen, lenken'. Die bei Waldes Verbindung mit lit. rẽkti (so betont!) 'schreien' usw, nötige Grundbedeutung 'schreien, brüllen' würde nur für wenige Worte der Sippe (etwa abg. po-roko 'Verweis' als 'Beschreiung') passen; eine Beziehung zu Tierstimmen liegt aber weder im Verbum, noch in irgend einem der Nomina vor. Im allgemeinen lassen sich nur solche Verba des Redens auf Lautnachahmungen zurückführen, deren Schwerpunkt in der Tätigkeit der Mundwerkzeuge liegt, d. h. die Worte des Sprechens, Schwatzens, Plapperns, nicht aber diejenigen, bei denen es auch auf den Inbalt des Gesprochenen ankommt, d. h. die Worte des Sagens, Mitteilens, Erzählens, die vielmehr auf eine konkrete Tätigkeit oder auf die Vorstellung des 'Zeigens, Richtunggebens' zurückgehen. Vom slavischen Standpunkt aus ist erstere Gattung in ihrer Grundlage imperfeltiv, letztere aber in ihrer Grundlage perfektiv; doch sind natürlich zu den Imperfektivverben Perfektiva und umgekehrt zugebildet worden. Vgl. einerseits 
abg. glagolati ipf. 'sprechen, reden', russ. gologólito 'plappern, scherzen'; russ. govoritb ipf. 'sprechen', abg. govoriti 'lärmen';

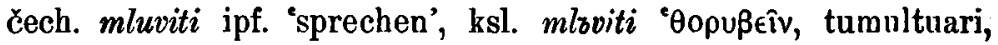
turbare'; anderseits serb. kâžêm kázati pf. 'sagen', abg. kazati 'zeigen, mahnen', poln. kazać 'befehlen, predigen'; abg. povédéti pf. 'berichten, erzählen, verkünden', poln. powiedziec pf. 'sagen', abg. vèdèti 'wissen'. Aus anderen Sprachzweigen sind neben Fällen wie lat. loquor 'spreche' zu griech. $\lambda \eta \eta$ kéw 'töne, schreie, spreche' und ahd. sprehhan 'sprechen' zu aisl. spraka 'prasseln"

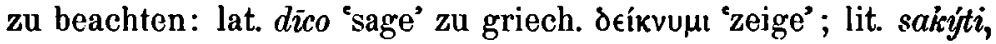
ahd. sagèn 'sagen', ksl. sočiti 'anzeigen', altes Kausativ zu got. saikan 'sehen'; nhd. berichten zu richten. Nun ist abg. rešti, das im allgemeinen durch serb. kázati, poln. powiedzieć, lat. dico, nhd. sagen zu übersetzen ist, das typische Perfektivrerbum gegenüber dem imperfektiven glagolati, dessen Bedeutungsentsprechungen serb. govòriti, poln. mówié, lat. loquor, uhd. sprechen sind, und in den meisten modernen slavischen Sprachen kommt rešti in der Hauptsache nur in der feierlichen Rede vor; es ist also von einer Bedeutung 'unartikulierte Laute ausstoBen, schreien, schwatzen' sehr weit entfernt. Übrigens spricht auch der slavische Ablaut in reka | rokı für die $e$-Reihe, während lit. $r \tilde{E} k t i$, ahd. ruohhōn 'brüllen', lat. racco (-a- aus -ə) eher auf eine langrokalische Wurzel weisen.

rapio. - Das hier angeführte litauische Verbum, über dessen Infinitiv Walde sich nicht im Klaren ist, lautet auf Grund von Szyrwid und Juškeviě aprèpiu aprèpti (betont -ébei Juškevič, doch kann damit auch $-\tilde{e}$ - gemeint sein, s. oben füligo; Szyrwid, der zwischen $-e$ - und $-\dot{e}$ - nicht unterscheidet (s. oben fodio und $l \bar{\imath} b o$ Fn.), schreibt überall $-e$-); Formen, die auf einen Infinitivstamm repe- weisen, sind mir nicht bekannt. Vielleicht kam die Länge ursprünglich nur dem Infinitiv za; vgl. dvesiu dvesti 'atmen'. Die aus Szyrwid zu berücksichtigenden Formen sind folgende : ne aprepiami Part. Präs. Pass. Nom. Plur. 'unbegreiflich' in Punktay Sakimu S. 43, Z. 8 f.; nopreptinay adv. 'indefinite, infinite' Dict. $179 \mathrm{~b}$. Ferner steht auch in der 4. Aufl. des Dict. s. v. ogarnąc das Präsens aprepiu 'umfasse', wofür dio 5. Aufl. 220 a aptepiu bietet; das am letztgenannten Orte stehende Nomen act. aptepimas 'Umfassung' steht in der 4. Aufl. (mir sind diese beiden Stellen aus der 4. Auflage nur durch Leskien Hs. Wb. bekannt) s. v. ogarnienie als apropimas, was 
wahrscheinlich ein Druckfehler ist ; vgl. indessen auch das vielleicht im Ablaut zu aprepti stehende literarische Verbum rópiu rópti 'mit einer Arbeit fertig werden', das ebenfalls vorzugsweise mit dem Präfix ap- gebraucht wird; beachtenswert ist die große Ähnlichkeit zwischen KLD's Beispiel vếns taĩ ne aprópia 'einer wird damit nicht fertig, kann es nicht bestreiten' mit dem Beispiel bei Juškevič: darbú (lies -bũ) aprépti ne gall 'du kannst die Arbeit nicht bewältigen', d. h. 'nicht in allen ibren Teilen umfassen'. Auch nhd. umfassen und französ. embrasser 'umarmen, umfassen' kommen in ähnlichen Wendungen vor; vgl. in beiden Sprachen den Satz : ein Geist, der fähig ist, alle Arten von Wissenschaften zu umfassen; un esprit capable d'embrasser toutes sortes de sciences. Ein *lepiu oder *lepiu 'fasse' scheint außer bei Szyrwid nicht belegt zu sein. Zu vermuten ist, daß die nur der letzten Auflage des Dict. angehörenden Formen aptepiu, aptepimas Schreib- oder Druckfehler sind oder auf einer Volksetymologie des Bearbeiters, der -rèpti nicht kannte, beruhen, wobei an lepùs 'weichlich, verzärtelt', lêpinti 'verzärteln' gedacht werden könnte.

rāpum. - Ksl. rěpzjz rěpïjz (nicht rěpij) ist eigentlich ein Pflanzenausdruck. Bei Sreznevskij Mat. wird das Wort durch die modern russischen Worte 1. repéjnik 'Odermennig, Klette', 2. šipr 'Stachel, Dorn, Zapfen' wiedergegeben; und bei Miklosich

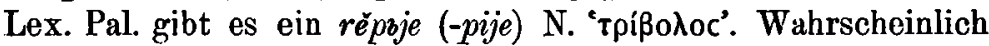
sind die Worte Ableitungen von rèpa 'Rübe'. Daß ein und derselbe Ausdruck für verschiedene ähnlich aussehende Pflanzen verwandt und auch auf formähnliche andere Gegenstände übertragen wird, ist ja eine ganz bekannte Erscheinung.

ravus. - Neben abg. rjevq, reva (re- wohl nur graphische Vernachlässigung der Palatalität; daher ist diese Form nachzustellen, wenn - sie überhaupt angeführt wird) 'brülle' kommt auch rovq vor; Infinitiv rjuti und ruti; ein Präsens rjuva (vielleicht Fehler für rjują, wie es bei Walde in Glossar steht; diese jüngere Form braucht nicht erwähnt zu werden) scheint es nicht zu geben; vgl. wegen des Verbums Leskien Hdb. ${ }^{5} 124$. - Das lettische Verbum für 'brüllen' lautet '́rükt (Präsens ŕüzu), nicht rukt; das ron Bielenstein Lett. Spr. I, 364 angeführte rïkt neben $\dot{r} u \bar{k} t$ beruht auf dialektischem Lautwandel, spielt also für die Sprachrergleichung keine Rolle. - Übrigens liegt in lett. raunas (Gen. Sing. F.) laiks 'Brunstzeit (der Katzen)' ein 
sicher urverwandtes Wort ohne Gutturalerweiterung vor, das als solches angeführt werden könnte. Dieselbe Bedeutungsentwicklung findet sich auch bei čech. řrije (alt), řije F. "Geschrei des Hirsches, Brunstzeit des Hirsches und Rehes', poln. ruja 'Brunstzeit, Rudel', klruss. rúja 'Brunstzeit'; ob lit. rujōs méni 'Brunstmonat, Herbstzeit, September', rũjaus ménù 'Erntemonat, August', lett. rüjas laiks 'Hegezeit des Wildes' (vgl. Leskien Abl. 306, Nom. 319) echt baltisch oder aus dem Slavischen entlehnt sind, läßt sich kaum entscheiden.

rēno. - Kašub.-masur. reno gegenüber abg.-gemslav. runo 'vellus' beruht wohl auf jüngerer dialektischer Lautentwicklung. Jedenfalls wird im Kašubischen (das Masurische ist mir in dieser Beziehung unbekannt) $-u-z u-e-$, allerdings nur in ursprünglich betonter Silbe (poln.-kašub. Kurzstufe). Da russ. runó, serb. rino auf Endbetonung (poln.-kašub. Langstufe) weisen, müßten wir für dieses Wort beide Betonungsarten annehmen, vgl. auch kašub. runo bei Ramult (Slownik jęz. pomorsk. czyli kaszubskiego, Krakau 1893). In Rozwadowskis von Walde zitierter $\Delta$ bhandlung ist mir sein Vorschlag, lat. rèno für ein slavisches Lehnwort zu halten, absolut unverständlich geblieben; kašub.-masur. reno könnte schon seines harten Anlautes wegen unter keinen Umständen auf urslav. *reno oder *rèno zurückgehen; höchstens könnten wir es auf eine Nebenform *rono (wäre poln. literar. ${ }^{*} r n o$ ) zurückführen, womit aber fürs Lateinische nichts gewonnen wäre, da das - $e$ - auch dann erst auf später Lautentwicklung beruhen würde.

reor. - Ksl. nerodz ist besser durch 'Vernachlässigung', als durch 'Geringschätzung', wiederzugeben, vgl. obersorb. njeroda 'Unordnung, Fahrlässigkeit, Liederlichkeit'. - Lies. ráditi (Präs. râdim, serb.) statt raditi; zuzufügen wäre wegen des rod- noch sloven. rọ́diti (Präs. rộdim) 'sorgen, sich kümmern'.

rīvus. - Lies $i z r o j b$, strojb, narojb, rojb (ksl.) statt izroj usw. rōbigo. - Lies rzžda (abg.) statt ružda.

rōbus, rōbur. - Poln. rdzen' 'Kern, Mark' wird ron Ulaszyn Mater. i prace komisyi językow. akademii umiejętności w Krakowie V, 276 auf eine Form *stržeń mit den Zwischenstufen *zdržen (vielleicht belegt, s. unten), *rdzžen zurückgeführt, mit der er russ. stérženz ds. vergleicht. Die Entwicklung von *stržeń (einsilbig mit konsonantischem $-r$-) $\mathrm{zu}{ }^{*} z d r z ́ e n$ wäre lautlich völlig normal, denn das stimmhafte $-\check{z}$ - bewirkt auch durch das 
-r- hindurch Stimmhaftigkeit der vorausgehenden stimmlosen Konsonanten. ${ }^{1)}$ Schwierig ist es nur, das auf eine Urform *strbženjo weisende *strżeń mit russ. stérženz aus *stbrženjz (wäre altpoln. *ścirż-, modern *ścier $\dot{z}-)$ in Einklang zu bringen; vgl. aber auch russ. stréżenz 'stärkste Strömung des Flusses im Wasser, Stromstrich', preuß. strigeno 'Gehirn'; doch ist die Verwandtschaft von stréžen $ъ$ mit stérženz semasiologisch unsicher (Bedeutungszentrum beider etwa 'Wirbel'?), und auf die Richtigkeit der preußischen Graphik ist in dergleichen Fällen kein starkes Gewicht zu legen. Jedenfalls können die mir ron Ulaszyn auf mein Befragen brieflich mitgeteilten apoln. (16. Jh.) zdrzen (wenn -rz- eine graphisch ungenaue Wiedergabe für -rź- ist,

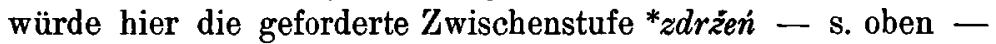
vorliegen) und kašub. drežen nur schwer auf Rozwadowskis Grundform *rzdjenjo zurückgeführt werden, und das - $z$ - erinnert stark an das russische $-\dot{z}$ - (für *rzdjenjz würde man kašub. eher *drezen erwarten, vgl. $d r \ell_{z} a^{*}$ Rost' $=$ poln. $\left.r d z a\right)$. Außerdem stände *rzdenjz formal ganz isoliert, während *strıženjz wenigstens an im Slavischen vorhandenes anknüpft. Die Frage bedarf noch genauerer Untersuchung; insbesondere müßten die apoln. und die kašub.Form erklärt werden, bevor wir zu einem positiven Resultat kommen. rubus. - Lett. rübs 'Kerbe, Falz' läßt sich auf eine Grundform * rumbas nicht zurückfübren, sondern, wenn es nicht altes $-\hat{u}$ - hat, nur auf *rambas, kann also zu lit. rum̃bas 'Narbe am Baum oder an einer Wunde, Saum an einem groben Rock' nur im Ablautsverhältnis stehen; vgl. auch Leskien Nom. 174, 189. Auf eine Wurzel der $u$-Reihe läßt sich das lettische Wort also nicht beziehen, das litauische nur durch Trennung von lett. ribs, was unnatürlich wäre.

rudis. - Lies rògoz (serb.) statt rogoz.

rugio. - Unter den Worten mit ${ }^{*} r \bar{u} k$ - wäre noch lett. rákt 'brüllen' ( $\dot{r}$ - statt $r$ - analogisch nach einer Bildung wie abg. rjeva rjuti) zu nennen; vgl. oben s. v. ravus. - Lit. rügóju rügóti 'jemandem etwas übel nehmen' dürfte identisch sein mit dem in iszrügoti 'ausschelten, tadeln, Vorwürfe machen' (Juškeviě; Nesselmann 449a wohl aus Szyrwid Dict., wo die Verbältnisse nicht ganz klar sind, s. unten) steckenden -rügóti, das aus russ.

1) Über derartige Assimilationserscheinungen im Polnischen, die vielfach von den uns sonst bekannten Assimilationen abweichen, orientiert Ulaszyn a. a. 0 . sehr eingehend und überzeugend. 
rugátb 'schimpfen, schmähen', refl. 'verhöhnen, verspotten' = abg. ragati se 'spotten' entlehnt ist. Das 'Übelnehmen' und das 'Spotten, Tadeln' sind begleitet von einem Gefühl des 'Unzufriedenseins', das in beiden Fällen durch 'Murren' oder durch ein entsprechendes Mienenspiel seinen Ausdruck finden kann. Die Bedeutungen sind nur scheinbar weit auseinandergehend, und jedenfalls hat Kurschat nicht den vollen Bedeutungsumfang bei seiner Verdeutschung des Wortes in seinem Lit.-Dtsch. Wtb. angegeben; bei Nesselmann 449 a wird das Simplex rugóti (da er das Wort offeubar nicht aus mündlicher Rede kannte, ist die Nichtbezeichnung der Länge bedeutungslos; außerdem könnte das Lehnwort auch mundartlich verschieden ausgesprochen werden) durch 'grollen, murren, nicht zufrieden sein, weil man nicht genug bekommen hat' wiedergegeben, und die letztgenannte Bedeutung durch das Beispiel svêcziai rugoja 'die Gäste sind unzufrieden, weil nicht genug da war', illustriert; im Russischen könnte man sehr wohl in derartigen Fällen das Verbum rugátbsja anwenden. Die Bedeutung 'murren', die Walde Ficks Verbindung von rügóti mit lat. rugìre 'brüllen' plausibel gemacht zu haben scheint, ist in der Sippe von abg. ragz 'Schimpf, Hohn', ragati sę 'spotten' auch sonst vorhanden, vgl. serb. rêgnèm régnuti 'knurren' (Walde s. v. ringor). - Merkwürdig berührt die Bedeutungsverwandtschaft von rūgóti mit surúgèlis, rūgsznŷs 'sauertöpfischer, mürrischer Mensch', die zu rúgstu rúgti 'sauer werden, gären' gehören (Leskien Abl. 307); doch können wir hierin kaum mehr als eine Assoziationsverschiebung sehen.

Bei Szyrwids Belegen für iszrūgóti 'Vorwürfe machen' ist der Lautwert der Wurzelsilbe nicht ganz klar. In vier von fünf Fällen, wo das Wort vorkommt, haben wir graphisches -u-, nämlich: 384 a izrugoimas ing akis s. v. uraganie sie 'insultatio, opprobrium, exprobratio'; 415b ißruguoiu (sic! lies -íju) s. v. wymawiam komu 'exprobro'; 418b ißrugoiu und ißrugaimas (sic!) s. v. wyrzucam na oczy 'exprobro, impropero' und wyrzucanie na oczy 'exprobratio'. Dagegen steht 384 a s. v. urqgam sie, natrzasam się z kogo 'insulto alicui, impropero' in der 5. Aufl. iżrungoiu mit -undurch Auflösung des in der 4. Aufl. 328 a stehenden $-\tilde{u}$-. Da der Zirkumflex in den allerdings nicht gar zu häufigen Fällen, wo er bei Szyrwid vorkommt, das Zeichen für $-n$ - oder $-m$ - ist, werden wir kaum daran zweifeln können, daß Szyrwid resp. der Herausgeber der 4. Auflage beim Schreiben tatsächlich rung- und nicht rüg- 
gesprochen hat, daß also die Auflösung des Zeichens durch den Herausgeber der 5. Auflage richtig ist; in dem auf der selben Seite stehenden iżrugoimas aber werden wir eine nachlässige Schreibung sehen müssen. Scheinbar liegt also eine Entlehnung nicht aus russ. rugátb, sondern aus dem gleichbedeutenden poln. ragać, vor; literarisch würde ein solches Wort *rangoju rangoti lauten. Es ist aber zu beachten, daß an den betreffenden Stellen auf S. 384a die polnischen Stichworte uragam sie, urqganie sie lauten. Es wäre also möglich, daß im Szyrwidschen Dialekte an sich nur ${ }^{*}$ rigoti oder ${ }^{*}$ rugoti gesprochen wurde, und der Verfasser resp. Herausgeber nur an diesen Stellen durch Einfluß der Stichworte das Wort polonisiert hat. Jedenfalls fällt es schwer, die dreimalige Schreibung rug- auf S. $415 \mathrm{~b}$ und $418 \mathrm{~b}$ bloß auf Vernachlässigung des Zirkumflexes zurückzuführen; denn iszrügóti ist ja nach Ausweis von Juškevič ein in Russisch-Litauen gebräuchliches Wort, das Szyrwid sehr wohl gekannt haben kann.

ruo. - Wegen kašub.-masur. reno s. o. s. v. rēno.

Sabīni. - Da im Altserbischen $z$ und $z$ lautlich zusammengefallen sind, und man in der Regel für beides $b$ schreibt, ist statt sebro (zwei Mal) sebrb zu schreiben, s. oben S. 186, vgl. auch unten traho.

saccus. - Lies sakulo (ksl.) statt sakulj.

saeta. - Ein dem lett. sënu sët entsprechendes Verbum ist auch im Litauischen vorhanden. Den Infinitiv séti führt Juškevič s. v. atsaininkas an. Vgl. ferner aus D. B. S. folgende Formen: pasijti $(i j=\ddot{e})$ 'binden' 209. 23, prisijti 'anbinden' 20.7, pasijtas 'gebunden' 39.12, pasijiusi, pasijjusi Part. Prät. Akt. Nom. Sing. F. 101. 14 u. 28. Vielleicht gehört hierher auch das Präsens prifienu bei Szyrwid Dict. $14 \mathrm{~b}$, das s. v. bite 'merces pro vapulando' ohne Bedeutungsangabe hinter dem Substantiv prifietis, Plur. prifeciey (-e- Fehler für -ie-) steht, augenscheinlich, um dio Etymologie des Nomens anzugeben.

sānus, satis. - Abg. syto ist nur Substantiv in der Bedeutung 'Sättigung, Sattheit'; das Adjektiv 'satt' lautet nur sytb.

scalpo. - Serb. prökola (so betont!) "Teil eines gespaltenen Ganzen' gehört zunächst zu abg. koljạ klati 'stechen, schlachten', das in einzelnen slavischen Sprachen auch 'spalten' bedeuten kann, vgl. Berneker s. v. kol'o, wo die semasiologische Seite der Sippe anschaulich dargestellt ist; zu beachten ist insbesondere auch abg. raskolz 'Spaltung, dıxovoía'. Waldes sonstigen 
Auffassungen von abg. kolja (s. v. clädës) gemäß müßte auch serb. prökola von lit. skeliu skelti 'spalten' usw. fern bleiben; über eine Möglichkeit, die beiden Sippen miteinander zu vereinigen, s. oben s. v. clā dēs.

scandula. - Lett. schk'edèns 'kleines, abgespaltenes Holzstück' ist besser mit $-\bar{e}-$ im Suffix zu schreiben, s. das oben s. v. augur Gesagte. Lett. schk'édu schk'ëdèt 1) intrs. "in Teile zergehen', 2) trs. 'zerstreuen, vergeuden' ist ein Deverbativ zu schk'é chu schk'ést 'scheiden, trennen, zerstreuen, vergeuden' = lit. skédžiu skésti 'verdünnen, scheiden, trennen' und gehört somit zu der von Walde s. v. scindo behandelten Wurzel *sqeid- und nicht, wie man aus unserer Stelle schließen könnte, zu dem nasalierten ${ }^{*}$ sqend-.

scateo. - Lit. su-skate 'hüpfte auf' ist mir unbekannt; Waldes Quellen (Vaniček 307f. und Fick $I^{4}, 565$ ) enthalten diese Form nicht.

scrobis. - Russ. skrobatto 'schaben, kratzen, scharren' ist eine bloß dialektische Nebenform zum gewöhnlichen skrebátb, das also besser, als jenes, anzuführen ist.

seco. - Zum Vokalismus von lat. sīca 'Dolch', lit. sĩkis M. 'Hieb, Mal' scheint zu stimmen klruss. syč M. 'der nach dem Abbrechen des Astes hinterbleibende Teil des Stammes'. - Wenn man die Pedersensche Zusammenstellung von abg. soch a 'Knüppel', poln. socha 'Pflugschar' mit lit. szakì, ai. šăkhā 'Ast, Zweig' wenigstens im etymologischen Teile retten will, dann kann man

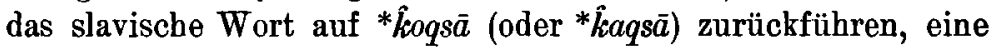
Grundform, die vielleicht nicht schlechter ist, als das bei Walde angeführte *sogsa oder *saqsā.

septem. - Statt sedmyjz stände besser sedmz (abg. 'septimus') im Anschlusse an das, was oben s. v. novem gesagt ist.

sequor. - Lit. sekì sèkti, lett. seku sekt (Präs. auch sủku aus *sanku) 'folgen' bedeuten auch 'sp üren, wittern'. Im Lettischen wird diese Bedeutung überall angeführt; fürs Litauische vgl. bei Juškevič at-sèkti 'aufspüren' im eigentlichen ('nach den Spuren finden') und im übertragenen Sinne, atsisenkì atsisekti 'finden' bei KDL und aus Szyrwid Dict. 174b neprilekamas, nefufekamas = nepamatomas, nepaiauciamas (so IV, 134 b; V fehlerhaft -cimas) s. v. nieczuty, co go nieczué "insensibilis, insensilis, qui nullo sensu percipi potest', und aus Punktay Sakimu 43, 9 und 87, 27 nenufekami Nom. Plur. 'unerforschlich'; dazu auch 
lit. péd-sakas 'Aufspürung der Fährte, Fährte', lett. sakstit iter. 'suchen, spüren nach etwas'. Wir können eine sekundäre Bedeutungsentwicklung im Baltischen selbst anuehmen, da wir in anderen Sprachzweigen keine Hindeutung darauf finden, daß die Bedeutung 'folgen' unursprünglich sei; indessen sei mit Rücksicht auf got. saikvan 'sehen', das ja gleichfalls ein Verbum sentiendi ist, darauf hingewiesen, daß die Sippen von sequor und von inquam, inseque (s. Walde s. v. inquam) eines Ursprungs sein könnten; aus der Grundbedeutung 'spüren, wittern' könnte sich einerseits 'folgen, verfolgen', anderseits 'wahrnehmen, sehen, zeigen, sagen' entwickelt haben. Neben ksl. sociti 'indicare', soks 'accusator' (d. h. 'criminis indicator'), bulg. sóča 'zeige', poln. soczyć 'verleumden, anschwärzen', osoka 'Anklage, Verleumdung', čech. alt sok 'Ankläger' und dgl., die gar zu gut zu got. saíhan 'sehen', lit. seku 'sage', priseku 'zeige, beweise' (oben s.v. inquam) stimmen, als daß sie davon getrennt werden können (anders Miklosich Vgl. Gram. 2, 24 und Meillet Études 226), gibt es auch russ. sočtto 'suchen, spüren, verfolgen', sačitb 'die Spur eines Wildes verfolgen', sakmá 'Spur, Fährte', osóka 'Treibjagd, Umstellen eines Wildes', osočtt alt und dial. 'das Lager eines wilden Tieres aufsuchen und einkreisen, umstellen', poln. soczyć 'worauf Jagd machen', osoczyc' 'das Wild einkreisen, zusammentreiben' (auch 'anklagen, verleumden'), saczyć, osaczyć ds., przysoczyć 'ertappen, erhaschen', serb. sök 'Ausfinder'. Interessant sind auch čech. sočiti 1) 'gegen etwas eifern, anfeinden, ver-

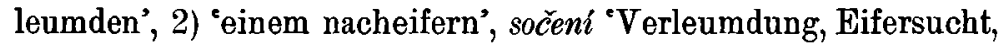
Eifer. Die Bedeutungen decken sich teilweise mit denen von balt. sek-, sak- 'folgen', rgl. insbesondere den Parallelismus von lit.priseku 'zeige, beweise', ksl. sociti 'indicare' und lett. seltt 'folgen, spüren, wittern', russ. sočitb 'suchen, spüren, verfolgen'; zur Ablautstufe in russ. sakmá usw. vgl. lit. péd-sokas = péd-sakas. Wir kommen indessen mit einer sekundären Bedeutungsentwicklung innerhalb des Slavischen von 'zeigen, anzeigen' zu 'verleumden, verfolgen' aus.

simila. - Im Slavischen gibt es zwar keine genaue Entsprechung von lit. sijöju sijoti (so mit Akzent) 'sieben', indessen bedeutet abg. sẽją séjati außer 'säen' auch 'sieben', eine Tatsache, die von den Grammatikern und Etymologen meistens ignoriert wird. Dasselbe gilt von dem Worte auch in den übrigen slavischen Sprachen, z. B. russ. sějatz, serb. sijati (-ijj- lautlich aus -ëjj-) 
'säen, sieben', poln. siać (lautlich aus *sĕjati, Präs. sieje) 'säen', odsiać, podsiać, przesiać 'durchsieben', wysiewać sitem 'aussieben, durchsieben'. Da in den übrigen indogermanischen Sprachen das entsprechende Verbum für 'säen' (s. Walde s. v. sero) nicht auch 'sieben' bedeutet, ist es wahrscheinlich, daß im Slavischen zwei ursprünglich verschiedene Verba zusammengeflossen sind, die allerdings, da die Bedeutungen sich nahe berühren, wurzelverwandt gewesen sein können. Solche Zusammenfälle pflegen bekanntlich dann stattzufinden, wenn eine oder mehrere Formen zufällig gleich sind, sodaß sie die anderen Formen nach sich ziehen. Wenn wir uns im vorliegenden Falle an die vorhandenen Tatsachen halten, dann müssen wir zunächst konstatieren, daß wir für eine aus der Ursprache orerbte Formgleichheit keine Grundlage haben: die Existenz eines ursprachlichen *sēio 'siebe' würde ebenso in der Luft schweben, wie diejenige eines Stammes *siiā- 'säen'. Wir können uns indessen vorstellen, daß im Urslavischen zu einem dem lit. sijóti entsprechenden Infinitiv *szjati 'sieben' nach dem Muster von lëją lıjati 'gießen', směja se smbjati se 'lachen', zěją zzjati 'gähnen' das Präsens sěją gebildet wurde, das mit sĕją 'säe' lautlich zusammenfiel und in der Folge die Verdrängung des Infinitivs *sbjati durch sëjati veranlaßte.

sodālis. - Lit. svõtas 'Hochzeitsgast, weitläufiger Verwandter' ist ein slavisches Lehnwort.

spargo. - Lett. sprauslät (auch sprauslìt, sprauschlēt) hat anlautendes $s p$-, nicht $p$ - allein, und bedeutet außer 'spritzen' noch 'prusten (wie ein Pferd); Klystier ansetzen'. Die Bedeutung 'prusten' erinnert an lett. prüschlèt 'schnauben (von Pferden), pusten' und legt es nahe, Zusammenhang mit der von Walde s. v. pruina (vgl. auch IF. 28, 148ff.) angeführten schallnachahmenden Sippe von abg. prychanzje 'das Schnauben', russ. prýskats 'spritzen' usw. anzunehmen, zu der aus dem Litauischen auch prausiù praũsti 'waschen', prusnà 'Maul. dicke Lippen (des Rindes)' gehört; allerdings befremdet bei dieser Sippe der Anlaut spr-.-D Die Bedeutungsverwandtschaft von sprauslät mitnhd.spritzen dürfte eine ebenso zufällige sein, wie diejenige des letztgenannten Wortes mit russ. pryskats; wenigstens liegt in der baltischen mit nhd. sprießen, spritzen verwandten Sippe von lett. spraujus 'dringe empor', lit. sprústi 'aus einer Klemme herausdringen' keine Bedeutungsentwicklung dieser Art vor, die eine Verwandtschaft oder auch bloß Assoziation mit sprauslät, prüschlèt rechtfertigen würde. 
specio. - Es leuchtet mir nicht ein, da $B$ in abg. pasa pasti 'hüten, weiden' zwei Worte verschiedenen Ursprungs zusammengeflossen seien. Daß in der slavischen Sippe gewisse Bedeutungen vorkommen, die a priori auf die Grundbedeutung 'worauf schauen' zurückgehen könnten, läßt sich zwar nicht leugnen; es gibt aber unter den nicht auf das Viehhüten bezüglichen Bedeutungen keine, die nicht mit den aus 'hüten' (die älteste Bedeutung war wohl 'Vieh hüten', s. oben pāsco) sich ergebenden Vorstellungen 'bewachen, beschützen, bewahren' eng verknüpft sind. Da nun ferner das slavische Verbum in der Sippe von lat. specio morphologisch ganz isoliert dastände, dagegen pasa = lat. $p \bar{a} s c o$ eine tadellose Wortgleichung ist, können wir uns mit letztgenannter Zusammenstellung als einziger beguügen. In klruss. pásty očýma 'sich scharf umsehen'(besser 'unverwandt hinsehen') ist die im Begriffe 'wachen' leise angedeutete Beziehung zum 'A ufpassen mit den Augen' verschärft zum Ausdruck gebracht worden (in lat. pasco oculos, nhd. augenweide liegt wohl eher die Vorstellung 'die Augen genießen lassen' vor). Russ. opasátbsja, klruss. opastysja 'sich hüten, sich in Acht nehmen', d. h. "seine Wachsamkeitauf eine nahende Gefahr richten", hat seine genaue Entsprechung in nhd. sich hüten, auf der hut sein; und in russ. zapasátb (so betont; wenn auch in der Umgangssprache nicht in allen Formen häufig, so doch kaum mit Recht als. dialektisch zu bezeichnen) 'vorrätig anschaffen, versorgen, versehen', zapász 'Vorrat' (sehr häufiges Wort) liegt wohl die Vorstellung "die kostbare Habe vor Mißbrauch hüten, schützen" vor.

spīro. - Lies pěchyrb (ksl.) statt pěchyrz. - Ksl. pachı̈ 'odor' ist ein nur aus einem russisch-kirchenslavischen Wörterbuch stammendes Wort, das ev. auf einer bloßen Abstraktion beruhen könnte; statt dessen wären besser russ. zápachz 'Geruch, Duft', páchnutb intr. imps. 'riechen, duften' anzuführen.

sublica. - Wie Petr (BB. 22, 275) sich den Zusammenhang von poln. sudno (ohne Akzent zu schreiben) 'Fahrzeug, Boot', sudzina 'Faß' mit abg. sb-sądz 'Gerät' (russ. soszidz ist auf der zweiten Silbe betont) denkt, ist nicht klar. Eine Teilung der mit sz-sqdz verwandten Worte in solche mit urslav. sudund solche mit urslav. sqd- (so scheint Walde Petr zu interpretieren; eine Tiefstufe zu slav. sud- sieht Petr wohl im russischen Lehnwort lit. sudas 'Gefäß'?) wird sich schwerlich durchführen lassen; poln. sudno ist übrigens wohl aus dem 
Berichtigungen u. Ergänzungen zu Waldes Lat. Etym. Wörterbuch. 261

Russischen entlehnt (Ulaszyn brieflich), und sicher enthält cech. sud ' $\mathrm{Faß}$ ' wegen poln. sąd Gen. sędu ds. altes -q. Waldes aus anderen Gründeu erhobene Bedenken an Petrs Etymologie sind also durchaus zu bestärken.

taedet. - Die hinter lit. tìngiu tingéti, abg. tęžq tęžiti stehende Bedeutungsangabe 'träge, unlustig sein' ist nur für das litauische Wort richtig und ist vielleicht nur durch ein Versehen in Waldes Manuskript an einen falschen Platz geraten. Für ksl. tẹziti gibt Miklosich die Bedeutungen 'trahere, gravare, molestum esse, vexare'. In der Bedeutung 'ziehen' gehört das Verbum zu abg. tegnati 'ziehen' und ist ein formales Denominativ von einem Nomen in der Bedeutung 'Ziehung', vgl. abg. tęźa 'Streit' (das Iterativ tęati 'ziehen' bedeutet refl. 'sich streiten'; te ža könnte allerdings auch ein jüngeres Deverbativ zum Reflexivverbum sein), russ. tjága 'das Ziehen, Schleppen', poln. ciqq $\dot{z}$ F. 'Gespann' (eigentlich 'Spannung'). Und in der Bedeutung 'beschweren, belästigen' gehört tęziti zu abg. tężbkち 'schwer", ksl. tęžz F., poln. ciqża, russ. tjága 'Schwere, Last'. Ursprünglich hat es wohl nur rein konkret 'schwer machen', resp. 'Beschwerde machen' bedeutet, späterhin auch in übertragenem Sinne 'quälen'. Beachtenswert ist bei diesem formal transitiven Tätigkeitsverbum die aus den Beispielen bei Miklosich zu ersehende Konstruktion mit dem Dativ, die an nhd. einem zur Last fallen, lat. molestum esse alicui erinnert. Ob tęžbkz und tegnati mit einander verwandt sind, was Meillet Etudes 255, 399 anzunehmen scheint, möge dahingestellt bleiben. Kaum aber können die Verbalabstrakta *težzo, *tęża, *tega 'Ziehung' und die Adjektivabstrakte *tęż usw. 'Schwere' für ursprünglich identisch gehalten werden, da sie auf psychologisch verschiedenen Derivationsprozessen beruhen, und somit werden wir auch in tezititi zwei verschiedene Worte zu sehen haben. In den Einzelsprachen allerdings haben sich die verschiedenen Nominalbildungen miteinander vermischt. Wenn auch die Etymologie der verschiedenen slavischen Wurzeln teg- wegen dieser Vermischungen viele Schwierigkeiten bereitet, so ist doch wenigstens das klar, daß sowohl tegnąti als auch tęż̈kz zur e-Reihe gehören; zu ersterem vgl. ksl. sztqga vzstqgz 'lorum', russ. túgij tugoj 'gespannt, straff, steif, fest, stark, hart' (auch 'schwer', s. unten, vielleicht sekundär durch Einfluß von potúgo 'Gewicht' und dgl.) und Walde s. v. tèmo, tendo (vielleicht trotz avest. 
צanj- 'ziehen' ursprünglich *ten-g zu *ten- 'ziehen' und mit sekundärer arischer Aspirata); und zu teg- 'schwer' vgl. abg. taga 'Beschwer, Betrübnis. Angst' und aisl. pungr (Meillet a. a. 0. 327). Also können beide Worte (die semasiologischen Bedenken wären eher zu beseitigen) aus lautlichen Gründen mit griech. cıkxóc 'ekel, wählerisch' nicht verwandt sein. Eher könnte lit. tingùs 'träge' zum griechischen Wort gehören, da wenigstens im Baltischen keine widerstrebende Ablautstufe vorhanden ist. Indessen ist $\mathrm{zu}$ beachten, daß das lit. Wort hauptsächlich 'arbeitsunlustig' und nicht überhaupt 'unlustig' bedeutet; daher ist die von Meillet 327 vertretene Verbindung desselben mit abg. tẹžzkz usw. (vgl. die annähernde Wortgleichung tingùs $=\left(\right.$ das ron Meillet erschlossene) ${ }^{*} t e g b(-k z)=$ russ. dial. tjagó $j$ 'schwer' = aisl. pungr) vorzuziehen; tingìs ist dann etwa als " beschwert, belastet, durch Körpergewicht in der Arbeit behindert, schwerfällig' aufzufassen, vgl. hierzu auch russ. túgij, tugój 'schwer, langsam'.

tālis. - Abg. daleks 'weit, entfernt' hat -e-, nicht -è-.

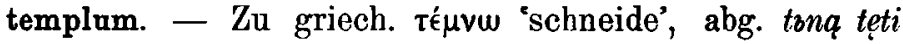
'spalten, hauen' gehört wohl auch lit. tinù tìnti mit dem Objekt dalgi 'die Sense durch Klopfen mittelst eines Hammers schärfen', das jedenfalls weder mit tịstu tinti 'schwellen', noch auch mit lett. tinu tìt 'flechten, winden, wickeln' (über diese Worte s. Walde s. v. tendo) eine Bedeutungsverwandtschaft aufweist.

tempus. - An lit. tenkì tekti 'sich hinerstrecken, hinreichen', got. peihan 'gedeihen, Fortgang baben' erinnert klruss. tjaknuty 'anrühren' (*tek-).

terreo. - Lit. trisau 'zittere' ist besser ohne Akzent zu schreiben.

tesqua. - Abg. tzšto 'leer' hat $-\dot{s}$-, nicht $-s-$.

timeo. - Lit. tếmytis 'sich etwas genau merken, im Gedächtnis behalten' ist entlehnt aus russ. dial. tjámitb 'begreifen, wahrnehmen, im Gedächtnis bewahren' (fehlt bei Walde) resp. klruss. t'amyty (nicht $t^{\prime} a$-) 'merken'; zum Lautlichen vgl. oben membrum und Walde Sabini. Die Vereinigung des slavischen Wortes mit

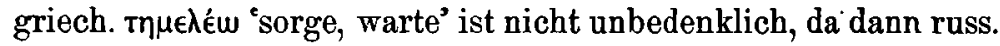
tjam- über *tem- auf eine unbelegte nasalinfigierte Wurzelgestalt zurückgeführt werden müßte, und wir überdies nicht sicher wissen, ob ${ }^{*}$ tenm- resp. ${ }^{*}$ tnm- überhaupt $\mathrm{zu}{ }^{*}$ tem- oder nicht eher zu *tèm- resp. *tom- geführt hätten, vgl. abg. pomènąti 'sich 
Berichtigungen u. Ergänzungen zu Waldes Lat. Etym. Wörterbuch. 263

erinnern' zu pamętz 'Gedächtnis' und tzna 'spalte' zu griech. $\tau$ té $u v \omega$ 'schneide' (eine neuerliche Einfübrung des Nasalvokals wie in pomenati wäre bei tem- ausgeschlossen, da wir keine vorbildlichen Formen mit erhaltenem -ẹ- konstruieren können). Wenn tjámito überhaupt ein aufs Urslavische zurückzuführendes Wort ist, dann wäre am ehesten eine Lautgestalt *tedm-, *tetmresp. *tebm-, *tepm- mit altem Ausfall des vor -m- stehenden Konsonanten anzunehmen, resp. auch *tegm- mit russischem Schwund des $-g$-, vgl. russ. tjanútz = abg. tegnati 'ziehen'. Eine Anknüpfung könnte ich dabei nur für ein *tepmiti finden, nämlich in russ. tjápatb 'fassen, ergreifen, hauen, beißen', wobei tjámitb zunächst in konkretem Sinne 'fassen' (die Bedeutungsentwicklung wie in nhd. begreifen, erfassen, neben greifen, fassen und in italien. capisco 'verstehe' neben lat. capio) bedeutet haben und von einem Substantir *tepmo oder dergl. 'das Fassen' abgeleitet sein müßte. Vielleicht sind aber tjáp- und tjám-junge Lautnachahmungen, beruhend auf Interjektionen des 'Fassens, Greifens' wie gemslav. cap- (Berneker s. v. capajo). Nicht unwahrscheinlich wäre für tjámitz auch fremder Ursprung, doch müßte die Quelle erst gefunden werden.

torpeo. - Lies toropětz (russ.) statt torpětb. Die genaue Bedeutung ist eigentlich nicht 'erschrecken', sondern 'bestürzt werden, aus der Fassung kommen'; häufiger als das Simplex ist das Kompositum otoropětz ds.

traho. - Sloven. trag, tražiti stehen nicht in Pleteršniks Wörterbuch; wenn sie nicht auf einer Verwechslung beruhen, sind sie jedenfalls seltene, veraltete Worte, deren Erwähnung schon deshalb unterbleiben kann, weil serb. trâg, tráżiti (bei Walde unakzentuiert) vollkommen genügen. Im Altserbischen schreibt man tragb statt tragb (s. oben S. 186 und Sabini). Das angeblich sloven. tr'̌ati 'laufen', das bei Pleteršnik nicht zu finden ist, ist durch serb. trěati ds., mit dem es verwechselt sein dürfte, zu ersetzen; auch ein bulg. tzrčá 'laufe' ist vorhanden. Das bei Miklosich Lex. Pal. und Vergl. Gramm. II, 31 fehlende ksl. trokı 'Lauf' bleibt vorsichtshalber besser beiseite. trua. - Abg. tvarb 'opus, Schöpfung' hat -z, nicht -r.

văe. - Lett. wājsch (nicht wajsch) F. wāja 'schwach' gehört nach Leskien Nom. 310 f., 320, 553 zu lit. pa-võjus 'Gefahr', pa-vojas Adj. 'gefahrvoll', vojes Part. 'leidend', votis 'Geschwür', lett. wāts ( $i$-Stamm) 'Wunde'. Daneben nennt er aus der Literatur 
auch Formen ohne $v$ - wie ojus 'Gefahr', paojeis Inst. Plur. Adj. 'gefährlich'. Mit der Interjektion lett. wai 'wehe, ach', haben diese Worte sicher nichts zu tun. [Vgl. vielmehr Idg. Jhb. 1, 60. K.-N.] Von wai abgeleitet ist aber das von Leskien Abl. 378 (fragend) mit wājsch verbundene vvaijät trs. 'wehe tun', das mit wajjāt 'schwächen, kränken' nicht zu verwechseln ist; waijät 'verfolgen, bedrängen' ist gleich lit. vajóti 'nachjagen' (Iter. zu vejù výti ds.) mit analogischem -aij- nach obigem semasiologisch assoziiertem waijāt. - Interessant ist serb. väjni Adj. 'dolorem afferens', das aber kaum mit lett. wäjjsch usw. verwandt, sondern eher von der Interjektion $v \hat{a} j$ ' wehe' abgeleitet ist.

vafer. - Lit. gudrùs (nicht gùdras) 'schlau, klug' dürfte altes - $u$ - haben wegen guvùs, güvìs, dial. gavùs 'gewandt, klug, pfiffig’ (Leskien Nom. 257, Juškevič s. v. guvùs), das seinerseits zu der von Walde s. v. vola behandelten Sippe von lit. gáunu gáuti 'bekommen', gáudyti 'fangen' gestellt wird. Als beste Bedeutungsparallelen vgl. abg. chytro 'geschickt', in den Einzelsprachen auch 'rasch, listig, schlau, klug' zu chytiti 'reißen, greifen, raffen', russ. chvatb 'kühner, gewandter, flinker Mensch', poln. chwatki 'schnell, behend' zu abg. chvatiti 'ergreifen'; vgl. ähnliches auch oben s. v. timeo. Interessant ist auch die bei Leskien Nom. $440 \mathrm{f}$. angeführte Erklärung von gudrùs als kurs viska nor pasëkt ir zinot ir moket ir matyt 'wer alles erreichen, wissen, können und sehen will'. Das dial. gavùs (s. oben) stimmt im Vokalismus zum Präteritum gavañ 'bekam'. Die Bedeutungen 'schlau, pfiffig' erinnern besonders an apgáuti 'übervorteilen, betrügen', vgl. auch gudráuti 'W inkelzüge machen' ('klügeln') bei Juškevič, der gudinti 'klug machen, bilden' unter anderem durch 'anlocken' wiedergibt. Wegen dieser baltischen Sippe und eventueller slavischer Verwandten s. KZ. 44, $156 \mathrm{ff}$. (vgl. klruss. hutýty 'verlocken, verführen' mit lit. gùdinti 'anlocken'). Nur ungern würde ich mndd. gouwe, gauwe 'rasch, schnell, der rasch begreift, klug', air. gāu, gō 'Unrichtiges, Lüge' (wegen dieser s. Walde s. v. bura und haud) beiseite lassen, vgl. aber unten vola.

valeo. - Die Annahme einer Entlehnung aus der Sippe von got. waldan 'walten' wäre höchstens für das eine oder andere baltische oder slavische Wort, nicht aber für die ganze Sippe von abg. vlada vlasti, lit. valdañ valdýti ansprechend, und wir können kaum ohne ein ererbtes $d$ - oder $d h$-Determinativ im 
Baltisch-Slavischen auskommen. Im Slavischen ist der Entlehnung sehr wenig günstig der Infinitiv vlasti, noch weniger aber das Substantiv vlastb F. 'Macht' (lett. walsts F. 'Gebiet, Gemeinde, Staat', lit. valszczius mögen durch das Slavische beeinflußt worden sein), denn in der Regel sind derartige Nomina nicht jünger, als die Infinitive, und sind im Slavischen selbst auch kaum mehr produktiv. Das Litauische seinerseits besitzt neben valdauch die Ablautstufen veld-, vild-, vgl. Leskien Abl. 354. Zu pavilsti 'ererben', pavildeti 'besitzen' nennt mir Professor Leskien (brieflich) Belege bei Daukša Litorskij Katichizis in der Wolterschen Ausgabe S. 13 und 33, und bei Bezzenberger Gesch. der lit. Spr.112. Das Verbum veldeti ist mehrfach belegt. KLD nennt ein biblisches pa-veldéti 'ererben' (dio Betonung vielleicht unsicher) und Juškevič ein àp-veldžiu (žemaitisch àpveldu) ap-veldeti 'Besitz ergreifen, erwerben'. Ferner bietet Szyrwid Dict. apweldžiu $226 \mathrm{~b}$ s. v. opanować co 'occupare, invadere, possidere', 230 b s. v. osiadam co 'occupo, usurpo possessionem, possideo agros', apwetdeimas 226 b s. v. opanowanie 'obsessio, circumsessio', und paweldźiu = tewaynisty apturiu $50 \mathrm{a} \mathrm{s}$. v. dziedzicze "hereditatem capio". Als Präsens nennt Kurschat pavéldu oder pavéldeju, die beide zu Szyrwid und Juškevič nicht stimmen und vielleicht bloße Konstruktionen sind. Ebenso können wir uns für die Stichbaltigkeit der Akzentuation in den Wörterbüchern nicht verbürgen. Wie wir s. v. pinus Fn. gesehen haben, besitzen die baltischen Sprachen die Neigung zur Schaffung einer sekundären e-Stufe, und wir können lit. veld- (preuß. weldanai Plur. neben waldüns 'Erbe' ist vielleicht ein Schreibfehler), da diese Ablautstufe in den übrigen Sprachzweigen fehlt, gut auf diese Weise erklären; doch ist dabei zu beachten, daß das sekundäre $-e$ - sehr alt sein muB, da es auch im Lettischen vorhanden ist und vor dem Wandel von $-e i$ - in $-\ddot{e}$ - eingetreten sein muß. Also wäre die Umbildung eines $-a$ - in $-e$ - bei einem germanischen Kulturwort nicht besonders wahrscheinlich. Lit. vild- dürfte ursprachliches *uld(h)- fortsetzen.

vannus. - Statt serb. vijati (so betont) 'worfeln' ist besser die abg. Entsprechung vějati (serb. -ij- lautgesetzlich aus -ëj-) anzuführen, das zwar in der Linguistik meist nur in der Bedeutung 'wehen' bekannt ist, tatsächlich aber auch 'worfeln' bedeutet. Die Bedeutungsdoppelheit von vëjati ist gemeinslavisch, vgl. ฉ. B. russ. vějato 'wehen, fächeln, schwingen, worfeln', poln. 
wiać (-ia- lautlich aus -ěja-; Präsens wieje) 'wehen, fächeln, Wind machen, wannen, worfeln, schwingen'; auch in serb. vije snijeg 'es schneit' ist die Bedeutung 'wehen' noch erhalten. Daher ist es besser, die Verbalnomina sloven. vévnica (besser $-\dot{e}-$ als -è-; bei Pleteršnik fehlendes Wort), poln. wiejaczka 'Worfschaufel' zu streichen, da diese Nomina keine im Verbum verloren gegangene Bedeutung enthalten und auch formal uninteressant sind. Bei vèjati wäre darauf hinzuweisen, daß es dasselbe Wort ist, wie das s. v. ventus erwähnte; auch wäre es gut, das Präsens vëja anzuführen, da dieses eine alte Präsensbildung ist, während der Infinitiv auf -ati eine urslavische Neubildung sein dürfte.

vārus. - Lett. sa-wāri 'Querstangen bei der Egge' enthält wegen der gleichbedeutenden sawari, sawares, sawires kein $r$-Suffix, sondern wurzelhaftes $-r$-, vgl. auch lit. per -varas 'Langbaum beim Leiterwagen'. Leskien Abl. 356 stellt die Worte $\mathrm{zu}$ lit. veriù ver̃ti 'öffnen und schließen, einfädeln'. Die dort zusammengestellten Worte gehören aber wahrscheinlich zu zwei verschiedenen Sippen 1. 'öffnen und schließen' und 2. 'reihen, knüpfen', die von Walde teils s. v. aperio, teils s. v. urvum behandelt werden. Für unsere Worte wäre Anschluß an beide Sippen möglich, wie sich überhaupt eine reinliche Trennung derselben im Baltischen kaum durchführen ließe.

vas, vadis. - Lies vadüti (lit.) statt vadüti. - Čech. závoditi bedeutet nicht 'wetten' sondern 'wettlaufen, wetteifern', ursprünglich überhaupt 'einen schnellen Lauf veranstalten' und gehört zu abg. vesti, voditi 'führen' als Denominativ von čech. závod 'Rennbahn, Wettlauf' = poln. zawód 'schnelles Laufen, Rennen, Galopp, Wettrennen' (dazu poln. w zawód 'im Galopp', čech. o závod 'um die Wette', d. h. 'im Wettlauf'), im Poln. auch 'das Führen, Hinleiten, Ansatz, Anfang, Unternehmen, Bestreben' usw. bedeutend. - Das angeblich cechische vadlja 'Wette' ist slovenisch und lautet mit Akzent vâdlja; laut brieflicher Mitteilung Professor Leskiens ist es ein germanisches Lehnwort.

ventus. - Wegen abg. věja vějati 'wehen, blasen, worfeln' s. oben s. v. vannus. Es empfiehlt sich die Bedeutung 'worfeln' nicht wegzulassen und auch das Präsens anzuführen, da es eine ältere Bildung ist, als der Infinitiv.

vereor. - Zur Sippe von vereor kann man hinzufügen lett. weru wert, meist reflexiv weriis wertës 'schauen, bemerken', 
wërīgs 'aufmerksam', wërïba 'Aufmerksamkeit' (das $-\bar{e}-$ nach dem Prät. wêru, wèrüs), wèrā nemt 'in Acht nehmen'. Letzteres ist zwar dem nhd. wahr nehmen nachgebildet, doch erscheint Entlehnung von wert aus dem Deutschen unmöglich. Dagegen kann lett. wairit 'hüten, abwehren' (wairut 'bemerken, beachten' Kontamination aus werrit ds., Iterativ zu wert, und aus wairit) eine Entlehnung aus got. warjan, ahd. werjan 'wehren, schützen' sein, wobei -ai- wohl Wiedergabe des noch nicht völlig zu -egewordenen umgelauteten $-a$ - ist. Bei abg. varovati se 'cavere' ist Entlehnung nicht notwendig; eine genaue Entsprechung könnte griech. ủpev́elv 'curare' sein. Für ein ebenfalls urverwandtes Wort halte ich abg. variti, prědt-variti 'antevertere'; wenigstens kenne ich kein Wort, aus dem dieses entlehnt sein könnte.

vergo. - Bei Erwähnung von Mikkolas Etyınologie für lit. rankà, abg. raka 'Hand', zu der Walde selbst keine Stellung nimmt, wäre es am Platze gewesen, die ältere Verbindung dieses Wortes mit lit. renkù riñkti 'auflesen, sammeln' gleichfalls anzuführen, die doch mindestens ebensogut, ja m. E. ungleich besser ist, als Mikkolas Zusammenstellung mit aisl. $r \bar{a}$, aschwed. vrā 'Ecke', vgl. jetzt darüber die sehr einleuchtende Abhandlung von Ulaszyn in Wörter und Sachen II, $200 \mathrm{ff}$. Statt der Schreibung werst wäre für das lettische Wort die etymologische Schreibung werft am Platze, um eine Verwechslung von wer/chu werfu werft 'wenden, drehen' mit dem gleichbedeutenden werschu wertu werst zu vermeiden. Die Bedeutung 'wenden, drehen' des erstgenannten Wortes, die von der Bedeutung des lit. verżiù veřxźt 'schnüren, einengen, pressen' abweicht, dürfte durch Assoziation an das zweitgenannte Wort (= lit. vercziù veřsti 'wenden, kehren') hervorgerufen worden sein, da beide Verba im Infinitiv und Futurum lautlich zusammenfallen; sie ist auch ins abgeleitete Verbum werfèt 'lenken, wenden' (beruhend auf dem Präteritalstamm *veržé- in lit. veržiaũ ; ähnliches s. oben s. v. mamphur) gedrungen.

vēscor. - Lett. wesels (nicht vesels) 'gesund' dürfte im Gegensatz zu dem entlehnten preuß. wessals 'froh' wegen der Bedeutungsdifferenz eher mit abg. veselz 'froh' urverwandt, als aus dem Slavischen entlehnt sein.

retus. - Statt vetuszas heißt das lit. Wort richtiger vetuszas; die Schreibung mit $-\dot{e}$ - bei KLD[ beruht auf einem Irrtum. 


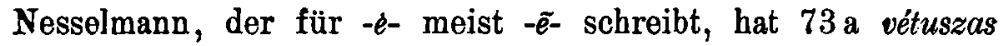
(die Betonung natürlich unsicher) und desgleichen vétuszis 'alter Ochs', dessen $-\ell-$ KLD[ ebenfalls fälschlich durch $-i$ - widergibt. DaB Nesselmann Kurschats Quelle war, ist zu ersehen daraus, daß beide dasselbe Beispiel vétusza (KLD[ - $-\dot{e}$ ) bóba "altes Weib" anführen. Vgl. auch Leskien Nom. 599 über die Schreibung der Worte. Ähnliche Fälle s. oben s. v. fiber und pecu.

viēsco. - Lit. i-gyjù $i$-gýti 'erlangen, gewinnen' ist $\mathrm{m}$. E. ein Kompositum von gyjù gýti 'heil werden, aufleben, sich erholen', das zu lat. vivo 'lebe' usw. gehört, doch ist der bei KLD angenommene Bedeutungseinfluß von seiten von gáunu gáuti 'bekommen' sehr wenig überzeugend. Wenn wir vom früheren Bedeutungszentrum 'ins Leben geraten' des Verbums gýti ausgehen, dann können wir trotz der aktionellen Verschiedenheit erinnern an eine ähnliche Bedeutungsentwicklung in russ. nažitu trs. 'erlangen, erwerben', z. B. nažito sebé dostojánije 'sich ein Vermögen erwerben', nažito mnógo dénego 'viel Geld verdienen' neben žitb intrs. 'leben'; vgl. auch im ähnlichen Sinne das lit. Kompositum sugyvénti zu gyvenù gyvénti in dem dialektischen Satze: ir sugivána ji viénu bernúku 'und sie gebar (brachte zum Leben, erwarb, erzielte, bekam) ein Knäblein' bei Doritsch Beiträge S. 75, Z. 18, der ebenda $\S 334$ russischen Einfluß annimmt. Das als Gegensatz zu nažitı dienende prožito 'vertun, verprassen' kann auch im Deutschen durch verleben übersetzt werden. Überhaupt werden Komposita von Intransitiven, besonders von Inchoativverben nicht selten transitivisch im Sinne von 'erlangen, erwerben' gebraucht, vgl. z. B. russ. do-búdu do-býtb 'erhalten, erlangen, erwerben, gewinnen' zu búdu 'werde', byts 'sein', ursprünglich auch 'werden'; do-státb 'erhalten, erlangen', zu stato 'werden', eigentlich 'sich hinstellen'; nhd. bekommen zu kommen (engl. become 'werden'!); erstehen zu stehen. Vielleicht kann man auch nhd. dial. etwas angeworden sein 'sich an etwas gewöhnt haben' (im Roman von E. von Oertzen 'Sie und ihre Kinder', Berlin, Warneck, 1911, S. 82 f., 88, 149 usw.) im Sinne von 'sich eine Gewohnheit zu eigen gemacht haben' auffassen.

vilis. - Die Zusammenstellung von lit. vỹlius (nicht výlius) 'Betrug, List' mit ags. wìl 'Bedrängnis, Kümmernis, Not, Elend', ist nicht unbedenklich wegen der Unursprünglichkeit der litauischen Länge, denn vỹlius ist ein Nomen act. mit dem Vokalis- 
mus des Präteritums zu viliu vyliau vilti (= lett. wil'u wilu wilt) 'betrügen', das zu der von Leskien Abl. 354 behandelten Sippe gehört, aus der jedoch die Worte in der Bedeutung "hoffen, vertrauen, Hoffnung' zu entfernen sind; vgl. über sie vielmehr Walde s. v. volo, velle. Da die Formen des Verbums in den Wörterbüchern usw. vielfach ungenau oder direkt falsch angegeben werden, muß ich meine Ansätze der finiten Formen rechtfertigen. Das Präsens viliu habe ich entnommen aus Szyrwids apwilu (Dict. 226a s. v. omylam) und priwilu (235a, 446 b s. v. oszukiwam, zdradzam), deren $-l$ - nach dem oben s. v. minus $\mathrm{G}_{\mathrm{A}-}$ sagten nur als $-l^{\prime}$ - gelesen werden kann, sowie aus apviliu apvilti 'anlocken, verführen, betrügen' (hier Verweis auf das Simplex vilti) und iszviliu iszvilti 'herauslocken, entlocken' bei Juškevič (geschrieben -lu, da er die $l$-Laute in Szyrwidscher Weise unterscheidet; aus dem Žemaitischen führt er die auf dialektisches *vilu weisende 3. Sing. iszvit an). Nesselmanns 80 a (nicht 86) von Leskien a. a. O. zitiertes Präsens vilu (Ness. villu; wegen -ll- s. oben caleo, vgl. auch derbiosus) ist seine schon besprochene (oben minus) nachlässige Wiedergabe der Szyrwidschen Form; er schreibt auch vylus für vỹlius, villóti für vilióti "betrügen, locken' usw. Leskiens Präteritum vylau dürfte ebenfalls aus Nesselmann stammen, der die Form so schreibt; die Richtigkeit von vyliau, die schon aus dem Präsens geschlossen werden kann, bestätigt sich durch Leskiens 3. Sing. refl. vylès und durch das iszvýliau (geschrieben išvýlau) bei Juškevič. Die Wurzel scheint als *uel- angesetzt werden zu müssen, vgl. preuß. po-wela 'sie verrieten', lit. veltas 'unnütz, vergeblich' usw. Vielleicht gehören die Worte zu der von Walde s. v. volvo behandelten Wurzel idg. *uel- 'drehen' (vgl. nhd. die worte verdrehen), zu der auch lit. valaĩ 'Schweifhaar des Pferdes', ai. vāla- $h$, vāra-h 'Schweifhaar' gezogen werden können; die Verbindung der leztgenannten Worte mit lat. adūlāre 'anwedeln' (Walde s. v. aduilo) läßt sich dann allerdings aus lautlichen Gründen schwer halten, wenn auch semasiologisch adūläre sehr gut zu lit. vilti passen würde. - An Entlehnung der baltischen Worte aus der Sippe von russ. viljátb "die Richtung ändern, wedeln, Winkelzüge machen', poln. wilić, witować 'verrückte, tolle Streiche machen', wilać 'wedeln', witośé 'Narrheit, Verrücktheit' wird man aus morphologischen Gründen kaum denken können, eher an Urverwandtschaft; doch befremdet dann die Länge des slavischen 
Wurzelvokals, die eher auf Ableitung vermittelst $l$-Suffixes von der Wurzel von abg. viti 'winden' weist, vgl. lit. vélà 'Draht', vëlióti 'wickeln', vylè 'Schwiele', lett. wile 'Saum' (Leskien Abl. 288, Nom. 462).

vireo. - Wegen ksl. żirz 'pascuum', lett. dfīras Plur. 'Gelage' vgl. IF. 24, 241 Fn. 2.

viriae. - Dasselbe $r$-Formans wie in air. far 'schief', ags. wir 'Metalldraht, gewundener Schmuck' usw. findet sich auch in dem sicher zur selben Wurzel gehörigen lit. $i$-vairus 'tortuosus, mannigfaltig, verschiedenartig' (Leskien Nom. 442, Juškevič jvairùs 'außergewöhnlich, sonderbar, verschiedenartig', in der Literatur und in den modernen Dialekten häufiges Wort); wegen der anklingenden lit. vỹrius 'Strudel', atvyrs 'Gegenstrom', ksl. virs 'Strudel' vgl. IF. 24, 241 Fn. 2.

ulva. - Sloven. láva 'tiefe, sumpfige Stelle neben einem Flusse oder in einem eingetrockneten Flußbette' wird von Berneker s. v. láva 2. als Lehnwort aus nhd. dial. kärnt. laue "kleine Lache" aufgefaßt.

umbra. - Das aus Szyrwid stammende lit. unksna 'Schatten' muß ohne Akzent geschrieben werden; das $\grave{u}$ - bei KLD[ beruht auf Willkür.

ūnus. - Wegen des $v$ - in lit. vënas 'unus' hätte Brugmanns Erklärung Demonstrativpronomina 110 zitiert werden müssen, da es sonst dem Leser rätselhaft erscheinen muß. Ich möchte allerdings Brugmanns Ansicht etwas modifizieren, da ich an lit. $\bar{e}$ aus ${ }_{o} i, \tilde{a} i$, , oi nicht glauben kann (s. auch oben s. v. pinus Fu.), und zwar zerlege ich das Wort in *ue- (oder $*_{u}(\bar{e}-)+{ }^{*} i n o-s$ und sehe in dem *ué- eine Ablautstufe zu dem $u$ in lett. winsch, wina 'er, sie', das Brugmann auch in vếnas sehen will, vgl. lat. ve- in vesscor, vē in vécors usw. (s. Walde sub verbis); der Stamm *ino- bedarf, da er in abg. jedbnz 'unus' (ähnlich auch lett. winsch) klar zutage tritt, keiner Erklärung. - Was slav. inb 'unus, alius' (wegen der Formen s. Berneker s. v.) anbetrifft, so zweifle ich wegen der westslavischen Verhältnisse daran, daß man mit dem urslavischen Ansatze ${ }^{*}$ z $z$ für alle Fälle auskommt. Čech. jiný 'alius' scheint mir wegen $j d u$ 'gehe' aus * $b d a$ und wegen $h r a$, alt jhra aus * $z r a$ (noch viele andere ähnliche Beispiele) auf urslav. ${ }^{*}$ inz resp. ${ }^{*}$ jinz hinzuweisen [vgl. Idg. Jhb. 1, 184. K.-N.]; ähnlich ist es auch in den übrigen westslav. Sprachen. Nur im Russ. und Südslav. kann man $i-, j i-, b-, j o-$ 
im absoluten Anlaut überhaupt nicht mehr auseinanderhalten. In unserem Falle liegen nun zwar in solchen adverbiellen Ver-

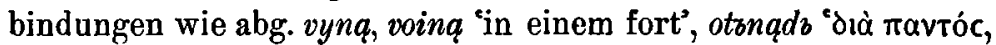

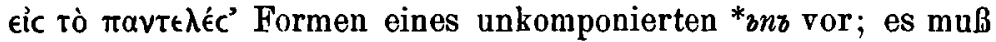
aber m. E. außer dem Kompositum *ed-znz noch irgend ein anderes längeres Wort existiert haben, das das Simplex * ${ }^{*}$ z teils verdrängt hat, teils lautlich mit ihm zusammengefallen ist. Wenn wir annehmen wollen, daß dieses längere Wort zunächst nur 'alius' bedeutet hat, so können wir es als *jinz aus *ioino-s auffassen und dem got. jains 'jener' gleichsetzen. Näher liegt aber doch wohl die Auffassung des Wortes als eines Kompositums von ъnъ. Das erste Kompositionsglied könnte dann, je nachdem man die Form als urslav. ${ }^{*} i n b$ oder $*^{*}{ }_{i n z}$ auffaßt, $e$-, $i e$ - oder $i o-$ gewesen sein. Soweit ich mich aus Bernekers Artikeln s. v. $e, e d e$, edonz, $i$ - (in $i-\dot{z} e$ ), jed(b)va usw. überzeugen kann, scheinen Komposita mit Formen des Pronominalstammes $*_{e-1} *_{0-}$ im Slavischen häufiger zu sein, als solche mit Formen des Stammes *ie- $\left.\right|^{*} i o-$, und so halte ich Zerlegung von inz in ${ }^{*} e+{ }^{*}{ }_{b n z}$ für das Wahrscheinlichste. Wenn ${ }^{*} e$ - die in griech. é-keîvoc 'jener', lat. e-quidem 'allerdings, fürwahr' belegte Partikel oder die bloße Stammform ist, kann man ${ }^{*} e$-bnz als ein Reimwort zu lit. vếnas aus *e-inas auffassen (dasselbe wäre auch bei ${ }^{*} j e-\imath n z$ der Fall). Anderseits wäre es denkbar, in slav. * ${ }^{e-}$ die jüngere Form desselben Nom. Akk. Sing. *ed- zu sehen, der in ${ }^{*} e d-b n z$ in der älteren Lautgestalt vorliegt.

vola. - Zu lit. gáunu gáuti 'erhalten, bekommen' scheinen auch lit. gũvìs 'gewandt, geschickt, klug, pfiffig', gudrùs 'schlau, klug' zu gehören, vgl. oben s. v. vafer. Schwierigkeit bereitet aber mndd. gauwe, gouwe 'rasch, schnell, der rasch begreift, klug', das an sich vortrefflich zu der litauischen Sippe stimmen würde, aber mit griech. érrún 'Bürgschaft', érruów 'einhändige' lautlich nicht zu vereinigen ist; besser passen würde air. gāu, go 'Unrichtiges, Lüge', das Walde aber zu lat. haud 'eben nicht, gerade nicht' (s. v. haud) zu stellen geneigt ist. Auch ein Zusammenhang des germanischen Wortes mit dem keltischen Worte kann nicht ohne weiteres angenommen werden, solange in keinem der beiden Sprachzweige semasiologische $Z$ wischenstufen bekannt sind. - Lies gũwejs (lett.) statt gūwejžs. - Aus dem Slavischen könnte man ksl. ogymati, pogymati 'betasten, streicheln' (von Berneker s. v. gymajo als dunkel bezeichnet; wohl Denominativ 
von einem Abstraktum *gyma 'das Anfassen') zu lit. gáuti usw. stellen; oder ist es ein formales Iterativ zu einem dem lett. gumstu gumt 'überfallen, sich auf einen senken' (Walde s. v. gemo) entsprechenden Verbum?

volo, velle. - Lit. vêlyti 'wünschen, gönnen, anraten’ ist wohl entlehnt aus klruss. vel'ity ds. (Brückner Lit.-Slav. Studien I, 152). - Statt wiliis ist vilius (lit. 'hoffe') zu schreiben, vgl. bei Szyrwid Dict. $162 \mathrm{~b}, 347 \mathrm{~b}, 375$ a wiluo/i $\mathrm{s}$. v. nadziejemam, spodziewamsie, tusze, und in Punktay Sakimu S. 123, Z. 19 die 3. Pers. wila/i mit graphischem $-l$ - für $-l^{\prime}$; die Schreibung vilis bei KLD[ beruht auf Nesselmanns (S. 80a) wilus, dessen $-l$ - ebenso zu erklären ist wie dasjenige in mailus vylus usw. (s. oben minus und vilis). Der Infinitiv ist von Leskien Abl. 354 richtig als viltis angegesetzt, vgl. bei Szyrwid $347 \mathrm{~b}$ das Part. praes. pass. wittas s. v. spodziany. - Als mögliche litauische Verwandte ron lat. volo usw. möchte ich noch pri-valã̃ pri-valýti 'bedürfen', pri-valùs 'nötig', prý-vole, pré-vole 'Bedürfnis' vorschlagen; wenigstens lassen sich diese Worte kaum mit valaũ valýti 'reinigen, reinigend fortschaffen, reinigend einbringen' vereinigen.

voltus. - Lett. wiltus 'Betrug' gehört zu wil'u wilt 'betrügen'; s. über dieses oben s. v. villis. - Lies véresz (russ.) statt veress.

vomo. - Statt vemalaz̃ lies vémalar̃ (lit.'Gespienes’). Bei KLD ist der ungebräuchliche Singular vémalas richtig geschrieben; beim Plural steht infolge eines Druckfehlers - $e-$. - Vielleicht gehört zu lit. vémti 'erbrechen' mit Ablaut lit. isz-voméju isz-vométi 'sich verflüchtigen' (von der Wärme, von Gasen) bei Juškevič. urrum. - Die Form verigy (abg.) ist, um Mißverständnisse zu vermeiden, als Plural zu bezeichnen.

Mitau. W. Frhr. v. d. Osten-Sacken.

\section{Der gotische Genitirns Pluralis auf $-\bar{e}$.}

In allen indogermanischen Sprachen, die in ihrer historischen Entwicklungsperiode noch die Verschiedenheit der urindogermanischen Vokalqualitäten $\check{e}: \delta$ erkennen lassen, weist die auf uridg. $-m$ ausgehende Form des pluralischen Genitivs 